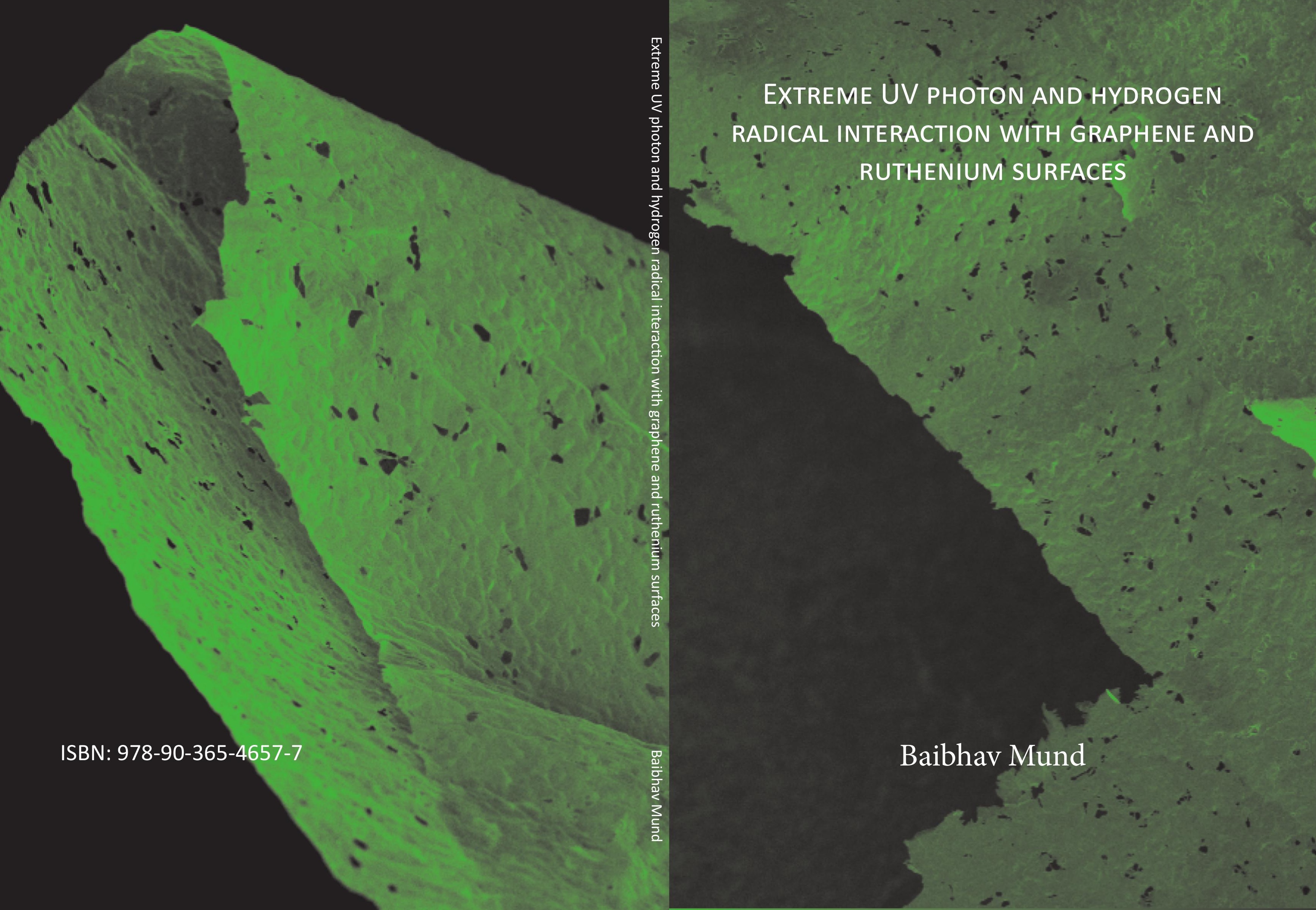




\section{EXTREME UV PHOTON AND HYDROGEN RADICAL INTERACTION WITH GRAPHENE AND RUTHENIUM SURFACES}

Baibhav Mund 
PhD Committee:

\section{Chairman:}

Prof. dr. ir. J.W.M. Hilgenkamp

University of Twente

\section{Supervisor:}

Prof. dr. F. Bijkerk

University of Twente

\section{Members:}

Prof. dr. P. Kelly

University of Twente

Prof. dr. J.C.T. Eijkel

University of Twente

Dr. A.A. Bol

Eindhoven University of Technology

Dr. ir. C.F.J. Flipse

Eindhoven University of Technology

Cover: Micrographs of graphene layer 4-6 $\mathrm{nm}$ thick as seen in a High resolution Scanning Electron microscope. 


\section{EXTREME UV PHOTON AND HYDROGEN RADICAL INTERACTION WITH GRAPHENE AND RUTHENIUM SURFACES}

\section{DISSERTATION}

to obtain

the degree of doctor at the University of Twente on the authority of the rector magnificus, Prof. dr. T.T.M. Palstra on account of the decision of the graduation committee, to be publicly defended on Thursday the $22^{\text {nd }}$ of November 2018 at 16.45 hours

by

\section{Baibhav Mund}

born on 28 September 1990

in Berhampur, India 
This dissertation has been approved by:

Supervisor: Prof. dr. F. Bijkerk

And the co-supervisor:

Dr. ir. J.M. Sturm

ISBN: 978-90-365-4657-7

(C) Baibhav Mund (2018) 


\section{This thesis is based on the following publications:}

Chapter 2: B. K. Mund, J. M. Sturm, C. J. Lee, and F. Bijkerk, "Aromatic structure degradation of single layer graphene on an amorphous silicon substrate in the presence of water, hydrogen and Extreme Ultraviolet light," Applied Surface Science, vol. 427, no. Part B, pp. 1033-1040, Jan. 2018.

Chapter 3: B. K. Mund, J. M. Sturm, W.T.E. van den Beld, C. J. Lee, and F. Bijkerk, "Etching processes of transferred and non-transferred multi-layer graphene in the presence of Extreme UV, $\mathrm{H}_{2} \mathrm{O}$ and $\mathrm{H}_{2}$ " - submitted to AIP advances.

Chapter 4: B. K. Mund, O. Soroka, J. M. Sturm, W.T.E. van den Beld, C. J. Lee, and F. Bijkerk, "Atomic $\mathrm{H}$ diffusion and $\mathrm{C}$ etching in multi-layer graphene monitored using a Y based optical sensor" - submitted to IOP Journal of Physics.

Chapter 5: B. K. Mund, J. M. Sturm, C. J. Lee, and F. Bijkerk, "Formation of H2O on a CO2 dosed Ru(0 001$)$ surface under Extreme Ultraviolet Light and H2," Applied Surface Science, vol. 456, pp. 538-544.

\section{$\widehat{N \mathscr{W O}} \begin{aligned} & \text { Toegepaste en } \\ & \text { Technische Wetenschappen }\end{aligned}$

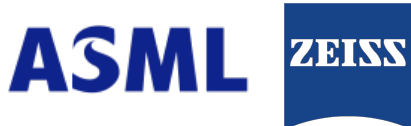 \\ MESA + university of twente.}

This research is supported by the Dutch Technology Foundation TTW (project number 140930), which is part of the Netherlands Organization for Scientific Research (NWO), and partly funded by the Ministry of Economic Affairs as well as ASML and ZEISS. This research is possible due to financial and facilitary contributions by ASML, ZEISS, Malvern Panalytical, and the Province of Overijssel through the Industrial Focus Group XUV Optics at the MESA+ Institute for Nanotechnology, University of Twente. 


\section{Table of Contents}

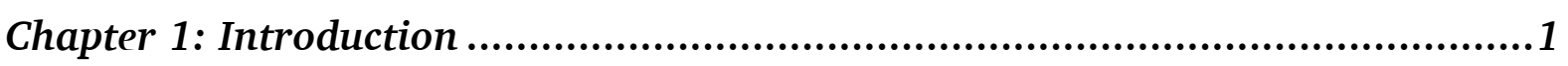

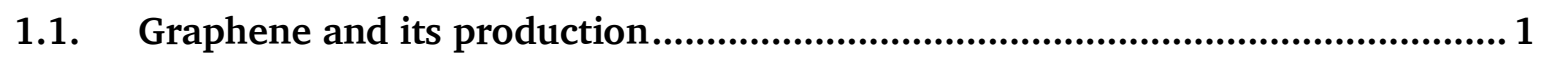

1.2. Characterization techniques and experimental methods ................................. 4

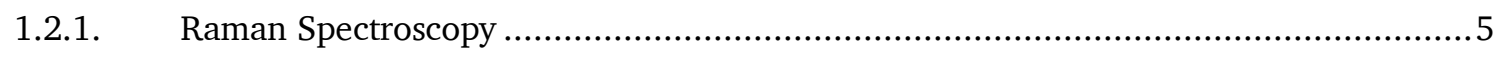

1.2.2. Reflection Absorption Infrared Spectroscopy (RAIRS) ..........................................

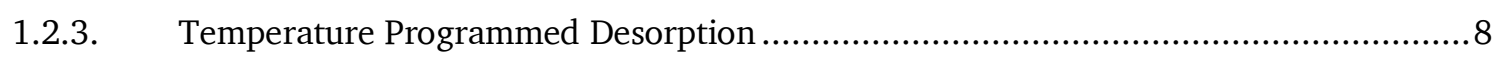

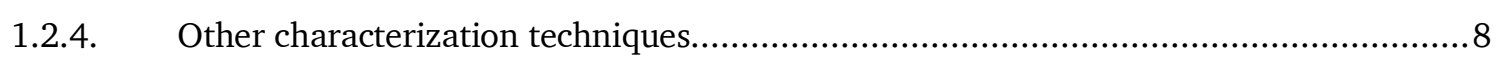

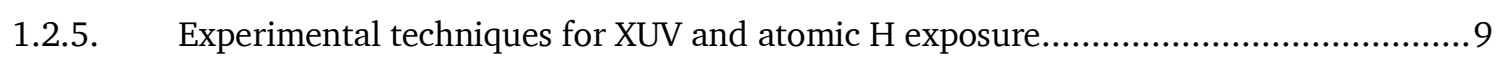

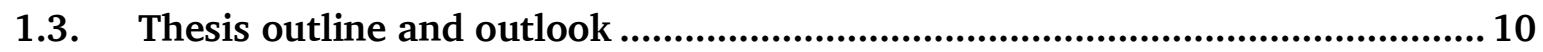

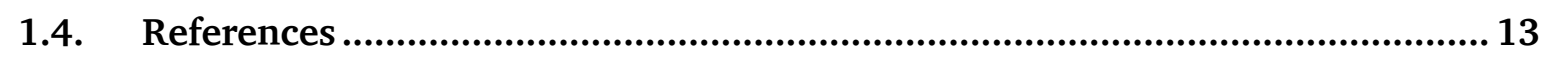

Chapter 2: Aromatic structure degradation of single layer graphene on an amorphous silicon substrate in the presence of water, hydrogen and Extreme Ultraviolet light ......................................................................20

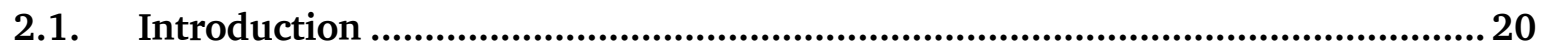

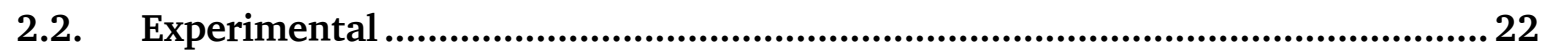

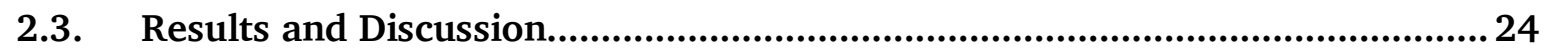

2.3.1. Formation of ketones and adsorbed $\mathrm{CO}_{2}$ on the surface of single layer graphene.......26

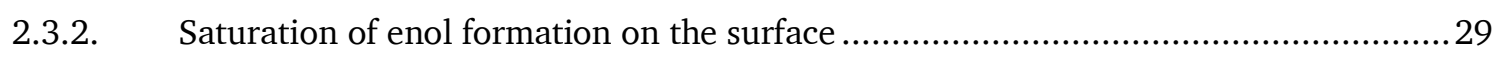

2.3.3. Temperature Programmed Desorption of water from graphene surface...................... 32

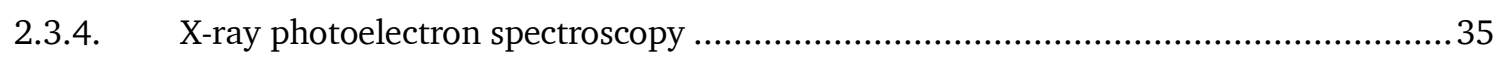

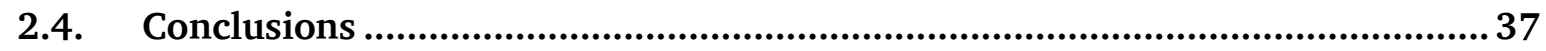

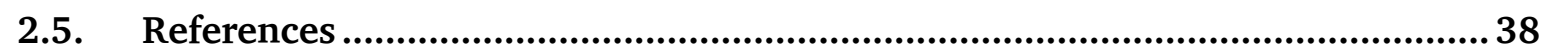

Chapter 3: Etching processes of transferred and non-transferred multi-layer graphene in the presence of Extreme $\mathrm{UV}, \mathrm{H}_{2} \mathrm{O}$ and $\mathrm{H}_{2}$..............................43

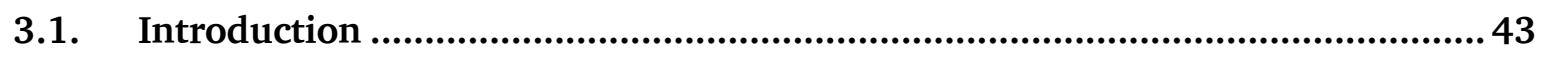

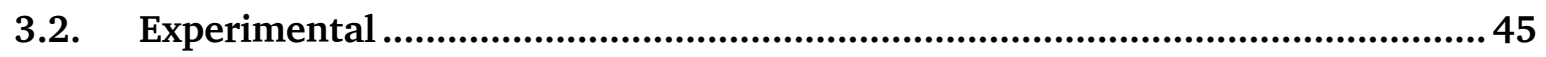

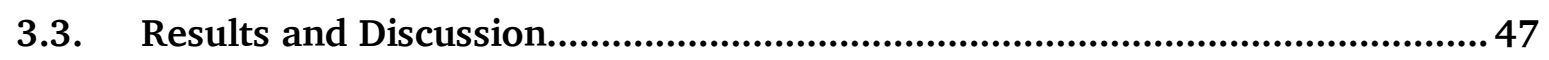

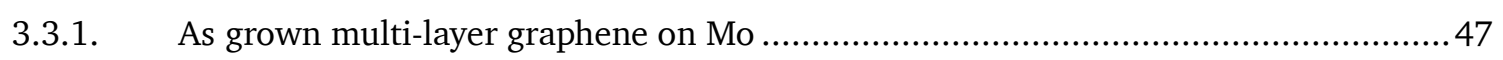




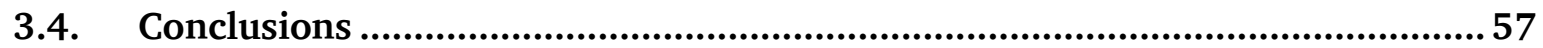

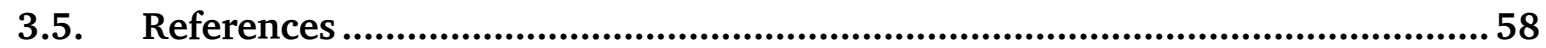

Chapter 4: Atomic $H$ diffusion and $C$ etching in multi-layer graphene monitored

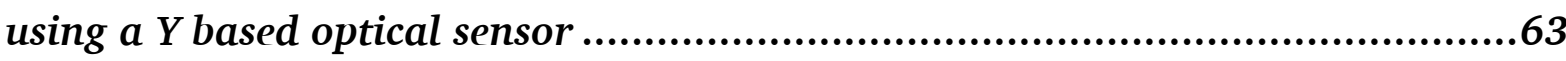

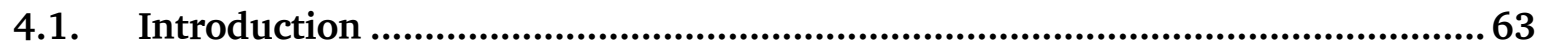

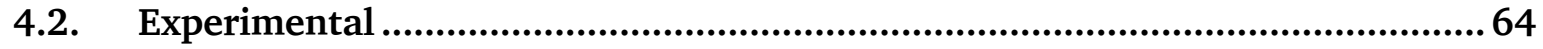

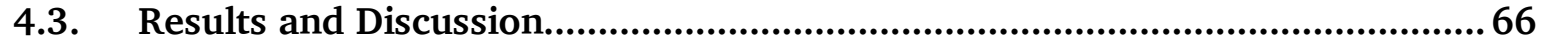

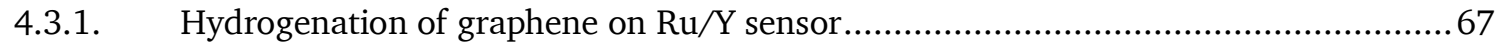

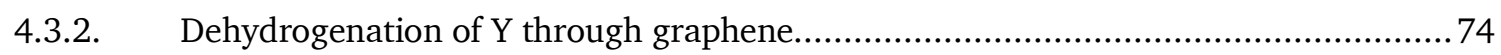

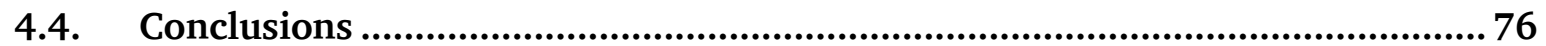

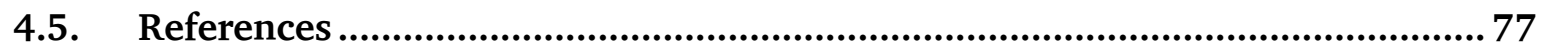

Chapter 5: Formation of $\mathrm{H}_{2} \mathrm{O}$ on a $\mathrm{CO}_{2}$ dosed $\mathrm{Ru}(0001)$ surface under Extreme

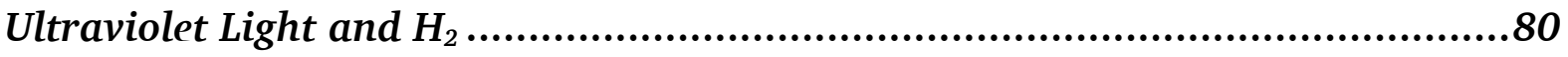

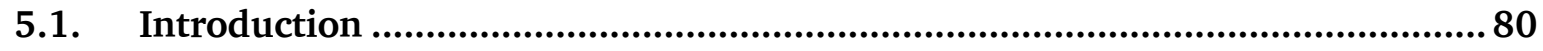

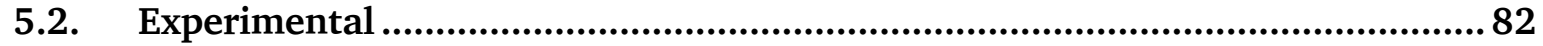

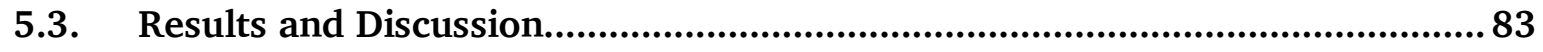

5.3.1. EUV induced surface water formation .................................................................... 84

5.3.2. Coverage of $\mathrm{Ru}(0001)$ surface with amorphous carbon/hydrocarbons .......................90

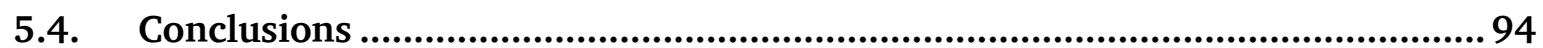

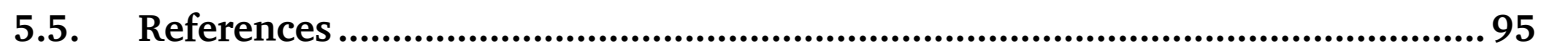

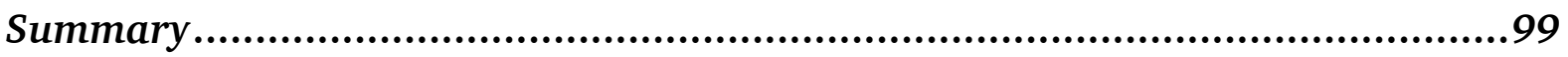

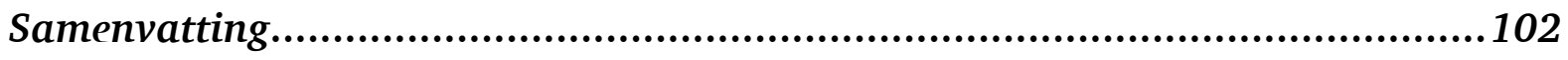





\section{Chapter 1: Introduction}

Graphene, at atomic scale thickness the thinnest known membrane material, is strong enough to be considered free-standing at macroscopic membrane dimensions. This feature gives rise to special physical properties and various optical application perspectives. ${ }^{1}$ The particular challenge explored in this thesis is to find the relevant physical and chemical processes that play a role in the use of graphene membranes and supported graphene films for short wavelength optical applications. In the Extreme UV to soft X-ray range, protective materials are required to shield sensitive optics (e.g. multilayer reflective and transmission optics), such as in the case of synchrotron radiation optics and extreme UV lithography optical systems. These protective materials need to be thin, strong and transparent. Current solutions for protective materials cannot yet fulfill all of these requirements at the same time, and 2D materials like graphene have new potential. In literature, graphene has been shown to surpass current materials for properties such as high tensile strength and transmission in the EUV to soft X-ray wavelengths while being one atomic layer thick. ${ }^{2,3}$

\subsection{Graphene and its production}

Basically, graphene is a single sheet of carbon, consisting only of hexagonally structured and covalently bound atoms. Graphene, a two dimensional allotrope of carbon, is known to be nearly optically transparent, conductive, flexible, with a high tensile strength and thermal stability. ${ }^{4}$ Each carbon atom is linked in this honeycomb lattice with four bonds, $0.142 \mathrm{~nm}$ apart: one $\sigma$ bond with three neighboring atoms and one $\pi$ bond, being slightly out of plane (shown in Figure 1.1). ${ }^{5}$ When graphene was first physically isolated in 2004, it increased its popularity for applications ranging from electronic (photovoltaics and electrodes) to chemical (water purification and waterproof ink) both of which are described later in this section. ${ }^{6-10}$ 


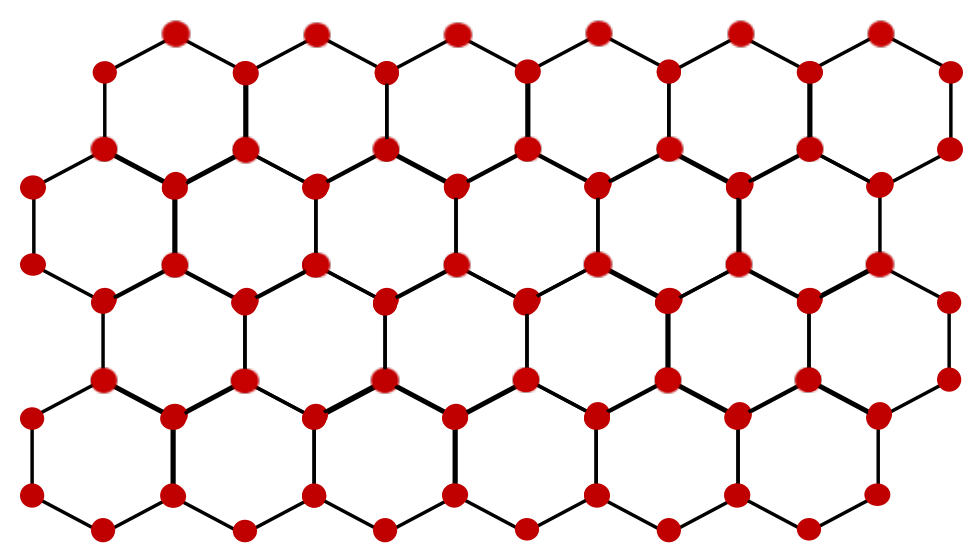

(a)

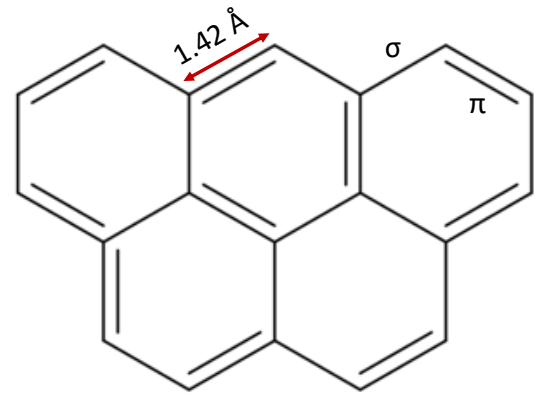

(b)

Figure 1.1. (a) Graphene hexagonal structure and (b) schematic structure shown on the right describing bond length and types.

Graphene production techniques seen earlier involved cleaving bulk graphite or reducing graphite oxide. ${ }^{11}$ Another method for producing graphene is growing it epitaxially by thermally decomposing bulk silicon carbide, with the drawback being that graphene could not be transferred onto another surface. ${ }^{12}$ However, these methods are not economically and technically feasible to produce graphene on a larger scale, therefore, chemical vapor deposition (CVD) was introduced to produce graphene. ${ }^{13}$ In a CVD process, graphene is grown on a polycrystalline or single crystalline metal such as copper or nickel.

When using $\mathrm{Cu}$ as the growth surface (which acts as a catalyst), $\mathrm{Cu}$, usually in the form of a thin foil, is exposed $\mathrm{CH}_{4}, \mathrm{H}_{2}$ and $\mathrm{Ar}$ and heated up to high temperatures of up to $1000{ }^{\circ} \mathrm{C}$. $\mathrm{CH}_{4}$, in turn, undergoes pyrolysis to form one layer of graphene on both sides of the $\mathrm{Cu}$ foil. ${ }^{14} \mathrm{In}$ order to study (electronic) properties of the formed graphene layer and/or use the formed graphene for applications, it is usually required to release the graphene layer from the $\mathrm{Cu}$ surface by exfoliation or separation. Therefore, a support polymer such as polymethylmethacrylate (PMMA) is used to facilitate the transfer process from the $\mathrm{Cu}$ foil onto a different substrate. After application of this support polymer, the $\mathrm{Cu}$ foil can be etched away, such that the graphene film can be placed on a substrate of choice. Finally, the PMMA is removed either by annealing or dissolving in acetone. ${ }^{13}$ However, the transfer process does cause additional issues: 
damage to the graphene layer during handling and PMMA residue left on graphene. Furthermore, as graphene mimics the orientation and morphology of the $\mathrm{Cu}$ layer it is grown on, contact between graphene and the alternate substrate is poor. ${ }^{15,16}$

Another method of transferring graphene involves multi-layer graphene growth on a molybdenum substrate. In this case, the molybdenum substrate is back etched using $\mathrm{H}_{2} \mathrm{O}_{2}$, leaving little residue as compared to PMMA. When using metals bi/few-layer (1$3 \mathrm{~nm}$ thick grown on $\mathrm{Ni}$ ) or multi-layer graphene is grown (5-8 nm grown on $\mathrm{Mo}$ ), whereas graphene growth on $\mathrm{Cu}$ which always results in a single layer. ${ }^{17,18}$ This is due to carbon's low solubility in $\mathrm{Cu}$, which results in surface adsorption and a self-limiting process. ${ }^{19}$ However, graphene on other metal surfaces are shown to grow via segregation or precipitation, resulting in few or multiple layers. ${ }^{20,21}$

Graphene is known to have high mechanical strength due to its covalently bound carbon lattice structure, with a tensile strength of $130 \mathrm{GPa}$. Perfect graphene is also known to be extremely elastic, with a Young's modulus of $1 \mathrm{TPa} .{ }^{2}$ However, due to defects in the lattice structure and damage during growth and/or transfer the experimental elastic modulus lowers to $500 \mathrm{GPa}$ or $170 \mathrm{~N} / \mathrm{m}^{2} .^{2,22}$ Despite that, the Young's modulus of graphene is much higher than common semiconductor materials such as silicon (165 GPa) and germanium (100 GPa). ${ }^{23}$

Optically, graphene is known to only absorb $2 \%$ of visible light and $0.1 \%$ of extreme ultraviolet (XUV) light $(\lambda=13.5 \mathrm{~nm})$ in the short-wavelength range per single layer. ${ }^{3}$ The optical absorption is related to the electronic properties of graphene, as electrons have very high mobility across graphene. Graphene's opacity for visible light is due to the fine structure constant which stipulates that absorption of light is dependent on the conductivity of the material. ${ }^{24}$ On the other hand, soft X-ray (SXR) and XUV absorption is dependent on absorption by core electrons and the secondary electron yield of a material. Graphene, being a single atomic layer of light atoms, therefore has a high SXR and XUV transmission. 
Contemporary and future generations of lithography are required to work with XUV light, which requires reflective optics for illumination and imaging, as well as transmissive optics for use in e.g. spectral purity filters and pellicles. ${ }^{25-27} \mathrm{XUV}(13.5 \mathrm{~nm})$ photons have a high photon energy of $92 \mathrm{eV}$, which creates a highly reactive environment in combination with background gases in lithography equipment. This may be detrimental to the optical materials inside the lithography tool. Furthermore, particulate contaminants generated in a lithography tool could adhere to the mask, which is imaged on the wafer. To prevent these issues, capping layers are placed on XUV optics and pellicles are placed on XUV masks. Both capping layers and pellicles are protective materials that need to be transparent and chemically inert. Additionally, capping layers need to impermeable to reactive gases and pellicles should be mechanically strong. Presently, current XUV capping layers and pellicles do not completely satisfy all the requirements such as transmission, tensile strength and chemical stability. In this thesis, we discuss XUV irradiation and its effect on a novel capping layer and pellicle candidate: graphene.

One of the main industrial interests in graphene is driven due to the possibility to use graphene as flexible conductor, such as in the case of wearable electronics like pressure and body motion sensors. ${ }^{28}$ Also, the high carrier mobility has driven interest in graphene as material for field effect transistors. ${ }^{29}$ This is done by modifying graphene (such as graphene oxide) to create an artificial band gap to act as a semiconductor, and eventually graphene transistors. ${ }^{30,31}$ Other commercial interests have included the use of graphene as a selectively permeable membrane for use in distillation of liquids such as ethanol and water, and as a supercapacitor which would be implemented as a high capacity battery. ${ }^{7,32-34}$ Furthermore, graphenic carbon can be used as a transmission window in SXR optics due to its high mechanical stability and transparency in the low energy photon region $(0.1-3 \mathrm{keV}) .{ }^{35}$

\subsection{Characterization techniques and experimental methods}

Graphene, being one atomic layer thick, with $\mathrm{sp}^{2}$ bonded atoms, is extremely difficult to characterize using spectroscopic techniques as the low thickness readily results in 
backscattering from its support substrate. This results in interference and makes it challenging to individually characterize graphene.

\subsubsection{Raman Spectroscopy}

Raman spectroscopy is used to observe low frequency modes $\left(400-4000 \mathrm{~cm}^{-1}\right)$ in a molecular system. Raman spectroscopy is dependent on inelastic scattering, when the surface is excited by a monochromatic source such as a laser. It is extremely weak in intensity, with less than $1 \%$ of inelastically scattered light (anti-Stokes Raman scattering), which needs to be filtered from the elastically scattered light (Rayleigh scattering). Modern Raman spectrometers employ the use of edge or notch filters to reduce the intensity of Rayleigh scattering.

Raman spectroscopy is a quick and non-destructive technique to analyze a graphene layer. Graphene is known to have three distinct peaks in a Raman spectrum: the D peak $\left(1350 \mathrm{~cm}^{-1}\right)$, the $\mathrm{G}$ peak $\left(1590 \mathrm{~cm}^{-1}\right)$ and the 2D peak $\left(2700 \mathrm{~cm}^{-1}\right)$. This is further described in Figure 1.2. The D peak is activated only in the presence of a vacancy defect, which means a perfect graphene layer would only have $\mathrm{G}$ and $2 \mathrm{D}$ peaks in the spectra. The $\mathrm{G}$ band is associated with an $\mathrm{E}_{2 \mathrm{~g}}$ phonon mode and is a first-order Raman scattering process in graphene. In contrast, the $\mathrm{D}$ and $2 \mathrm{D}$ peaks originate from a second order process, due to a double resonance Raman process. In addition, another peak $2450 \mathrm{~cm}^{-}$ ${ }^{1}\left(G^{*}\right)$ is recorded, which was first reported in graphite, and its interpretation is still a point of contention. ${ }^{36}$ Furthermore, the $2 \mathrm{D}$ peak intensity and width is directly dependent on the number of graphene layers, with a higher intensity translating to a lower number of graphene layers. ${ }^{37}$ 


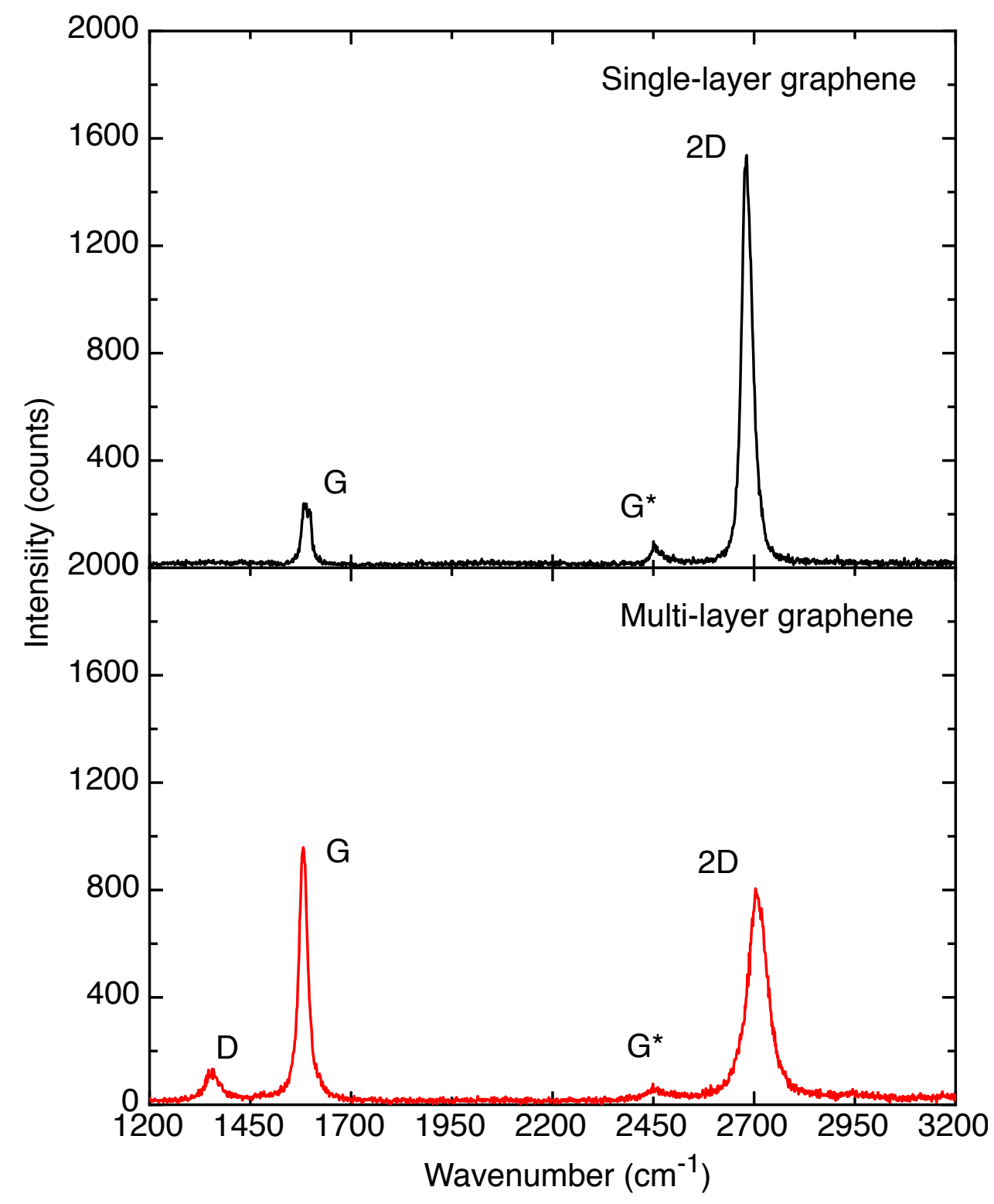

Figure 1.2. Raman spectra (excitation wavelength $=514 \mathrm{~nm}$ ) of both single and multi-layer graphene. The $D, G, G^{*}$ and $2 D$ peaks in a Raman spectrum are noted in each case.

The defect density of graphene is often expressed in the ratio of $I(D) / I(G)$ with a higher ratio indicating a more defective graphene layer. However, in some cases the underlying substrate for supported graphene interferes with the measurement of $\mathrm{I}(\mathrm{D}) / \mathrm{I}(\mathrm{G})$ ratios. ${ }^{38}$ For example, when using an underlying substrate such as $\mathrm{Si}$, fluorescence is seen in Raman spectra, which interferes with the D and G peaks of graphene, making a measurement of $\mathrm{I}(\mathrm{D}) / \mathrm{I}(\mathrm{G})$ impossible. Therefore, it is more suitable to transfer graphene onto a metal surface. ${ }^{38,39}$ 
Using Raman spectroscopy, it is also possible to quantify defects in graphene. In this case, the $\mathrm{I}(\mathrm{D}) / \mathrm{I}(\mathrm{G})$ ratio is instrumental to calculating the inter-defect distance between point-like defects in the graphene layer for a specific laser energy. ${ }^{40}$

\subsubsection{Reflection Absorption Infrared Spectroscopy (RAIRS)}

Infrared spectroscopy is used to study the interaction between vibrational modes of molecules or molecular groups on a surface. As bond structures absorb resonant IR frequencies characteristic to their structure, the IR absorption of molecules adsorbed on a surface is highly dependent on the orientation and vibronic coupling with respect to the surface. Vibrational modes are only IR active when changes in dipole moment take place. ${ }^{41}$

RAIRS requires the use of an infrared light beam reflected from an IR reflective surface (usually a metal) with an adsorbed layer of molecules (such as $\mathrm{H}_{2} \mathrm{O}$ or $\mathrm{CO}_{2}$ ). Depending on the adsorbed species, the change in vibrational modes, phase transitions and out of plane interactions can be studied in-situ. In the case of a metal, RAIRS is extremely useful to analyze catalytic reactions occurring between an adsorbed specie and the surface. ${ }^{42,43}$

Furthermore, like Raman spectroscopy, RAIRS is a non-destructive technique. Graphene, if defective by exposure to reactive hydrogen species, could result in vibrational modes of C-H bonds with peaks at $2800-3000 \mathrm{~cm}^{-1}$, due to dangling $\mathrm{C}$ bonds at the edges of graphene or large scale defects within graphene. ${ }^{44}$

However, RAIRS signals are extremely weak and susceptible to minute changes to the surface. Moreover, in-plane vibrational modes cannot be discerned for molecules or molecular groups on metallic samples, due to dipole selection rules. Peak intensities of vibrations observed by this technique often depend on interaction of molecular 
groups with their surrounding and therefore quantitative estimation of coverage of molecules from RAIRS alone is not possible. ${ }^{45}$

\subsubsection{Temperature Programmed Desorption}

Temperature Programmed Desorption (or thermal desorption spectroscopy), as the name implies, measures the temperature at which certain adsorbed molecules desorb from the sample surface. For this technique, sample heating is controlled using a temperature controller and a thermocouple (or other temperature sensor). For controlled surface desorption studies, the aperture of the housing of a mass spectrometer is placed extremely close to the surface $(\sim 1 \mathrm{~mm})$, to avoid background signal from desorption of molecules from e.g. the sample mounting. By monitoring peak intensities from the mass spectrometer versus desorption temperature, TPD provides the desorption energy and quantitative coverage of the adsorbed molecules on the surface. Unlike Raman spectroscopy, TPD involves heating and therefore irreversible changes the coverage of adsorbed molecules and/or surface during measurement. ${ }^{46,47}$

As TPD involves measuring small molecular masses, residual gases within the experimental chamber will adversely affect the measurements. The technique therefore requires the use of an Ultra High Vacuum system.

\subsubsection{Other characterization techniques}

Scanning Electron microscopy is a characterization method to examine the topography, morphology, orientation and composition of materials. An electron beam is used to scan a conducting sample surface. On non-conducting samples, measurements would suffer from charge accumulating on the surface. Fine structural features of transferred graphene sheets like wrinkles, folding lines, layers of graphene, or defects, can be easily determined. As reported in literature, graphene is highly sensitive to SEM imaging conditions. Therefore a low acceleration voltage (1 keV) has to be used to image the layer. ${ }^{48}$ Other mechanical intricacies such as bulging and 
trenches and presence of trapped gas within graphene or graphene layers can be determined when using a SEM. ${ }^{49}$

Atomic Force Microscopy can be used to determine the topography, roughness and thickness of the graphene layer. Tapping mode AFM is a usually non-destructive method to investigate the roughness of a graphene layer based on the interaction between the AFM tip and the surface. Furthermore, stress-displacement curves can be used to study the elastic strength of a free-standing membrane. In this case, stress is applied with an AFM tip onto a free-standing graphene drum shape, until the freestanding film fractures. Using a stress-displacement equation, a 2D elastic modulus can be calculated for a specific free-standing graphene layer. ${ }^{2}$

X-ray photoelectron spectroscopy (XPS) is used to measure the elemental composition and atomic concentration of the topmost few $\mathrm{nm}$ of a sample. Additionally, the measured binding energy of photoelectrons can be used to probe chemical shifts due to formation of (thin film) compounds or molecules at or near the surface. Graphene, being mostly $\mathrm{sp}^{2}$ carbon, has a binding energy of $284.3 \pm 0.1 \mathrm{eV}$. ${ }^{50}$ The elemental composition of different carbon bonds can also be determined, such as C-O groups, indicating the formation of defects and oxygenated graphene layers. Furthermore, the ratio of $\mathrm{sp}^{2}$ to $\mathrm{sp}^{3}$ bonded carbon atoms can be distinguished using XPS. This ratio is highly dependent on preparation method and contaminants in graphene/carbon. ${ }^{51-53}$

\subsubsection{Experimental techniques for $\mathrm{XUV}$ and atomic $\mathrm{H}$ exposure}

To generate the XUV photons used in this thesis experiments, a Philips XUV Alpha Source (Xe plasma discharge) is used at a repetition rate of $500 \mathrm{~Hz}$. XUV light is filtered by reflecting off a Mo/Si multilayer mirror (55\% at $13.5 \mathrm{~nm}$ ) and transmitting through a Si/Mo/Zr membrane (35\% transmission at $13.5 \mathrm{~nm}){ }^{25}$ A combined peak transmission of $19 \%$ is achieved at $13.5 \mathrm{~nm}$ with a full width half maximum (FWHM) of $0.2 \mathrm{~nm}$. Additionally, a broad reflectivity peak of $9 \%$ at $21.5 \mathrm{~nm}$ with a FWHM of $3.1 \mathrm{~nm}$ is also observed. ${ }^{3,54,55} \mathrm{XUV}$ pulse fluence is shown to vary from 90 to 110 
$\mu \mathrm{J} / \mathrm{cm}^{2}$, with an average intensity of $35-55 \mathrm{~mW} / \mathrm{cm}^{2}$ (sample spot size $3 \mathrm{~mm}$ at FWHM) during the exposure.

Atomic hydrogen exposure of graphene is conducted in a vacuum chamber with a base pressure of $1 \times 10^{-7} \mathrm{mbar}$ and a hydrogen pressure of $1.3 \times 10^{-2}$ mbar. Molecular hydrogen $(115 \mathrm{sccm})$ is split into hydrogen radicals by flowing past a W filament (heated to $2000{ }^{\circ} \mathrm{C}$, measured by a Raytek IR temperature sensor). Water cooling is used to maintain the sample temperature between $30-40{ }^{\circ} \mathrm{C}$, measured using a K-type thermocouple. The filament is placed $5 \mathrm{~cm}$ away from the sample surface, and a hydrogen flux of $10^{18}$ at. $\mathrm{cm}^{-2} . \mathrm{s}^{-1}$ is estimated from the etch rate of a carbon film. ${ }^{56}$

\subsection{Thesis outline and outlook}

Graphene has been proposed as a candidate for protective materials in the Extreme UV to soft X-ray range, due to its chemical inertness, high mechanical strength and high optical transmission. The core of this thesis deals with the chemical and physical interaction of (potential) protective layers in soft X-ray and XUV optics. The use of graphene in these applications requires detailed knowledge of potential damage mechanisms. Previous research focused on XUV and electron induced chemical reactions of small molecules as water and hydrogen with single and multi-layer graphene. ${ }^{52,53,57}$ Also, experiments with small molecules without XUV are of importance to understand the chemical reactivity of graphene. For instance, graphene has been known to fully hydrogenate into an insulator (graphane) when exposed to 0.1 mbar of 1: $9 \mathrm{H}_{2}$ /Ar mixture at room temperature. ${ }^{58}$ In addition, graphene has been known to first damage then etch when exposed to hydrogen at high temperatures of $800{ }^{\circ} \mathrm{C}$, or when exposed to short bursts of oxygen plasma. ${ }^{59-61}$ This removal of carbon is initiated by the gradual evolution of $\mathrm{sp}^{2}$ bonded carbon atoms to $\mathrm{sp}^{3}$ amorphous carbon. ${ }^{62}$

In this thesis, the knowledge on these damage mechanisms is enlarged by comparing the reactivity of transferred single and multilayer graphene films with previous results on non-transferred graphene layers. ${ }^{52,53,57}$ Furthermore, in-situ spectroscopy during and immediately after exposure is employed. This knowledge on high energy photon impact on graphene in the presence of background gases is also relevant for electron 
beam lithography of graphene, where the aim is to locally etch graphene, without drastically changing the quality of unexposed areas. ${ }^{63}$

Graphene, while being a great candidate as protective material, can also be used in other aspects of lithographic production such as integrated circuits. ${ }^{64}$ Conventional lithographic device patterning involves the use of resists, which are light sensitive and organic. However, due to its organic nature, resist removal from graphene has proven to be difficult as harsh chemical processes and contamination can alter the electronic properties of graphene, such as mobility and doping. ${ }^{65,66}$ While in the case of application of graphene as protective layer, chemical modifications by photo-induced reactions or radical species are undesired. Therefore, selective photon or electroninduced chemical modification could be used as a resist-free patterning approach in applications where graphene has to be structured. ${ }^{66}$

Firstly, in Chapter 2, the reactivity of transferred single-layer graphene is studied. In this case, the damage mechanism of transferred single-layer graphene (on aSi) and its aromatic structure degradation is studied when dosed with $\mathrm{H}_{2} \mathrm{O}$ and exposed to XUV light in the presence of hydrogen. This degradation is attributed to the oxidation by reactive $\mathrm{O}$ species generated through XUV induced dissociation of water. While previous research on graphene damage mainly relied on post exposure characterization with e.g. Raman spectroscopy, the work in this chapter employs in-situ RAIRS to probe oxidative damage as function of XUV exposure and background $\mathrm{H}_{2}$ pressure. ${ }^{53,57}$ It is established that the rate of oxidation slows down with repeated exposures of XUV at the same hydrogen pressure, indicating oxidation at point defects and/or grain boundaries begins to decline.

Aromatic structure breakdown of graphene is further studied in Chapter 3, where multi-layer graphene is used instead of single-layer graphene. MLG is studied in two forms: as-grown on Mo and transferred onto a Si surface. Firstly, as-grown graphene on Mo is shown to be resistant to oxidation when dosed with water and exposed to $\mathrm{XUV}$ in the presence of $\mathrm{H}_{2}$. However, in the same experimental conditions, transferred 
MLG is shown to oxidize and form keto-enol groups. Furthermore, this oxidation is shown to occur only at the interface of the graphene layer and the underlying substrate.

The reactivity of multi-layer graphene is further explored in Chapter 4 where MLG is tested in a different film geometry as a diffusion barrier for atomic hydrogen. Previous density functional calculations and molecular dynamics simulations indicated that graphene could be an efficient diffusion barrier for small molecules. ${ }^{67}$ Experimentally, multi-layer graphene (5-10 nm thick) has been shown to act as a diffusion barrier of metal atoms against Si. ${ }^{68}$ In this chapter we experimentally tested the application of MLG as diffusion barrier against hydrogen on samples of a lateral length scale of $1 \mathrm{~cm}$. MLG is transferred onto a $\mathrm{Ru} / \mathrm{Y}$ sensor which is used to probe hydrogenation of the $\mathrm{Y}$ film and compared to a similar thickness of amorphous carbon. The results show that both graphene and carbon can act as a diffusion barrier for underlying layers, however, graphene is shown to delay hydrogenation due to its slower etching rate than carbon.

Chapter 5, on the other hand, deals with $\mathrm{Ru}$, which is a frequently used reference protective capping material for XUV lithography. Depending on XUV flux and background pressure of hydrocarbons and water, carbon and/or ruthenium oxide contamination can form on a $\mathrm{Ru}$ capping layer, which can be removed by hydrogen radicals. ${ }^{69,70}$ Previous studies on this topic investigated carbon growth and oxidation separately, or focused on the balance between different contamination and cleaning mechanisms. ${ }^{45-47,71}$ Most literature results evaluate contamination in terms of XUV reflection loss, or thickness of the formed carbon or oxide layers. ${ }^{69,72}$ In this study, we focus more on the molecular mechanisms of contamination and cleaning reactions, employing in-situ RAIRS and TPD. As model system, a Ru(0001) crystal is dosed with $\mathrm{CO}_{2}$ (a molecule containing both carbon and oxygen) and exposed to XUV and $\mathrm{H}_{2}$. Earlier results had shown that $\mathrm{CO}_{2}$ dissociates on contact with the Ru surface. ${ }^{71}$ In this study, the role of XUV and $\mathrm{H}_{2}$ is further explored. The results show that CO dissociates to form amorphous carbon and water, due to photo-chemical processes and hydrogen radicals formed by XUV. As formation of amorphous carbon on $\mathrm{Ru}$ limits reactive free 
sites on the surface, $\mathrm{CO}_{2}$ dissociation also declines, which is proven by dosing $\mathrm{CO}_{2}$ repeatedly on the surface without removal of carbon.

\subsection{References}

(1) Geim, A. K. Graphene: Status and Prospects. Science 2009, 324 (5934), 15301534.

(2) Lee, C.; Wei, X.; Kysar, J. W.; Hone, J. Measurement of the Elastic Properties and Intrinsic Strength of Monolayer Graphene. Science 2008, 321 (5887), 385388.

(3) Henke, B. L.; Gullikson, E. M.; Davis, J. C. X-Ray Interactions: Photoabsorption, Scattering, Transmission, and Reflection at $\mathrm{E}=50-30,000 \mathrm{eV}, \mathrm{Z}=1-92$. Atomic Data and Nuclear Data Tables 1993, 54 (2), 181-342.

(4) Geim, A. K.; Novoselov, K. S. The Rise of Graphene. Nature materials 2007, 6 (3), 183-191.

(5) Cooper, D. R.; D’Anjou, B.; Ghattamaneni, N.; Harack, B.; Hilke, M.; Horth, A.; Majlis, N.; Massicotte, M.; Vandsburger, L.; Whiteway, E.; et al. Experimental Review of Graphene. ISRN Condensed Matter Physics 2012, 2012, 56.

(6) Geim, A. K.; Novoselov, K. S. The Rise of Graphene. Nature materials 2007, 6 (3), 183-191.

(7) Joshi, R. K.; Carbone, P.; Wang, F. C.; Kravets, V. G.; Su, Y.; Grigorieva, I. V.; Wu, H. A.; Geim, A. K.; Nair, R. R. Precise and Ultrafast Molecular Sieving Through Graphene Oxide Membranes. Science 2014, 343 (6172), 752-754.

(8) Li, X.; Chen, W.; Zhang, S.; Wu, Z.; Wang, P.; Xu, Z.; Chen, H.; Yin, W.; Zhong, H.; Lin, S. 18.5\% Efficient Graphene/GaAs Van Der Waals Heterostructure Solar Cell. Nano Energy 2015, 16, 310-319.

(9) Novoselov, K. S.; Jiang, D.; Schedin, F.; Booth, T. J.; Khotkevich, V. V.; Morozov, S. V.; Geim, A. K. Two-Dimensional Atomic Crystals. Proceedings of the National Academy of Sciences of the United States of America 2005, 102 (30), 10451-10453.

(10) Avouris, P. Graphene: Electronic and Photonic Properties and Devices. Nano letters 2010, 11, 4285-4294. 
(11) Bunch, J. S.; van der Zande, A. M.; Verbridge, S. S.; Frank, I. W.; Tanenbaum, D. M.; Parpia, J. M.; Craighead, H. G.; McEuen, P. L. Electromechanical Resonators From Graphene Sheets. Science 2007, 315 (5811), 490-493.

(12) Mishra, N.; Boeckl, J.; Motta, N.; Iacopi, F. Graphene Growth on Silicon Carbide: a Review. Phys. Status Solidi A 2016, 213 (9), 2277-2289.

(13) Yong, V.; Hahn, H. T. Graphene Growth with Giant Domains Using Chemical Vapor Deposition. CrystEngComm 2011, 13 (23), 6933-6936.

(14) Bae, S.; Kim, H.; Lee, Y.; Xu, X.; Park, J.-S.; Zheng, Y.; Balakrishnan, J.; Lei, T.; Ri Kim, H.; Song, Y. I.; et al. Roll-to-Roll Production of 30-Inch Graphene Films for Transparent Electrodes. Nature nanotechnology 5, 2010, 574-578.

(15) Zande, A. M. V. D.; Barton, R. A.; Alden, J. S.; Ruiz-Vargas, C. S.; Whitney, W. S.; Pham, P. H. Q.; Park, J.; Parpia, J. M.; Craighead, H. G.; McEuen, P. L. LargeScale Arrays of Single-Layer Graphene Resonators. Nano letters 2010, 10 (12), 4869-4873.

(16) Van Lam, D.; Kim, S. M.; Cho, Y.; Kim, J. H.; Lee, H. J.; Yang, J. M.; Lee, S. M. Healing Defective CVD-Graphene Through Vapor Phase Treatment. Nanoscale 2014, 6 (11), 5639-5644.

(17) Wu, J.; Ma, L.; Samanta, A.; Liu, M.; Li, B.; Yang, Y.; Yuan, J.; Zhang, J.; Gong, Y.; Lou, J.; et al. Growth of Molybdenum Carbide-Graphene Hybrids From Molybdenum Disulfide Atomic Layer Template. Adv. Mater. Interfaces 2017, 4 (4), 1600866.

(18) Losurdo, M.; Giangregorio, M. M.; Capezzuto, P.; Bruno, G. Graphene CVD Growth on Copper and Nickel: Role of Hydrogen in Kinetics and Structure. Physical chemistry chemical physics : PCCP 2011, 13 (46), 20836-20843.

(19) Kim, K. S.; Zhao, Y.; Jang, H.; Lee, S. Y.; Kim, J. M.; Kim, K. S.; Ahn, J. H.; Kim, P.; Choi, J. Y.; Hong, B. H. Large-Scale Pattern Growth of Graphene Films for Stretchable Transparent Electrodes. Nature 2009, 457 (7230), 706-710.

(20) Li, X.; Cai, W.; An, J.; Kim, S.; Nah, J.; Yang, D.; Piner, R.; Velamakanni, A.; Jung, I.; Tutuc, E.; et al. Large-Area Synthesis of High-Quality and Uniform Graphene Films on Copper Foils. Science 2009, 324 (5932), 1312-1314.

(21) Li, X.; Cai, W.; Colombo, L.; Ruoff, R. S. Evolution of Graphene Growth on Ni and $\mathrm{Cu}$ by Carbon Isotope Labeling. Nano letters 2009, 9 (12), 4268-4272. 
(22) Zhou, L.; Wang, Y.; Cao, G. Estimating the Elastic Properties of Few-Layer Graphene From the Free-Standing Indentation Response. J. Phys.: Condens. Matter 2013, 25 (47), 475301.

(23) Wortman, J. J.; Evans, R. A. Young"S Modulus, Shear Modulus, and Poisson"S Ratio in Silicon and Germanium. J. Appl. Phys. 1965, 36 (1), 153-156.

(24) Nair, R. R.; Blake, P.; Grigorenko, A. N.; Novoselov, K. S.; Booth, T. J.; Stauber, T.; Peres, N. M. R.; Geim, A. K. Fine Structure Constant Defines Visual Transparency of Graphene. Science 2008, 320 (5881), 1308-1308.

(25) Soer, W. A.; Jak, M. J. J.; Yakunin, A. M.; van Herpen, M. M. J. W.; Banine, V. Y. Grid Spectral Purity Filters for Suppression of Infrared Radiation in LaserProduced Plasma EUV Sources; Schellenberg, F. M., La Fontaine, B. M., Eds.; SPIE, 2009; Vol. 7271.

(26) Pollentier, I.; Lee, J. U.; Timmermans, M.; Adelmann, C.; Zahedmanesh, H.; Huyghebaert, C.; Gallagher, E. E. Novel Membrane Solutions for the EUV Pellicle: Better or Not?; Proc. SPIE, 2017 10143, EUV Lithography VIII, 101430L.

(27) Naulleau, P. P.; Scaccabarozzi, L.; Smith, D.; Diago, P. R.; Casimiri, E.; Dziomkina, N.; Meijer, H. Investigation of EUV Pellicle Feasibility. 2013, 8679, 867904.

(28) Kim, H.; Ahn, J.-H. Graphene for Flexible and Wearable Device Applications. Carbon 2017, 120, 244-257.

(29) Reddy, D.; Register, L.F.; Carpenter, G.D.; Banerjee, S.K.; Graphene Field-Effect Transistors. J. Phys. D: Appl. Phys. 2011, 44 (31), 313001.

(30) Novoselov, K. S.; Geim, A. K.; Morozov, S. V.; Jiang, D.; Zhang, Y.; Dubonos, S. V.; Grigorieva, I. V.; Firsov, A. A. Electric Field Effect in Atomically Thin Carbon Films. Science 2004, 306 (5696), 666-669.

(31) Standley, B.; Mendez, A.; Schmidgall, E.; Bockrath, M. Graphene-Graphite Oxide Field-Effect Transistors. Nano letters 2012, 12 (3), 1165-1169.

(32) Koenig, S. P.; Wang, L.; Pellegrino, J.; Bunch, J. S. Selective Molecular Sieving Through Porous Graphene. Nature nanotechnology 2012, 7 (11), 728-732. 
(33) Homaeigohar, S.; Elbahri, M. Graphene Membranes for Water Desalination. NPG Asia Mater 2017, 9 (8), e427.

(34) Ke, Q.; Wang, J. Graphene-Based Materials for Supercapacitor Electrodes - a Review. Journal of Materiomics 2016, 2 (1), 37-54.

(35) Huebner, S.; Miyakawa, N.; Kapser, S.; Pahlke, A.; Kreupl, F. High Performance $\mathrm{X}$-Ray Transmission Windows Based on Graphenic Carbon. IEEE Trans. Nucl. Sci. 2015, 62 (2), 588-593.

(36) Nemanich, R. J.; Solin, S. A. First- and Second-Order Raman Scattering From Finite-Size Crystals of Graphite. Phys. Rev. B 1979, 20 (2), 392-401.

(37) Ferrari, A. C.; Basko, D. M. Raman Spectroscopy as a Versatile Tool for Studying the Properties of Graphene. Nature nanotechnology 2013, 8 (4), 235-246.

(38) Wang, Y. Y.; Ni, Z. H.; Yu, T.; Shen, Z. X.; Wang, H. M.; Wu, Y. H.; Chen, W.; Shen Wee, A. T. Raman Studies of Monolayer Graphene: the Substrate Effect. J. Phys. Chem. C 2008, 112 (29), 10637-10640.

(39) Wang, Q. H.; Jin, Z.; Kim, K. K.; Hilmer, A. J.; Paulus, G. L. C.; Shih, C.-J.; Ham, M.-H.; Sanchez-Yamagishi, J. D.; Watanabe, K.; Taniguchi, T.; et al. Understanding and Controlling the Substrate Effect on Graphene ElectronTransfer Chemistry via Reactivity Imprint Lithography. Nat Chem 2012, 4 (9), 724-732.

(40) Cancado, L. G.; Jorio, A.; Ferreira, E. H.; Stavale, F.; Achete, C. A.; Capaz, R. B.; Moutinho, M. V.; Lombardo, A.; Kulmala, T. S.; Ferrari, A. C. Quantifying Defects in Graphene via Raman Spectroscopy at Different Excitation Energies. Nano letters 2011, 11 (8), 3190-3196.

(41) Greenler, R. G. Infrared Study of Adsorbed Molecules on Metal Surfaces by Reflection Techniques. J. Chem. Phys. 1966, 44 (1), 310-315.

(42) Greenler, R. G. Design of a Reflection-Absorption Experiment for Studying the Ir Spectrum of Molecules Adsorbed on a Metal Surface. Journal of Vacuum Science and Technology 1975, 12 (6), 1410-1417.

(43) Greenler, R. G.; Snider, D. R.; Witt, D.; Sorbello, R. S. The Metal-Surface Selection Rule for Infrared Spectra of Molecules Adsorbed on Small Metal Particles. Surface Science 1982, 118 (3), 415-428.

(44) Uspenskii, Y. A.; Seely, J. F.; Kjornrattanawanich, B.; Windt, D. L.; Bugayev, Y. A.; Kondratenko, V. V.; Artyukov, I. A.; Titov, A. A.; Kulatov, E. T.; Vinogradov, 
A. V. Determination of the Optical Constants of Amorphous Carbon in the EUV Spectral Region 40-450 eV; 2006; Vol. 6317.

(45) Sturm, J. M.; Lee, C. J.; Bijkerk, F. Reactions of Ethanol on Ru(0001). Surface Science 2013, 612, 42-47.

(46) Liu, F.; Sturm, J. M.; Lee, C. J.; Bijkerk, F. Coexistence of Ice Clusters and Liquid-Like Water Clusters on the Ru(0001) Surface. Physical chemistry chemical physics : PCCP 2017, 19 (12), 8288-8299.

(47) Liu, F.; Sturm, J. M.; Lee, C. J.; Bijkerk, F. Extreme UV Induced Dissociation of Amorphous Solid Water and Crystalline Water Bilayers on Ru(0001). Surface Science 2016, 646, 101-107.

(48) Kochat, V.; Nath Pal, A.; Sneha, E. S.; Sampathkumar, A.; Gairola, A.; Shivashankar, S. A.; Raghavan, S.; Ghosh, A. High Contrast Imaging and Thickness Determination of Graphene with in-Column Secondary Electron Microscopy. J. Appl. Phys. 2011, 110 (1), 014315.

(49) Lee, J.; Zheng, X.; Roberts, R. C.; Feng, P. X. L. Scanning Electron Microscopy Characterization of Structural Features in Suspended and Non-Suspended Graphene by Customized CVD Growth. Diamond and Related Materials 2015, 54, 64-73.

(50) Díaz, J.; Paolicelli, G.; Ferrer, S.; Comin, F. Separation of the Sp3 and sp ${ }^{2}$ Components in the C1s Photoemission Spectra of Amorphous Carbon Films. Phys. Rev. B 1996, 54 (11), 8064-8069.

(51) Lee, D. W.; Seo, J. W. Sp 2/Sp 3Carbon Ratio in Graphite Oxide with Different Preparation Times. J. Phys. Chem. C 2011, 115 (6), 2705-2708.

(52) Gao, A.; Zoethout, E.; Sturm, J. M.; Lee, C. J.; Bijkerk, F. Defect Formation in Single Layer Graphene Under Extreme Ultraviolet Irradiation. Applied Surface Science 2014, 317, 745-751.

(53) Gao, A.; Rizo, P. J.; Zoethout, E.; Scaccabarozzi, L.; Lee, C. J.; Banine, V.; Bijkerk, F. Extreme Ultraviolet Induced Defects on Few-Layer Graphene. J. Appl. Phys. 2013, 114 (4), 044313.

(54) Astakhov, D. I.; Goedheer, W. J.; Lee, C. J.; Ivanov, V. V.; Krivtsun, V. M.; Koshelev, K. N.; Lopaev, D. V.; van der Horst, R. M.; Beckers, J.; Osorio, E. A.; et al. Exploring the Electron Density in Plasma Induced by EUV Radiation: II. 
Numerical Studies in Argon and Hydrogen. J. Phys. D: Appl. Phys. 2016, 49 (29), 295204.

(55) Kieft, E. R.; van der Mullen, J. J. A. M.; Kroesen, G. M. W.; Banine, V. TimeResolved Pinhole Camera Imaging and Extreme Ultraviolet Spectrometry on a Hollow Cathode Discharge in Xenon. Phys. Rev. E 2003, 68 (5), 056403.

(56) Braginsky, O. V.; Kovalev, A. S.; Lopaev, D. V.; Malykhin, E. M.; Rakhimova, T. V.; Rakhimov, A. T.; Vasilieva, A. N.; Zyryanov, S. M.; Koshelev, K. N.; Krivtsun, V. M.; et al. Removal of Amorphous C and Sn on Mo:Si Multilayer Mirror Surface in Hydrogen Plasma and Afterglow. J. Appl. Phys. 2012, 111 (9), 093304.

(57) Gao, A.; Lee, C. J.; Bijkerk, F. Graphene Defect Formation by Extreme Ultraviolet Generated Photoelectrons. Journal of Applied Physics 2014, 116 (5), 054312.

(58) Elias, D. C.; Nair, R. R.; Mohiuddin, T. M. G.; Morozov, S. V.; Blake, P.; Halsall, M. P.; Ferrari, A. C.; Boukhvalov, D. W.; Katsnelson, M. I.; Geim, A. K.; et al. Control of Graphene's Properties by Reversible Hydrogenation: Evidence for Graphane. Science 2009, 323 (5914), 610-613.

(59) Behr, M. J.; Gaulding, E. A.; Mkhoyan, K. A.; Aydil, E. S. Hydrogen Etching and Cutting of Multiwall Carbon Nanotubes. J. Vac. Sci. Technol. B 2010, 28 (6), 1187.

(60) Yang, R.; Zhang, L.; Wang, Y.; Shi, Z.; Shi, D.; Gao, H.; Wang, E.; Zhang, G. An Anisotropic Etching Effect in the Graphene Basal Plane. Advanced materials 2010, 22 (36), 4014-4019.

(61) Al-Mumen, H.; Rao, F.; Li, W.; Dong, L. Singular Sheet Etching of Graphene with Oxygen Plasma. Nano-Micro Letters 2014, 6 (2), 116-124.

(62) Ferrari, A. C. Raman Spectroscopy of Graphene and Graphite: Disorder, Electron-Phonon Coupling, Doping and Nonadiabatic Effects. Solid State Communications 2007, 143 (1-2), 47-57.

(63) Sommer, B.; Sonntag, J.; Ganczarczyk, A.; Braam, D.; Prinz, G.; Lorke, A.; Geller, M. Electron-Beam Induced Nano-Etching of Suspended Graphene. Scientific Reports 5, 2015, 7781.

(64) Park, J.-U.; Nam, S.; Lee, M.-S.; Lieber, C. M. Synthesis of Monolithic Graphene-Graphite Integrated Electronics. Nature materials 11, 2012, 120125. 
(65) Lin, Y.-C.; Lu, C.-C.; Yeh, C.-H.; Jin, C.; Suenaga, K.; Chiu, P.-W. Graphene Annealing: How Clean Can It Be? Nano letters 2011, 12 (1), 414-419.

(66) Prezioso, S.; Perrozzi, F.; Donarelli, M.; Bisti, F.; Santucci, S.; Palladino, L.; Nardone, M.; Treossi, E.; Palermo, V.; Ottaviano, L. Large Area Extreme-UV Lithography of Graphene Oxide via Spatially Resolved Photoreduction. Langmuir : the ACS journal of surfaces and colloids 2012, 28 (12), 5489-5495.

(67) Petucci, J.; LeBlond, C.; Karimi, M.; Vidali, G. Diffusion, Adsorption, and Desorption of Molecular Hydrogen on Graphene and in Graphite. J. Chem. Phys. 2013, 139 (4), 044706.

(68) Hong, J.; Lee, S.; Lee, S.; Han, H.; Mahata, C.; Yeon, H.-W.; Koo, B.; Kim, S.-I.; Nam, T.; Byun, K.; et al. Graphene as an Atomically Thin Barrier to Cu Diffusion Into Si. Nanoscale 2014, 6 (13), 7503-7511.

(69) Chen, J.; Louis, E.; Wormeester, H.; Harmsen, R.; van de Kruijs, R.; Lee, C. J.; van Schaik, W.; Bijkerk, F. Carbon-Induced Extreme Ultraviolet Reflectance Loss Characterized Using Visible-Light Ellipsometry. Measurement Science and Technology 2011, 22 (10), 105705.

(70) Madey, T. E.; Faradzhev, N. S.; Yakshinskiy, B. V.; Edwards, N. V. Surface Phenomena Related to Mirror Degradation in Extreme Ultraviolet (EUV) Lithography. Applied Surface Science 2006, 253 (4), 1691-1708.

(71) Pachecka, M.; Sturm, J. M.; Lee, C. J.; Bijkerk, F. Adsorption and Dissociation of CO 2on Ru(0001). J. Phys. Chem. C 2017, 121 (12), 6729-6735.

(72) Chen, J.; Louis, E.; Lee, C. J.; Wormeester, H.; Kunze, R.; Schmidt, H.; Schneider, D.; Moors, R.; van Schaik, W.; Lubomska, M.; et al. Detection and Characterization of Carbon Contamination on EUV Multilayer Mirrors. Opt. Express 2009, 17 (19), 16969-16979. 


\section{Chapter 2: Aromatic structure degradation of single layer graphene on an amorphous silicon substrate in the presence of water, hydrogen and Extreme Ultraviolet light}

In this work we study the reaction of water and graphene under Extreme Ultraviolet (EUV) irradiation and in the presence of hydrogen. In this work, single layer graphene (SLG) on amorphous Si as an underlying substrate is dosed with water (0.75 ML) and exposed to EUV ( $\lambda=13.5 \mathrm{~nm}, 92 \mathrm{eV}$ ) with partial pressures of $\mathrm{H}_{2}$ in the background. The results show that the aromatic structure of graphene, when exposed to EUV and $\mathrm{H}_{2}$, breaks down into aryl ketones and enols of 1,3 di-ketone. Infrared (IR) spectroscopy shows that SLG oxidizes, with increasing $\mathrm{H}_{2}$ pressure leading to the grain boundary edges of graphene forming ketones and carboxylic acids. In situ and post exposure analyses also reveal that EUV exposure reduces the $\mathrm{sp}^{2}$ content of the graphene layer, with the $\mathrm{sp}^{3}$ content increasing, resulting in a more defective graphene layer.

\subsection{Introduction}

Graphene, a two dimensional hexagonally packed network of covalently bound carbon atoms, has a number of unique physical, thermal and chemical properties. ${ }^{1-8}$ It is known to be impermeable to gases ${ }^{9}$, and has been theoretically shown to act as a diffusion barrier even against molecular hydrogen. ${ }^{10}$ Graphene can be grown on an industrial scale via chemical vapor deposition and transferred onto both flat ${ }^{11}$ and arbitrary profile substrates ${ }^{12}$, broadening its scope for potential applications.

In the optical regime, single layer graphene combines the highly desirable properties of being simultaneously conductive and transparent in the visible ${ }^{13}$, and EUV ${ }^{14}$ wavelengths. These properties make it a promising candidate for transparent 
conducting electrodes, required for touch screens, and, potentially EUV adaptive optics. Furthermore, the high transparency in the EUV range is attractive because most optics require a protective top layer to protect them from the highly reactive environment, induced by radiation. ${ }^{15}$

Perfect single layer graphene (SLG) is known for its low chemical reactivity due to the densely packed nature of $\mathrm{sp}^{2}$ hybridized carbon atoms. ${ }^{16}$ Unfortunately, during chemical vapor deposition and graphene transfer, defects are generated, ${ }^{17}$ which can behave as initiation points for graphene to react with its environment. ${ }^{18}$ Nevertheless, graphene has been proposed as a useful material in chemically harsh environments, such as Deep Ultraviolet, X-ray systems and Extreme Ultraviolet (EUV) Lithography systems. EUV lithography (EUVL) systems represent a particular challenge: EUVL systems operate at a wavelength of $13.5 \mathrm{~nm}$, in vacuum, and the main optical components are expected to last for the lifetime of the system ( $>10$ years). The optics and background gases, however, are exposed to ionizing radiation, creating a rich environment for surface chemistry that may modify the surface of the optics. ${ }^{19-21}$ To reduce the influence of residual gases - mainly water and hydrocarbons - the pressure is increased to a few $\mathrm{Pa}$, by adding hydrogen. ${ }^{22}$ The balance between hydrogen as a reducing agent and water as an oxidizing agent allows a dynamic equilibrium between competing processes to be managed. ${ }^{23}$ However, the conditions under which such a balance can be achieved varies from material to material. Before graphene can be used in such a system, it is critical to understand its physical and chemical stability, and to determine the reaction pathways that are most favorable under various partial pressures of $\mathrm{H}_{2}$ and $\mathrm{H}_{2} \mathrm{O}$.

Since graphene is a one atom thick layer of carbon atoms, chemical reactivity is highly dependent on the underlying substrate. Current techniques, such as in-situ Raman spectroscopy, can be used to study the generation of defects in graphene. Due to the zero-band gap nature of graphene, the Raman scattering cross section is large, making it the preferred manner to characterize graphene. However, for most other materials, the Raman scattering cross section is much smaller, making it difficult to identify 
detailed modifications to the structure and molecular composition of the graphene. Furthermore, even though the normal modes of water are both Raman and IR active, Raman spectroscopy is less sensitive to changes in hydrogen bonded water networks. ${ }^{24}$ Finally, Raman spectroscopy is susceptible to fluorescence from (in our case) the amorphous Si substrate, which is stronger than the Raman signal by a factor of $10^{6}-$ $10^{8}$. Therefore, infrared spectroscopy is the preferable method to study surface chemistry of water and its interaction with graphene.

Previous research has shown that defects are generated in single layer graphene during EUV exposure. ${ }^{25,26}$ Here, we present an investigation into the reactions of graphene on an amorphous Si layer in an EUV environment. For these experiments, the surface is characterized in-situ using Reflection Absorption Infrared Spectroscopy (RAIRS) during EUV exposure, and temperature programmed desorption (TPD) spectroscopy before and after EUV exposure. RAIRS is used to observe changes in molecular orientation of water and chemical structure of graphene and revealing the pathway by which graphene oxidizes in the presence of water and hydrogen. On the other hand, TPD provides a quantitative measure of the number of molecules that desorb from the surface at a given temperature, providing an accurate measure of the different adsorbed molecules and their binding energies.

X-ray photoelectron spectroscopy (XPS) measurements are carried out ex-situ, before and after EUV exposure, to quantitatively estimate the elemental composition and the chemical state of the surface. This is used to confirm the end result of graphene oxidation.

\subsection{Experimental}

Single layer graphene is grown by chemical vapor deposition on a polycrystalline copper foil (purity 99.9\%, Alfa Aesar). The copper foil is introduced into a furnace at $1100{ }^{\circ} \mathrm{C}$ with a gas flow of $100 \mathrm{sccm}$ of $\mathrm{CH}_{4}, 500 \mathrm{sccm}$ of Ar and $6 \mathrm{sccm}$ of $\mathrm{H}_{2}$ leading to single layer graphene being grown on both sides of the $\mathrm{Cu}$ foil. The single layer graphene $[10 \mathrm{~mm} \times 10 \mathrm{~mm}]$ is then transferred using the wet transfer method ${ }^{27}$ on to 
an amorphous Si surface. The graphene layer is transferred using a PMMA support layer, which is removed by annealing at $350^{\circ} \mathrm{C}$ with $\mathrm{Ar}$ and $\mathrm{H}_{2}$ for $\sim 3 \mathrm{hrs}$.

The substrate onto which the graphene is transferred is based on a Si wafer, which had a Mo layer ( $9 \mathrm{~nm}$ thick) deposited on it, followed by $22 \mathrm{~nm}$ of amorphous silicon. Both layers are deposited by sputter deposition, and the thicknesses are known via deposition calibration based on X-ray reflectivity measurements. The amorphous silicon is not protected from atmosphere after removal from the deposition chamber, thus, the top $\sim 1-2 \mathrm{~nm}$ is oxidized. The molybdenum layer is necessary to reflect infrared radiation, allowing reflection absorption infrared spectroscopy (RAIRS) to be performed in situ.

All surface chemistry experiments are performed in the same experimental setup ${ }^{28,29}$ sequentially without breaking vacuum. The chamber's base pressure is maintained at 5 $\times 10^{-9}$ mbar. During experiments, hydrogen is introduced to the chamber, increasing the background pressure up to $1 \times 10^{-5}$ mbar. The chamber is equipped with RAIRS, TPD spectroscopy, surface cleaning facilities, surface dosing, and attached to an EUV source.

RAIRS spectra are measured at grazing incidence using an FTIR spectrometer (Bruker Vertex 70V), equipped with a liquid $\mathrm{N}_{2}$ cooled detector. Each spectrum is summed over 256 scans with a resolution of $4 \mathrm{~cm}^{-1}$, with background scans being recorded at the lowest possible stable sample temperature of $80 \mathrm{~K}$. To obtain TPD spectra, the sample temperature is ramped from $80 \mathrm{~K}$ to $450 \mathrm{~K}$ at a rate of $1 \mathrm{~K} / \mathrm{sec}$. The sample is placed normal to the entrance of a cone that is attached to a differentially pumped quadrupole mass spectrometer (QMS - Hiden Analytical). The cone has an entrance aperture of 4 $\mathrm{mm}$, located $\sim 2 \mathrm{~mm}$ away from the sample. The temperature is measured using a thermocouple attached to the sample with a Mo clamp. To prevent damage to graphene, the sample temperature is limited to $450 \mathrm{~K}$, which is sufficient to remove water, CO, and hydrogen. Based on experiments on a ruthenium (0001) surface using the same chamber, we show that the background deposition rate of all chamber contaminants is very low $\left(<0.005\right.$ monolayers (ML) per hour). ${ }^{19}$ 
Deionized water, cleaned using the freeze-pump-thaw process, is dosed on the sample through a retractable quartz tube connected to a pinhole. Surface coverage is calibrated against TPD spectra obtained from a clean Ru surface. ${ }^{28}$

The chamber is attached to a Xe plasma discharge EUV source (Philips EUV Alpha Source 2) with a repetition rate of $500 \mathrm{~Hz}$. The source is filtered by reflection from a $\mathrm{Mo} / \mathrm{Si}$ multilayer mirror (55\% reflectivity at $13.5 \mathrm{~nm}$ ) and transmission through a $\mathrm{Si} / \mathrm{Mo} / \mathrm{Zr}$ membrane $(35 \%$ transmission at $13.5 \mathrm{~nm}){ }^{30}$ This results in a peak reflectivity of $19 \%$ at $13.5 \mathrm{~nm}$ with a FWHM of $0.2 \mathrm{~nm}$ and a broad reflectivity peak of $9 \%$ at 21.5 $\mathrm{nm}$ with a FWHM of $3.1 \mathrm{~nm} .{ }^{14,21,31}$ The EUV beam has an average intensity of $35-55$ $\mathrm{mW} / \mathrm{cm}^{2}$, and a profile that is approximately Gaussian with a full width half maximum (FWHM) of $3 \mathrm{~mm}$. Over the course of the experiments, the EUV pulse fluence varied from $90-110 \mu \mathrm{J} / \mathrm{cm}^{2}$.

The general experimental procedure consisted of: the graphene is first cooled to 80 $\mathrm{K}$, and a reference RAIRS spectrum is obtained. The sample surface is dosed with water, and the chamber is filled to a chosen background pressure of hydrogen. The sample is then exposed to EUV and RAIRS spectra are obtained before EUV exposure, and every 10 minutes during the exposure. After EUV exposure, a TPD spectrum is obtained. The range of exposure conditions are summarized in Table 2.1.

After TPD/RAIRS experiments had been completed, ex situ X-ray photoelectron spectra (XPS) are measured using monochromatic Al-K $\alpha$ radiation, employing a Thermo Fisher Theta probe instrument with a beam spot size of $1 \mathrm{~mm}$ in diameter. Parallel angle resolved XPS spectra are measured in an angle range from $26^{\circ}-80^{\circ}$, the displayed spectra correspond to a take-off angle of $34^{\circ}$.

\subsection{Results and Discussion}

The graphene on Si sample is exposed to EUV with additional $\mathrm{H}_{2}$ partial pressures of 0 mbar, at $10^{-7}$ mbar, $10^{-6} \mathrm{mbar}, 10^{-5} \mathrm{mbar}$ (seen in Table 2.1). All the exposures are 1 hour long. The cumulative EUV dose for this experiment is calculated to be $0.32-0.39$ 
$\mathrm{J} / \mathrm{cm}^{2}$, which is not enough for significant heating (we do not observe an increase in temperature during EUV irradiation), eliminating thermodynamically driven processes from consideration. Thus, photon and photoelectron-driven processes are responsible for the observed changes in surface structure and composition.

For these experiments, RAIRS OH peaks, such as libration modes $\left(750-950 \mathrm{~cm}^{-1}\right)$ and bending modes $\left(1500-1700 \mathrm{~cm}^{-1}\right)$ are too weak for the water coverage used. $\mathrm{OH}$ stretching modes from water $\left(3000-3700 \mathrm{~cm}^{-1}\right)$ are visible, but did not provide any significant information about the structure and interaction of water on the surface and are therefore not shown. ${ }^{32}$

Table 2.1. Experimental conditions of the surface and chamber with initial water dose, partial pressure of $\mathrm{H}_{2}$ and the final water coverage after exposure.

\begin{tabular}{|l|l|l|l|}
\hline Experiment & $\begin{array}{l}\text { Initial Water Dose } \\
(\mathrm{ML})\end{array}$ & $\begin{array}{l}\text { Partial pressure } \\
\left(\mathrm{H}_{2}\right)\end{array}$ & $\begin{array}{l}\text { Final Water coverage } \\
(\mathbf{M L})\end{array}$ \\
\hline No EUV & $0.75 \mathrm{ML}$ & $2 \times 10^{-9} \mathrm{mbar}$ & 0.75 \\
\hline EUV & $0.75 \mathrm{ML}$ & $3 \times 10^{-9} \mathrm{mbar}$ & 0.75 \\
\hline $\mathrm{EUV}$ & $2.25 \mathrm{ML}$ & $1 \times 10^{-7} \mathrm{mbar}$ & 3.00 \\
\hline $\mathrm{EUV}+\mathrm{H}_{2}$ & $0.75 \mathrm{ML}$ & $1 \times 10^{-7} \mathrm{mbar}$ & 0.98 \\
\hline $\mathrm{EUV}+\mathrm{H}_{2}$ & $0.75 \mathrm{ML}$ & $1 \times 10^{-6} \mathrm{mbar}$ & 1.42 \\
\hline $\mathrm{EUV}+\mathrm{H}_{2}$ & $0.75 \mathrm{ML}$ & $1 \times 10^{-5} \mathrm{mbar}$ & 3.56 \\
\hline
\end{tabular}


2.3.1. Formation of ketones and adsorbed $\mathrm{CO}_{2}$ on the surface of single layer graphene

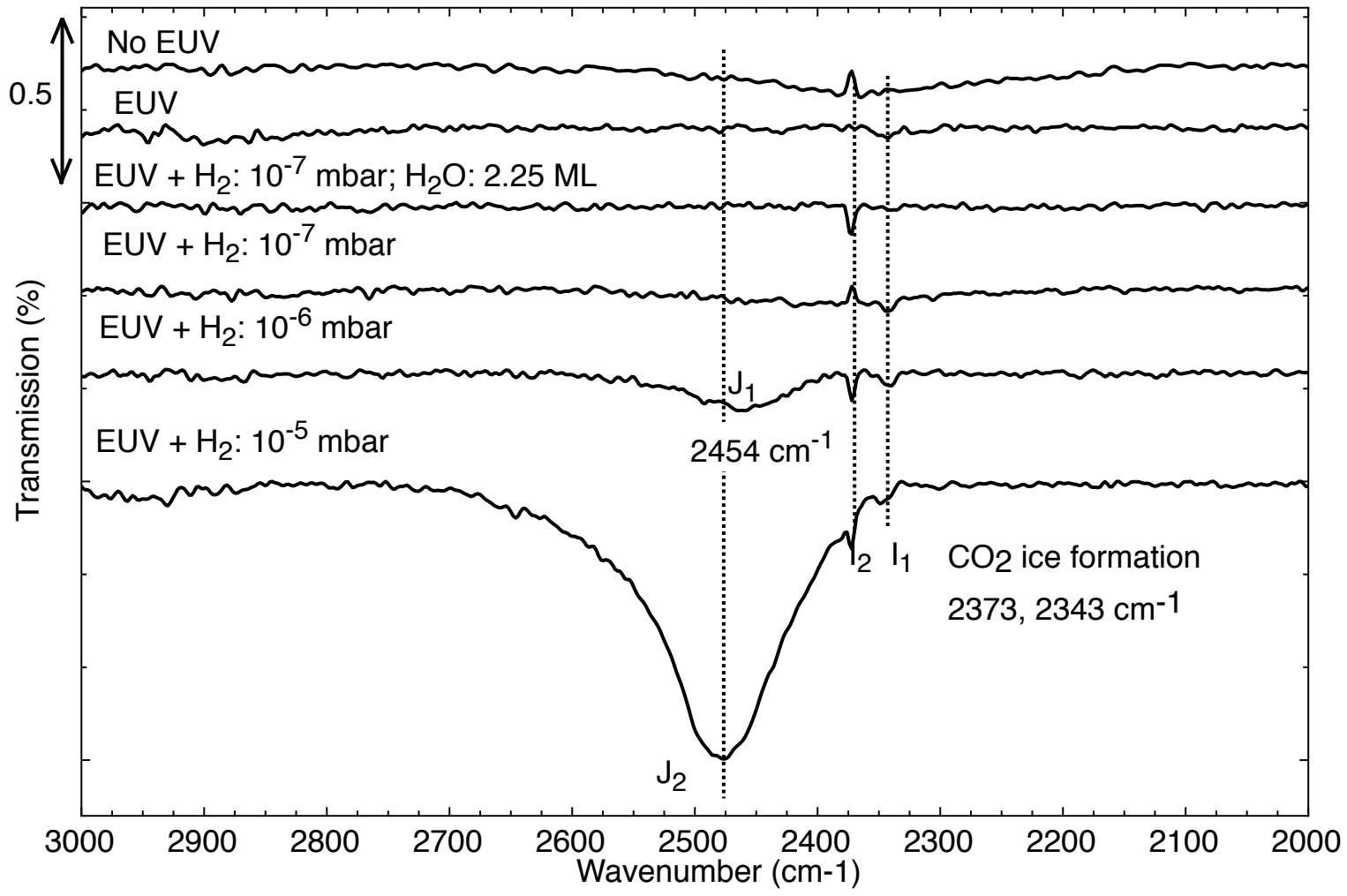

Figure 2.1. RAIRS spectra of the $\mathrm{C}=\mathrm{O}$ stretch peak of $\mathrm{CO}_{2}$, enols and aryl ketone as seen on the surface of the single layer graphene. Water dose is 0.75 ML unless otherwise specified. A new background spectrum is taken before each exposure, directly before dosing $\mathrm{H}_{2} \mathrm{O}$ to the surface.

As detailed in Gerakines et al. ${ }^{33}$, the formation of $\mathrm{CO}_{2}$ is evidenced by vibrational modes in the $2200-2400 \mathrm{~cm}^{-1}$ region. In Figure 2.1, an asymmetric $\left(v_{\text {as }}\right) \mathrm{C}=\mathrm{O}$ stretch peak is present at $2343 \mathrm{~cm}^{-1}$ and $2373 \mathrm{~cm}^{-1}$ (peak $\mathrm{I}_{1}, \mathrm{I}_{2}$ ), indicating the presence of $\mathrm{CO}_{2}$. When only water is present on the surface, in the absence of EUV, an inverse peak is seen for $\mathrm{I}_{2}$, indicating removal of $\mathrm{CO}_{2}$ from the surface. Subsequently, at higher partial pressures $\left(10^{-6}, 10^{-5} \mathrm{mbar}\right)$ of $\mathrm{H}_{2}$ in the presence of EUV, the peak reappears, indicating $\mathrm{CO}_{2}$ as a possible end product of carbon oxidation. 
With an increase in $\mathrm{H}_{2}$ concentration, a broad peak starts to form at $2454 \mathrm{~cm}^{-1}$ (peak $\mathrm{J}_{1}$ ). This corresponds to literature reports for a $\mathrm{C}=\mathrm{O}$ stretch for keto-enol formation, specifically the $\mathrm{C}=\mathrm{O}$ stretches for aryl ketones and the enol forms of a 1,3-diketone (as shown in Fig. 2.2) ${ }^{34}$ Enol of 1,3 - diketones are more favorable due to their increased stability when forming a six membered ring - hydrogen bonded in this case. $\mathrm{As}_{2}$ pressure increases, this $\mathrm{C}=\mathrm{O}$ stretch forms a broad peak at $2477 \mathrm{~cm}^{-1}$ (peak $\mathrm{J}_{2}$ ), which confirms the formation of ketones on the surface. ${ }^{32}$ In addition, a blue-shift is seen for peak $\mathrm{J}$ as the hydrogen pressure is increased, indicating more keto-enol vibrations detected on the surface. ${ }^{34}$ These ketones are formed due to graphene oxidizing and breaking down into aryl and keto-enol structures, due to EUV induced $\mathrm{H}_{2}$ and $\mathrm{H}_{2} \mathrm{O}$ dissociation on the surface. $\mathrm{H}$ radicals, formed by EUV-induced dissociation of $\mathrm{H}_{2}$, create defect sites in the graphene layer, which are subsequently oxidized by $\mathrm{OH}$ groups or $\mathrm{O}$ formed by EUV-induced $\mathrm{H}_{2} \mathrm{O}$ dissociation. As indicated in Table 2.1, exposure to a higher pressure of $\mathrm{H}_{2}$ results in additional water being deposited on the sample, due to contamination of the gas line. In order to check whether the formation of keto-enol species is indeed related to EUV induced reactions in the presence of $\mathrm{H}_{2}$ and $\mathrm{H}_{2} \mathrm{O}$ and not to EUV exposure with larger $\mathrm{H}_{2} \mathrm{O}$ coverages, a control experiment with initially higher dosed water coverage $(2.25 \mathrm{ML})$ and low $\mathrm{H}_{2}$ pressure $\left(1 \times 10^{-7} \mathrm{mbar}\right)$ is carried out. Under these conditions (Fig. 2.1, $3^{\text {rd }}$ line from top) no keto-enol formation is observed, proving that presence of $\mathrm{H}_{2}$ pressures $>1 \times 10^{-6} \mathrm{mbar}$ and adsorbed water are both needed for EUV-induced keto-enol formation. Assuming that, for the low exposures in this study, the majority of ketone formation occurs along grain boundaries (see Figure 2.2), the most likely forms are enols of 1,3-diketone and hydroxyl aryl ketones. 


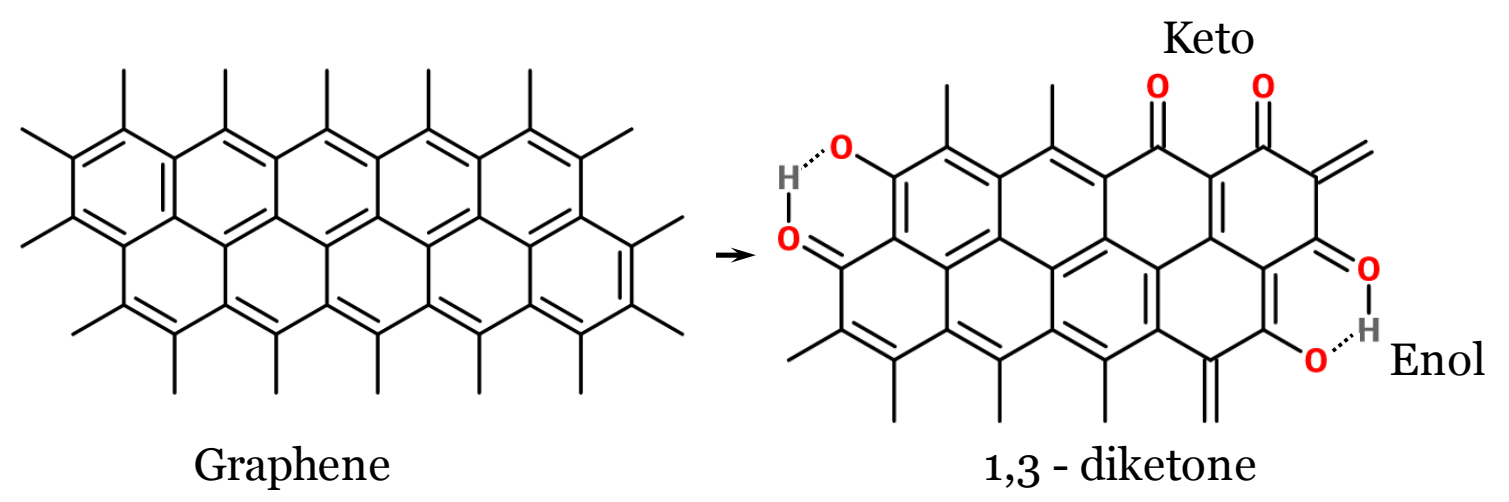

Figure 2.2. Graphene breaking down into hydroxyl aryl groups and subsequently forming ketones. Aryl ketones and keto-enol tautomerism have the same stretch vibration absorbed at $2400-2500 \mathrm{~cm}^{-1} .^{34}$

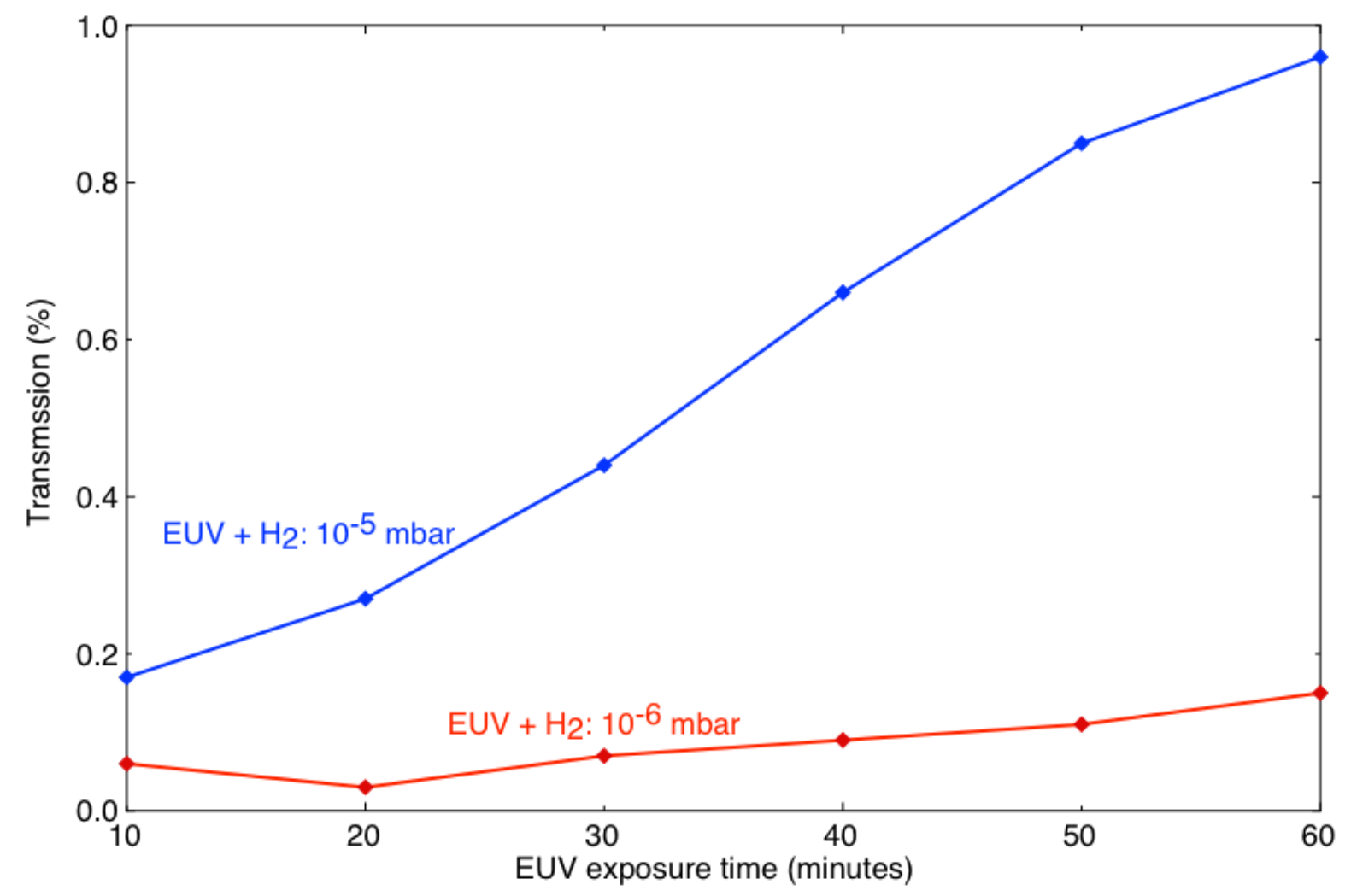

Figure 2.3. Growth of keto-enol $\mathrm{C}=\mathrm{O}$ stretch (peak $\mathrm{J}$ ) as compared to EUV exposure time at different $\mathrm{H}_{2}$ pressures. The vertical axis indicates the negative peak intensity in the RAIRS transmission plot, so a higher value indicates larger surface coverage. 
Keto-enol formation is only seen at a high hydrogen pressure $\left(10^{-5}-10^{-6} \mathrm{mbar}\right)$, due to higher defect creation by EUV-induced radicals, which is compared in Figure 2.3. At a $\mathrm{H}_{2}$ pressure of $10^{-6}$ mbar and $10^{-5}$ mbar, the height of peak $\mathrm{J}$ increases at a rate of $0.0015 \% / \mathrm{min}$ and $0.0132 \% / \mathrm{min}$ respectively. This increase in peak height is 8.8 times the rate at $10^{-6} \mathrm{mbar}$, indicating that graphene begins oxidizing rapidly with a higher partial pressure of $\mathrm{H}_{2}$.

Two locations are most likely for oxidation, and the formation of enols and ketones: point defects and grain boundaries. Point defects can be effectively determined using Raman spectroscopy. Results from Cancado et al. ${ }^{35}$ state that $\mathrm{I}_{\mathrm{D}} / \mathrm{I}_{\mathrm{G}}$ ratios of graphene can be used to specify the inter defect distance. A graphene reference layer produced with the same growth process, but transferred onto a Ni surface instead of a Si surface has an $I_{D} / I_{G}$ of 0.75 , which translates to an inter-defect distance of $14 \mathrm{~nm}$. Since the typical grain size of our graphene is $\sim 100 \mathrm{~nm}$, corresponding to a typical grain area of $\sim 8000 \mathrm{~nm}^{2}$, this inter-defect distance would correspond to $\sim 100$ point defects per grain, one order lower than the oxidation sites available through grain boundaries. ${ }^{36}$ Therefore, it is likely that the RAIRS spectral changes are dominated by ketone formation along the grain boundaries which leads to grain boundaries unzipping at higher $\mathrm{H}_{2}$ pressures, to form more sites for oxidation. ${ }^{36}$

\subsubsection{Saturation of enol formation on the surface}

As discussed earlier, enols of 1-3 di-ketone are most likely formed due to the preferential oxidation of graphene along grain boundaries. Further sequential experiments are conducted to test if oxidation saturates: e.g., that the grain boundaries become fully oxidized and oxidation then slows. This can be seen in Figure 2.4 where the growth of the $\mathrm{C}=\mathrm{O}$ stretch from enols and aryl ketone (peak $\mathrm{J}$ ) for different exposures is shown. As noted earlier, peak $\mathrm{J}$ first appears when the $\mathrm{H}_{2} \mathrm{O}$ covered surface is exposed to EUV and molecular $\mathrm{H}_{2}$ at $10^{-6}$ mbar (trace I), indicating that graphene is starting to oxidize. As mentioned previously, this peak increases with increasing mol. $\mathrm{H}_{2}$ pressure (trace II). Following these exposures, the surface is again exposed to EUV 
and $\mathrm{H}_{2}$ at $10^{-6} \mathrm{mbar}$ (trace III). As seen in curve III in Figure 2.4, there is no indication of further (out of plane) enol or aryl ketone formation on the surface for this partial pressure. This is because oxidation of the graphene layer at $\mathrm{H}_{2}$ pressure of $10^{-6} \mathrm{mbar}$ has saturated, and for further oxidation to happen, the $\mathrm{H}_{2}$ pressure needs to be increased to create additional defect sites where water can react. Furthermore, at a subsequent exposure at an $\mathrm{H}_{2}$ partial pressure of $10^{-5} \mathrm{mbar}$ (trace IV) enol and aryl ketone growth is much slower than in the previous experiment at the same pressure (trace II), indicating that the oxidation process is saturating.

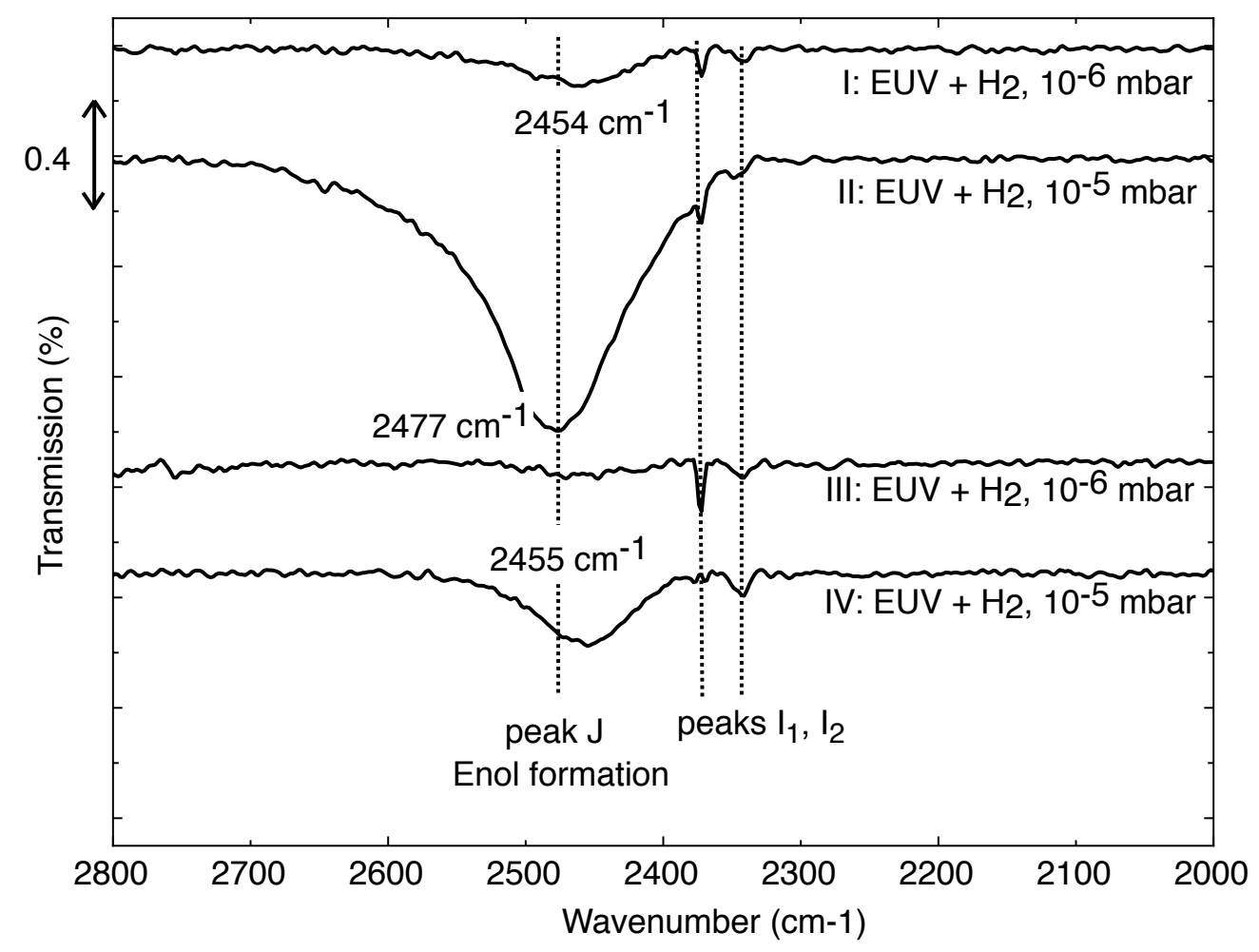

Figure 2.4. Change in keto-enol formation (peak $J$ ) after subsequent exposures of EUV and $\mathrm{H}_{2}$ to the graphene layer at $10^{-6}$ and $10^{-5} \mathrm{mbar}$. A new background spectrum is taken after each exposure.

This growth for peak $\mathrm{J}$ can be quantified in Figure 2.5 where the change in keto-enol formation is measured over the course of one hour at different EUV exposures and $\mathrm{H}_{2}$ pressures. As seen in Table 2.2, the rate of growth of peak $\mathrm{J}$ is shown to reduce with increasing molecular $\mathrm{H}_{2}$ pressure in the presence of EUV, indicating that keto-enol formation saturates as exposure time to EUV and $\mathrm{H}_{2}$ increases. 


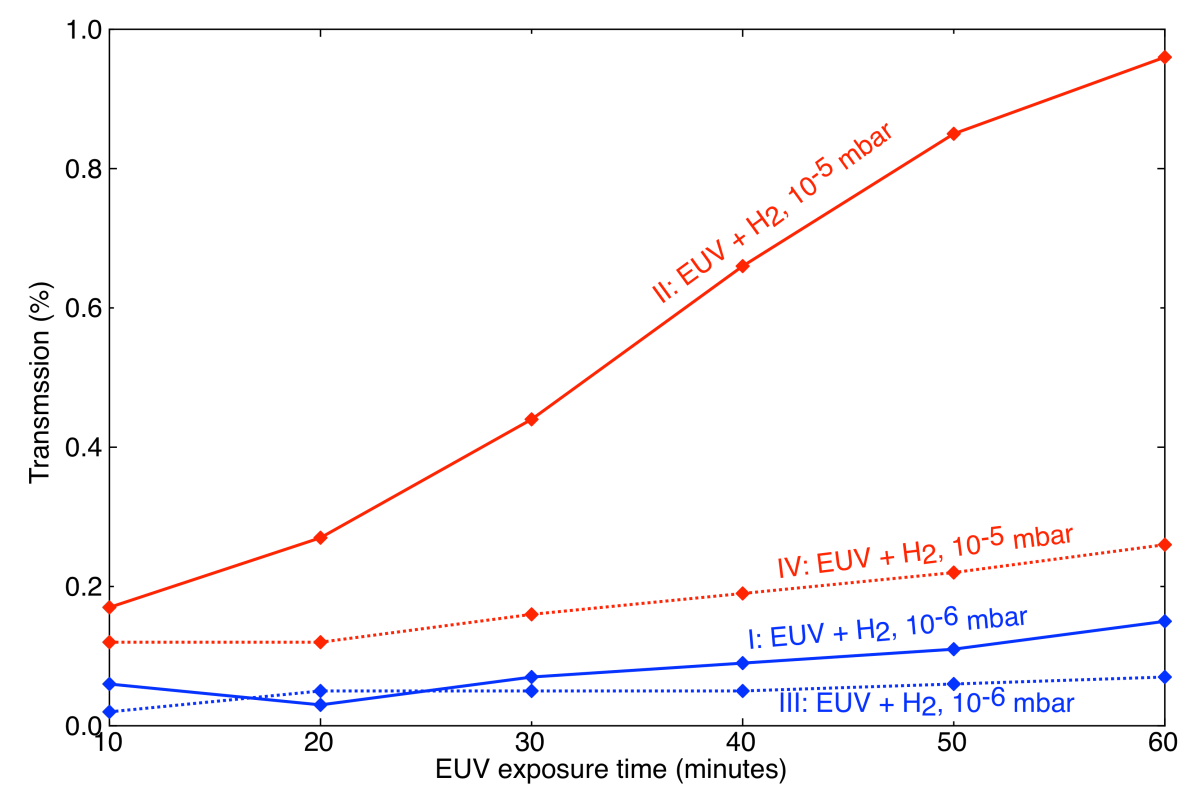

Figure 2.5. Change in keto-enol formation (peak $\mathrm{J}$ ) over time after subsequent exposures of EUV and $\mathrm{H}_{2}$ to the graphene layer at $10^{-6}$ and $10^{-5}$ mbar. A new background spectrum is taken after each exposure.

Table 2.2. Rate of growth of keto-enol formation (peak $\mathrm{J}$ ) as seen in Figure 2.5.

\begin{tabular}{|l|l|}
\hline Traces & $\frac{\text { Transmission \% }}{\text { minute }}$ \\
\hline I : EUV $+\mathrm{H}_{2}, 10^{-6} \mathrm{mbar}$ & 0.0015 \\
\hline II: $\mathrm{EUV}+\mathrm{H}_{2}, 10^{-5} \mathrm{mbar}$ & 0.0132 \\
\hline III: $\mathrm{EUV}+\mathrm{H}_{2}, 10^{-6} \mathrm{mbar}$ & 0.0008 \\
\hline IV: EUV $+\mathrm{H}_{2}, 10^{-5} \mathrm{mbar}$ & 0.0023 \\
\hline
\end{tabular}




\subsubsection{Temperature Programmed Desorption of water from graphene surface}

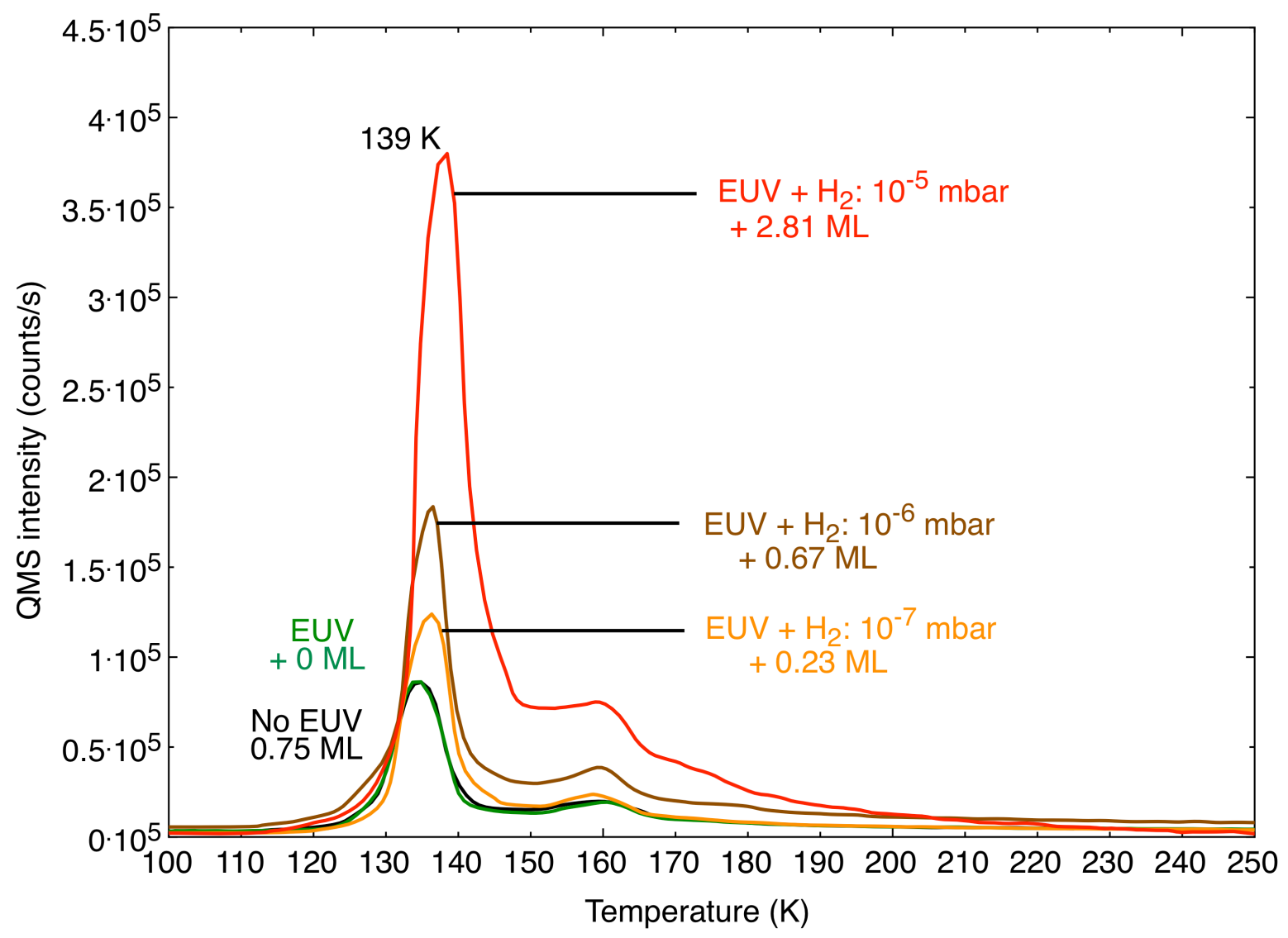

Figure 2.6. TPD spectra of $\mathrm{H}_{2} \mathrm{O}$ after deposition of water and exposure to $\mathrm{EUV}$ and $\mathbf{H}_{2}$. The numbers refer to additional water seen on the surface as compared to the surface without EUV and $\mathrm{H}_{2}$. The spectra have been smoothed over 4 values.

In Figure 2.6, the temperature programmed desorption of water from the graphene/Si surface is shown. When the surface is exposed to EUV, the coverage of water does not change significantly. An increase in water coverage is observed for higher hydrogen pressures; $0.23 \mathrm{ML}$ for $10^{-7} \mathrm{mbar}$ of $\mathrm{H}_{2}, 0.67 \mathrm{ML}$ for $10^{-6} \mathrm{mbar}$ of $\mathrm{H}_{2}$ and 2.81 ML for $10^{-5}$ mbar of $\mathrm{H}_{2}$. The amount of water desorbed for increasing $\mathrm{H}_{2}$ partial pressures is high due to water contamination from the $\mathrm{H}_{2}$ line.

Also, two distinct peaks can be seen for the TPD spectra in Figure 2.6, indicating that water has two binding modes on the substrate. When water is first dosed on the cold 
surface, it forms an H-bonded 2D ice network on the graphene layer. ${ }^{37}$ As more water is deposited on top of the surface, a 3D ice network forms. The desorption peak seen at $\sim 139 \mathrm{~K}$ in Figure 2.6 is due to $\mathrm{H}_{2} \mathrm{O}$ molecules desorbing from 3D ice networks. Following this, the graphene bound $\mathrm{H}_{2} \mathrm{O}$ molecules in 2D ice networks are the next to desorb at $\sim 160 \mathrm{~K}$.

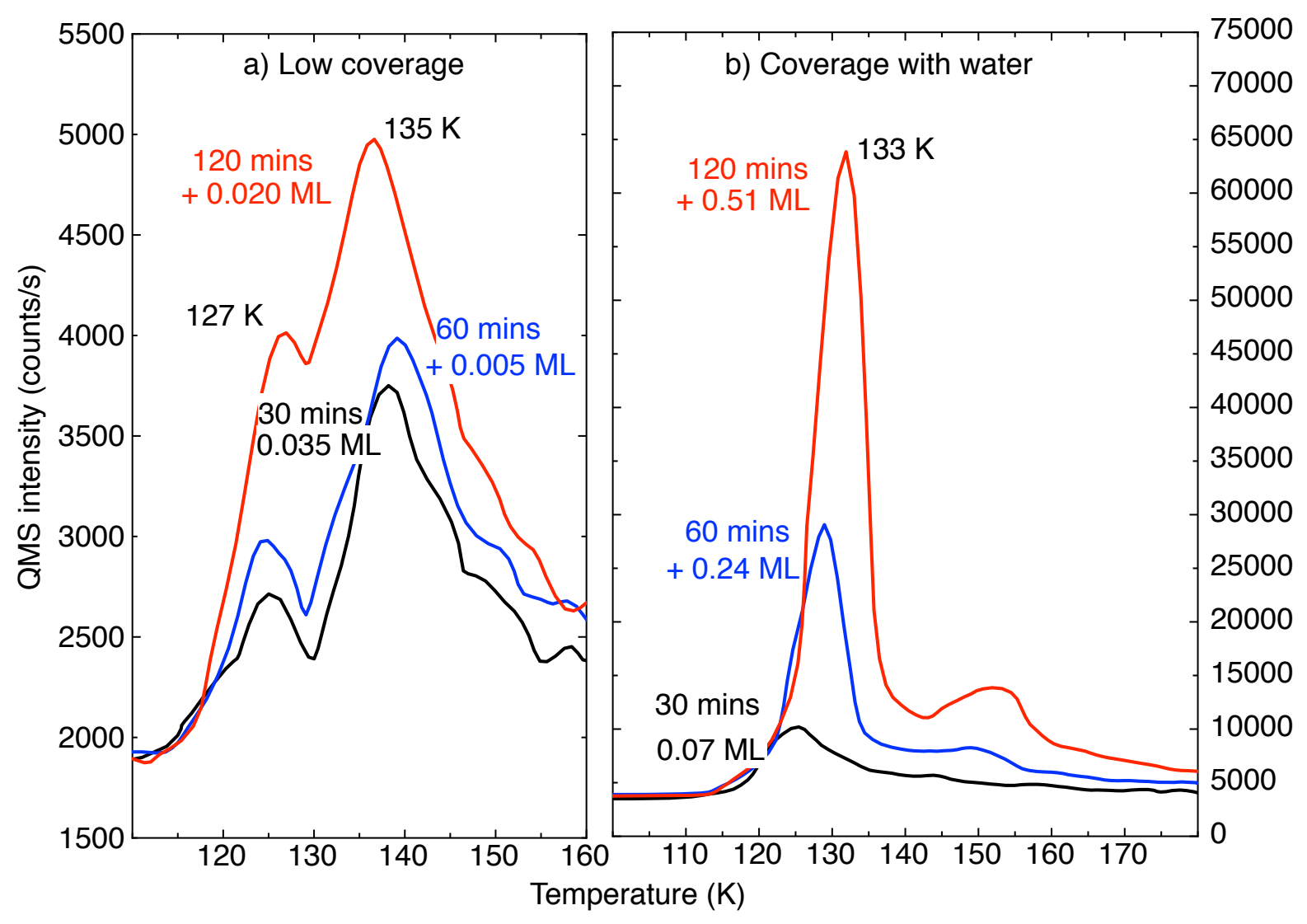

Figure 2.7. Control experiments for residual gas in chamber with (a) low coverage and (b) coverage ( $0.01 \mathrm{ML})$ with water on the surface.

For very low coverage of water, when the surface is left for 120 minutes in the chamber with no water dosed on the surface, Figure 2.7(a) shows that water coverage on the surface increases with time due to residual gases. This is also clearly noted for low coverages in Figure 2.7(b) as well, when a small amount of water (0.01 ML) is dosed on the surface. Compared to the case with no initial coverage, the amount of water in Fig. 2.7(b) increases by a factor of 3.4 and 7.3 for 60 and 120 minutes, relative to 30 minutes exposure to residual gas, respectively. In comparison, in Fig. 2.7(a), the 
water on the surface increases by a factor of 0.1 and 0.6 for the same periods of 60 and 120 minutes, indicating that water is more likely to attach to water molecules than it is to the graphene layer. Additionally, the two peaks seen for low coverages in Fig 2.7(a) illustrate that a $2 \mathrm{D}$ water network is the first to form, with water molecules attaching to the defects and grain boundaries of graphene, and then water attaching to the defect bound water. Similarly in Fig. 2.7(b), a common leading edge is seen, such that the desorption peak shifts to a higher temperature for increasing coverage, indicating peaks the two peaks in Fig 2.7(a) converging to form a singular peak. Consequently, this becomes the first desorption peak in Figure 2.6. This $0^{\text {th }}$ order desorption behavior is characteristic for desorption of water adsorbed to other water molecules as shown in Clay et al. ${ }^{38}$ Since graphene is known to be hydrophobic in nature, ${ }^{39}$ water clusters are more likely to form, such that $0^{\text {th }}$ order desorption of water can be observed, even for sub monolayer coverages. 


\subsubsection{X-ray photoelectron spectroscopy}

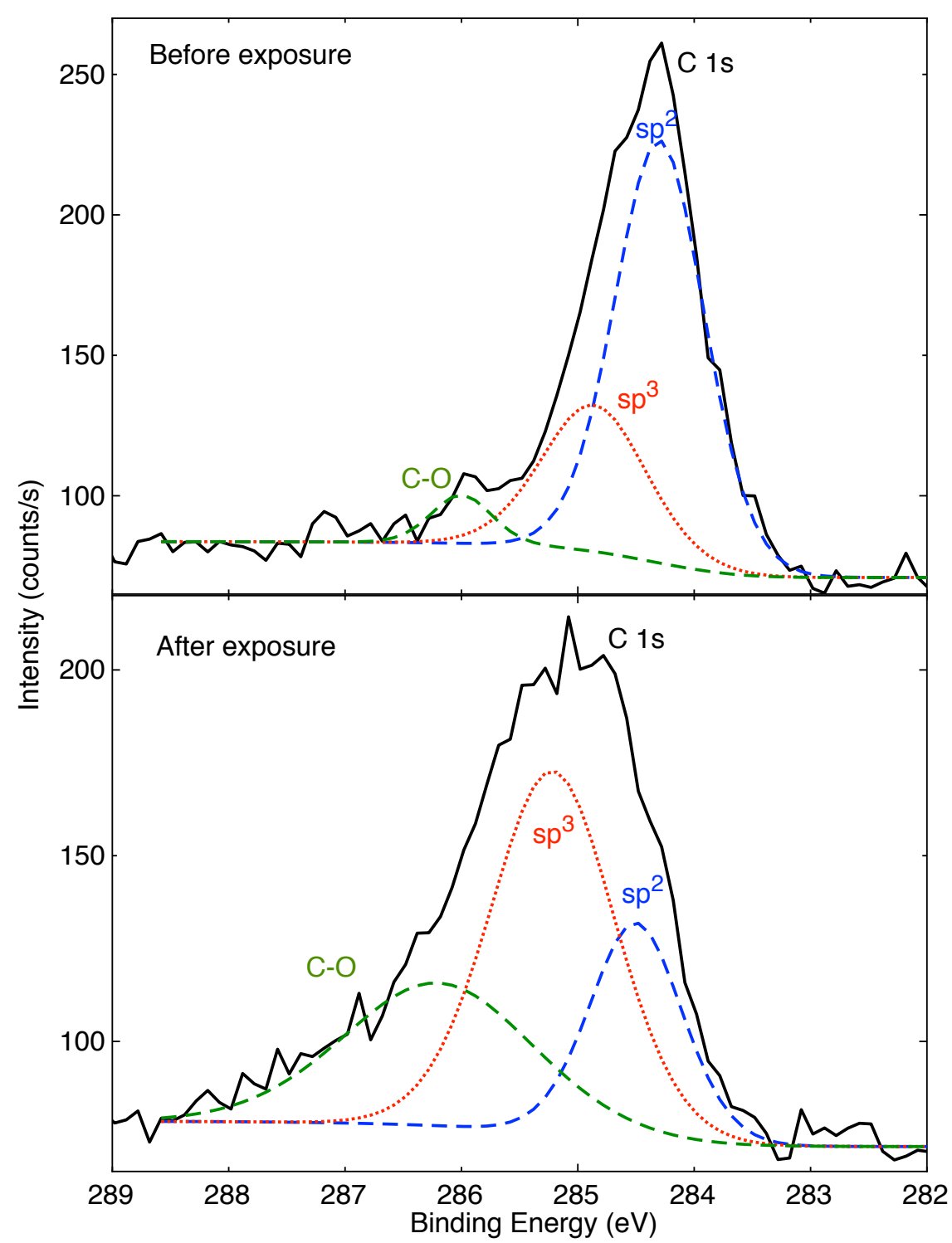

Figure 2.8. XPS spectra of graphene covered Si sample before (top) and after (bottom) exposure to EUV and $\mathrm{H}_{2}$. The C1s spectra is raw data, while $\mathrm{sp}^{2}, \mathrm{sp}^{3}$ and C-O curves are fitted.

Figure 2.8 shows the XPS spectra and fit for the C 1s peak of graphene before and after it is exposed to multiple doses of $\mathrm{H}_{2} \mathrm{O}$, EUV and $\mathrm{H}_{2}$ seen in Figures 2.1-2.7. Table 2.3 lists the atomic concentration of $\mathrm{sp}^{2}, \mathrm{sp}^{3}$ and $\mathrm{C}-\mathrm{O}$ bonds along with the full width 
half maximum of the fitted $\mathrm{sp}^{2}$ peak for the unexposed graphene sample and the sample exposed to EUV.

Notably, the $\mathrm{sp}^{2}$ bond concentration decreases from $13 \pm 1 \%$ to $6 \pm 4 \%$ after exposure, while, in contrast, the $\mathrm{sp}^{3}$ concentration increases from $5 \pm 1 \%$ to $12 \pm 4 \%$. The increase in $\mathrm{sp}^{3}$ bonding is a consequence of combination of oxidation and hydrogenation, as expected. It should be noted that the separation of the $\mathrm{sp}^{2}$ and $\mathrm{sp}^{3}$ peaks is not sufficient to make a unique peak fit for the exposed sample, which has been reflected in the error margins of the quantification.

Table 2.3. Atomic concentration of $\mathrm{C} 1 \mathrm{~s}$ spectral components, carbon thickness, native $\mathrm{SiO}_{2}$ concentration of the substrate of graphene samples before and after exposure to multiple doses of EUV and $\mathrm{H}_{2}$. The $\mathrm{C}$ thickness is measured using angle resolved XPS.

\begin{tabular}{|c|c|c|c|c|c|c|c|}
\hline Sample & $\begin{array}{l}\mathrm{C} \mathrm{sp}^{2} \\
\text { (atomic } \\
\% \text { ) }\end{array}$ & $\begin{array}{l}\mathrm{C} \mathrm{sp}^{3} \\
\text { atomic } \\
\%\end{array}$ & $\begin{array}{l}\mathrm{C}-\mathrm{O} \\
\text { (atomic } \\
\% \text { ) }\end{array}$ & $\begin{array}{l}\text { Si-O } \\
\text { (atomic } \\
\% \text { ) }\end{array}$ & $\begin{array}{l}\text { O 1s } \\
\text { (atomic } \\
\% \text { ) }\end{array}$ & $\begin{array}{l}\mathrm{sp}^{2} \\
\text { FWHM } \\
(\mathrm{eV})\end{array}$ & $\begin{array}{l}\text { Carbon } \\
\text { thickness } \\
(\mathrm{nm})\end{array}$ \\
\hline $\begin{array}{l}\text { Unexposed } \\
\text { graphene on } \\
\mathrm{Si}\end{array}$ & $13 \pm 1$ & $5 \pm 1$ & $1.0 \pm 0.3$ & $16 \pm 1$ & $26 \pm 1$ & $\begin{array}{l}0.90 \pm \\
0.1\end{array}$ & 0.34 \\
\hline $\begin{array}{l}\text { Exposed } \\
\text { graphene on } \\
\mathrm{Si}\end{array}$ & $6 \pm 4$ & $12 \pm 4$ & $7 \pm 2$ & $15 \pm 1$ & $26 \pm 1$ & $0.9 \pm 0.2$ & 0.40 \\
\hline
\end{tabular}

The concentration of C-O groups increases from $1 \%$ to $7 \%$, confirming that graphene oxidizes in the presence of adsorbed water, and exposure to EUV and $\mathrm{H}_{2}$. It should be noted that the high $\mathrm{sp}^{2}$ content of pristine graphene results in a tail of the $\mathrm{sp}^{2}$ peak extending up to the binding energy range where $\mathrm{C}-\mathrm{O}$ bonds are detected for exposed 
graphene. ${ }^{40}$ Therefore, the quantified amount of C-O species may be overestimated for the unexposed sample.

Finally, a slight increase in carbon thickness is observed, due to the deposition of amorphous hydrocarbons from residual hydrocarbons in the EUV source, or due to sample handling. ${ }^{41,42}$

\subsection{Conclusions}

Single layer graphene on an amorphous silicon substrate exposed to EUV radiation in the presence of water and hydrogen, is shown to break down from its signature aromatic structure through the formation of ketone and enol groups, such as the enol forms of 1,3-diketone, most likely at the grain boundaries and/or point defects. This formation is noted via RAIRS, which indicates that ring structure degradation occurs through graphene oxidation, due to the water present on the surface. Additionally, this can be confirmed by XPS which shows an increase in the bond percentage of oxygen bound to carbon on the surface after EUV exposure. Meanwhile, $\mathrm{sp}^{2}$ bonds in graphene cleave to form $\mathrm{sp}^{3}$ bonds, also confirmed via XPS, due to EUV photons and/or hydrogen radicals breaking $\mathrm{sp}^{2}$ bonds, leading to graphene becoming more defective. Furthermore, the rate of the oxidation process at given water coverage and hydrogen pressure slows down and nearly saturates over time, while still $\mathrm{sp}^{2}$ carbon is left after the exposure. This behavior could be attributed to saturation of the reaction occurring at grain boundaries and point defects. Finally, this work shows that the balance of EUVinduced photochemistry of graphene in the presence of water and hydrogen is very different from ruthenium, an important reference capping material for EUV optics ${ }^{43}$. While for ruthenium an increased pressure of $\mathrm{H}_{2}$ leads to (complete) reduction of the oxidation of the Ru resulting from EUV induced reactions of water, in case of graphene the oxidation reaction is enhanced by a higher hydrogen pressure. This shows that a balance between oxidation and reduction of a graphene cap can most likely not be obtained, such that the use of graphene with a low defect density is of utmost importance. 


\subsection{References}

(1) Geim, A. K.; Novoselov, K. S. The Rise of Graphene. Nature materials 2007, 6 (3), 183-191.

(2) Geim, A. K. Graphene: Status and Prospects. Science 2009, 324 (5934), 15301534.

(3) Hu, S.; Lozada-Hidalgo, M.; Wang, F. C.; Mishchenko, A.; Schedin, F.; Nair, R. R.; Hill, E. W.; Boukhvalov, D. W.; Katsnelson, M. I.; Dryfe, R. A. W.; et al. Proton Transport Through One-Atom-Thick Crystals. Nature 516 (7530), 227230.

(4) Novoselov, K. S.; Jiang, D.; Schedin, F.; Booth, T. J.; Khotkevich, V. V.; Morozov, S. V.; Geim, A. K. Two-Dimensional Atomic Crystals. Proceedings of the National Academy of Sciences of the United States of America 2005, 102 (30), 10451-10453.

(5) Lee, C.; Wei, X.; Kysar, J. W.; Hone, J. Measurement of the Elastic Properties and Intrinsic Strength of Monolayer Graphene. Science 2008, 321 (5887), 385388.

(6) Han, M.; Özyilmaz, B.; Zhang, Y.; Kim, P. Energy Band-Gap Engineering of Graphene Nanoribbons. Physical Review Letters 2007, 98 (20).

(7) Bolotin, K. I.; Sikes, K. J.; Jiang, Z.; Klima, M.; Fudenberg, G.; Hone, J.; Kim, P.; Stormer, H. L. Ultrahigh Electron Mobility in Suspended Graphene. Solid State Communications 2008, 146 (9-10), 351-355.

(8) Zhang, Y.; Tan, Y. W.; Stormer, H. L.; Kim, P. Experimental Observation of the Quantum Hall Effect and Berry's Phase in Graphene. Nature 2005, 438 (7065), 201-204.

(9) Bunch, J. S.; Verbridge, S. S.; Alden, J. S.; van der Zande, A. M.; Parpia, J. M.; Craighead, H. G.; McEuen, P. L. Impermeable Atomic Membranes From Graphene Sheets. Nano letters 2008, 8 (8), 2458-2462.

(10) Berry, V. Impermeability of Graphene and Its Applications. Carbon 2013, 62 (0), 1-10.

(11) Zande, A. M. V. D.; Barton, R. A.; Alden, J. S.; Ruiz-Vargas, C. S.; Whitney, W. S.; Pham, P. H. Q.; Park, J.; Parpia, J. M.; Craighead, H. G.; McEuen, P. L. Large- 
Scale Arrays of Single-Layer Graphene Resonators. Nano letters 2010, 10 (12), 4869-4873.

(12) Suk, J. W.; Kitt, A.; Magnuson, C. W.; Hao, Y.; Ahmed, S.; An, J.; Swan, A. K.; Goldberg, B. B.; Ruoff, R. S. Transfer of CVD-Grown Monolayer Graphene Onto Arbitrary Substrates. ACS Nano 2011, 5 (9), 6916-6924.

(13) Nair, R. R.; Blake, P.; Grigorenko, A. N.; Novoselov, K. S.; Booth, T. J.; Stauber, T.; Peres, N. M. R.; Geim, A. K. Fine Structure Constant Defines Visual Transparency of Graphene. Science 2008, 320 (5881), 1308-1308.

(14) Henke, B. L.; Gullikson, E. M.; Davis, J. C. X-Ray Interactions: Photoabsorption, Scattering, Transmission, and Reflection at $\mathrm{E}=50-30,000 \mathrm{eV}, \mathrm{Z}=1-92$. Atomic Data and Nuclear Data Tables 1993, 54 (2), 181-342.

(15) Bayraktar, M.; Wessels, W. A.; Lee, C. J.; van Goor, F. A.; Koster, G.; Rijnders, G.; Bijkerk, F. Active Multilayer Mirrors for Reflectance Tuning at Extreme Ultraviolet (EUV) Wavelengths. J. Phys. D: Appl. Phys. 2012, 45 (49), 494001.

(16) Jiang, D.-E.; Sumpter, B. G.; Dai, S. Unique Chemical Reactivity of a Graphene Nanoribbon's Zigzag Edge. J. Chem. Phys. 2007, 126 (13), 134701.

(17) Liu, L.; Qing, M.; Wang, Y.; Chen, S. Defects in Graphene: Generation, Healing, and Their Effects on the Properties of Graphene: a Review. A Special Issue on $1 D$ NanomaterialsSynthesis, Properties, and Applications 2015, 31 (6), 599-606.

(18) Denis, P. A.; Iribarne, F. Comparative Study of Defect Reactivity in Graphene. J. Phys. Chem. C 2013, 117 (37), 19048-19055.

(19) Pachecka, M.; Sturm, J. M.; Lee, C. J.; Bijkerk, F. Adsorption and Dissociation of CO 2on Ru(0001). J. Phys. Chem. C 2017, acs.jpcc.7b00021.

(20) Madey, T. E.; Faradzhev, N. S.; Yakshinskiy, B. V.; Edwards, N. V. Surface Phenomena Related to Mirror Degradation in Extreme Ultraviolet (EUV) Lithography. Applied Surface Science 2006, 253 (4), 1691-1708.

(21) Astakhov, D. I.; Goedheer, W. J.; Lee, C. J.; Ivanov, V. V.; Krivtsun, V. M.; Koshelev, K. N.; Lopaev, D. V.; van der Horst, R. M.; Beckers, J.; Osorio, E. A.; et al. Exploring the Electron Density in Plasma Induced by EUV Radiation: II. Numerical Studies in Argon and Hydrogen. J. Phys. D: Appl. Phys. 2016, 49 (29), 295204. 
(22) Mertens, B. M.; van der Zwan, B.; de Jager, P. W. H.; Leenders, M.; Werij, H. G. C.; Benschop, J. P. H.; van Dijsseldonk, A. J. J. Mitigation of Surface Contamination From Resist Outgassing in EUV Lithography. Microelectronic Engineering 53 (1-4), 659-662.

(23) Klebanoff, L. E.; Malinowski, M. E.; Clift, W. M.; Steinhaus, C.; Grunow, P. Use of Gas-Phase Ethanol to Mitigate Extreme UV/Water Oxidation of Extreme UV Optics. Journal of Vacuum Science \& Technology A: Vacuum, Surfaces, and Films 2004, 22 (2), 425-432.

(24) Sun, Q. The Raman $\mathrm{OH}$ Stretching Bands of Liquid Water. Vibrational Spectroscopy 51 (2), 213-217.

(25) Gao, A.; Zoethout, E.; Sturm, J. M.; Lee, C. J.; Bijkerk, F. Defect Formation in Single Layer Graphene Under Extreme Ultraviolet Irradiation. Applied Surface Science 2014, 317, 745-751.

(26) Mitoma, N.; Nouchi, R.; Tanigaki, K. Photo-Oxidation of Graphene in the Presence of Water. J. Phys. Chem. C 2013, 117 (3), 1453-1456.

(27) Li, X.; Cai, W.; An, J.; Kim, S.; Nah, J.; Yang, D.; Piner, R.; Velamakanni, A.; Jung, I.; Tutuc, E.; et al. Large-Area Synthesis of High-Quality and Uniform Graphene Films on Copper Foils. Science 2009, 324 (5932), 1312-1314.

(28) Liu, F.; Sturm, J. M.; Lee, C. J.; Bijkerk, F. Extreme UV Induced Dissociation of Amorphous Solid Water and Crystalline Water Bilayers on Ru(0001). Surface Science 2016, 646, 101-107.

(29) Sturm, J. M.; Lee, C. J.; Bijkerk, F. Reactions of Ethanol on Ru(0001). Surface Science 2013, 612, 42-47.

(30) Soer, W. A.; Jak, M. J. J.; Yakunin, A. M.; van Herpen, M. M. J. W.; Banine, V. Y. Grid Spectral Purity Filters for Suppression of Infrared Radiation in LaserProduced Plasma EUV Sources; Schellenberg, F. M., La Fontaine, B. M., Eds.; SPIE, 2009; Vol. 7271, pp 72712Y-72712Y-9.

(31) Kieft, E. R.; van der Mullen, J. J. A. M.; Kroesen, G. M. W.; Banine, V. TimeResolved Pinhole Camera Imaging and Extreme Ultraviolet Spectrometry on a Hollow Cathode Discharge in Xenon. Phys. Rev. E 2003, 68 (5), 056403.

(32) Silverstein, R. W.; Bassler, G. C. Spectrometric Identification of Organic Compounds. Journal of Chemical Education 1962, 39 (11), 546-553. 
(33) Gerakines, P. A. Infrared Band Strengths: Laboratory Techniques and Applications to Astronomical Observations. Bulletin of the American Astronomical Society 2002, 34, 911.

(34) Silverstein, R. M.; Webster, F. X.; Kiemle, D. J.; Bryce, D. L. Spectrometric Identification of Organic Compounds; John Wiley \& Sons, 2014.

(35) Cancado, L. G.; Jorio, A.; Ferreira, E. H.; Stavale, F.; Achete, C. A.; Capaz, R. B.; Moutinho, M. V.; Lombardo, A.; Kulmala, T. S.; Ferrari, A. C. Quantifying Defects in Graphene via Raman Spectroscopy at Different Excitation Energies. Nano letters 2011, 11 (8), 3190-3196.

(36) Ruiz-Vargas, C. S.; Zhuang, H. L.; Huang, P. Y.; van der Zande, A. M.; Garg, S.; McEuen, P. L.; Muller, D. A.; Hennig, R. G.; Park, J. Softened Elastic Response and Unzipping in Chemical Vapor Deposition Graphene Membranes. Nano letters 2011, 11 (6), 2259-2263.

(37) Clemens, A.; Hellberg, L.; Gronbeck, H.; Chakarov, D. Water Desorption From Nanostructured Graphite Surfaces. Physical chemistry chemical physics : PCCP 2013, 15 (47), 20456-20462.

(38) Clay, C.; Haq, S.; Hodgson, A. Intact and Dissociative Adsorption of Water on Ru(0001). Chemical Physics Letters 2004, 388 (1), 89-93.

(39) Werder, T.; Walther, J. H.; Jaffe, R. L.; Halicioglu, T.; Koumoutsakos, P. On the Water-Carbon Interaction for Use in Molecular Dynamics Simulations of Graphite and Carbon Nanotubes. J. Phys. Chem. B 2003, 107 (6), 1345-1352.

(40) Díaz, J.; Paolicelli, G.; Ferrer, S.; Comin, F. Separation of the Sp3 and Sp2 Components in the C1s Photoemission Spectra of Amorphous Carbon Films. Phys. Rev. B 1996, 54 (11), 8064-8069.

(41) Chen, J.; Louis, E.; Wormeester, H.; Harmsen, R.; van de Kruijs, R.; Lee, C. J.; van Schaik, W.; Bijkerk, F. Carbon-Induced Extreme Ultraviolet Reflectance Loss Characterized Using Visible-Light Ellipsometry. Measurement Science and Technology 2011, 22 (10), 105705.

(42) Chen, J.; Louis, E.; Lee, C. J.; Wormeester, H.; Kunze, R.; Schmidt, H.; Schneider, D.; Moors, R.; van Schaik, W.; Lubomska, M.; et al. Detection and Characterization of Carbon Contamination on EUV Multilayer Mirrors. Opt. Express 2009, 17 (19), 16969-16979. 
(43) Nishiyama, I.; Oizumi, H.; Motai, K.; Izumi, A.; Ueno, T.; Akiyama, H.; Namiki, A. Reduction of Oxide Layer on Ru Surface by Atomic-Hydrogen Treatment. $J$. Vac. Sci. Technol. B 2005, 23 (6), 3129. 


\section{Chapter 3: Etching processes of transferred and non-transferred multi- layer graphene in the presence of Extreme $\mathrm{UV}, \mathrm{H}_{2} \mathrm{O}$ and $\mathrm{H}_{2}$}

In this work we expose transferred multi-layer graphene (i.e. graphene separated from the substrate used for graphene growth and placed onto a carrier sample) to Extreme Ultraviolet light and water, in the presence of hydrogen. We see that graphene oxidizes by breaking down its aromatic structure into the enol form of 1,3-diketone. Furthermore, this oxidation is compared with studies on as-grown multi-layer graphene samples, which are shown not to oxidize. Our work shows that oxidation is most likely limited to a few layers of graphene at the interface between the graphene and the substrate onto which it is transferred. This is attributed to the influence of water trapped from the transfer process, in combination with a higher secondary electron yield of the substrate compared to graphene.

\subsection{Introduction}

Graphene, a 2D hexagonal lattice structure of carbon with covalently bound atoms, has been shown to possess a number of unique physical, thermal, and chemical properties. ${ }^{1-8}$ Defect-free single layer graphene has been known to be impermeable to gases $^{9,10}$, whereas defective multi-layer graphene has been shown to be effective as a membrane ${ }^{11}$, and can be used to transfer protons through atomic defects. ${ }^{12}$ Multi-layer graphene as a membrane has been introduced as a potential candidate for inexpensive water desalination ${ }^{13}$, food packing ${ }^{14}$, and anti-corrosion paint. ${ }^{15}$

Optically, graphene is known to have highly desirable traits such as being transparent in both visible ${ }^{16}$ and Extreme Ultraviolet (EUV) wavelengths ${ }^{17,18}$. These properties make graphene an attractive candidate for transparent conductive electrodes, such as flexible 
screens for smartphones and wearable devices, and EUV optics. Also, high transparency in the EUV regime is seen as being very desirable, as most optics in EUV applications require a layer to protect them from chemical processes induced by high photon-energy radiation ${ }^{5}$.

Single layer graphene, known for its low chemical reactivity, is highly susceptible to the formation of defects during growth, via chemical vapor deposition, and graphene transfer ${ }^{19}$. These can initiate points for oxidation and further defect formation when graphene interacts with its environment ${ }^{20}$. Furthermore, for single layer graphene, being one atomic layer thick, its chemical reactivity is highly dependent on the substrate on which it is transferred. In chemically reactive environments these drawbacks could be unfavorable for using single layer graphene as a protective layer. Multi-layer graphene has been provided as an alternative, which would still maintain most of the properties of single layer graphene, while being less reactive and more robust due to its larger thickness. ${ }^{21}$ Furthermore, optical components are required to last the full lifetime of beamline or imaging optics. ${ }^{22}$ Therefore, it is important to understand the physical, chemical and electronic stability of multi-layer graphene and its reaction pathways in an EUV environment.

Previous research has shown that single-layer graphene in an EUV environment starts to oxidize when dosed with less than a monolayer of water (0.75 ML) and exposed in a partial pressure of $10^{-5} \mathrm{mbar} \mathrm{H}_{2}{ }^{23}$. This oxidation is in the form of an enol form of 1,3-diketone which is characterized in-situ using Reflection Absorption Infrared Spectroscopy (RAIRS). It is surmised that this diketone formation is due to the aromatic structure breakdown of graphene. The formation of the diketone is shown to saturate for prolonged exposure to water, EUV and $\mathrm{H}_{2}$ under identical exposure conditions.

In this work, we further expand on 1,3-diketone formation and look for its prevalence in multi-layer graphene under the same EUV exposure conditions and in-situ RAIRS characterization. We show that as-grown multi-layer graphene is resistant to oxidation when dosed with $\mathrm{H}_{2} \mathrm{O}$ and exposed to EUV and $\mathrm{H}_{2}$. However, transferred MLG is shown 
to oxidize, due to the secondary electron interaction of water trapped between the interface between the graphene layer and the underlying substrate.

\subsection{Experimental}

As a substrate, $300 \mathrm{~nm} \mathrm{SiO}$ is grown on a $\mathrm{Si}(100)$ wafer by dry oxidation at $1100{ }^{\circ} \mathrm{C}$. Next, $70 \mathrm{~nm}$ of Mo is sputter deposited. Subsequently, the multi-layer graphene is grown by chemical vapor deposition (CVD) at $1000{ }^{\circ} \mathrm{C}$ using a feedstock of $\mathrm{Ar} / \mathrm{H}_{2} / \mathrm{CH}_{4}$ at 8 mbar in a cold-wall reaction chamber (VG Scienta at the NanoLab facilities at the University of Twente). The resultant graphene layer is then transferred onto an amorphous Si surface on a $10 \times 10 \mathrm{~mm}$ substrate, using $\mathrm{H}_{2} \mathrm{O}_{2}$ as an etchant. This transfer process is performed without the use of any support polymer (e.g. PMMA) as commonly used for the transfer of single layer graphene, enabling a residue-free graphene transfer. $^{24}$

The substrates onto which MLG is transferred have a top layer of $22 \mathrm{~nm}$ of amorphous $\mathrm{Si}(\mathrm{aSi})$ on top of $9 \mathrm{~nm}$ of Mo deposited on a Si wafer. Both layers of Mo and aSi are sputter deposited, with their thicknesses calibrated by X-ray reflectivity measurements. Since the amorphous silicon is not protected from the environment after deposition, the top $1 \sim 2 \mathrm{~nm}$ of the surface is oxidized. The Mo layer is sandwiched between the aSi layer and the Si wafer to provide a reflective surface for IR radiation, to conduct RAIRS characterization, which is performed in-situ.

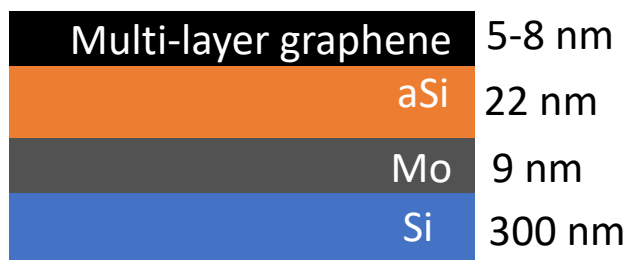

Figure 3.1. Schematic representation of multi-layer stack used for transferred multi-layer graphene experiments. 
For EUV exposure experiments, the MLG-on-aSi sample is mounted on a 3-axis positioning manipulator in Ultra-High Vacuum conditions and maintained at a base pressure of $10^{-10}$ mbar. A K-type thermocouple is fixed to the sample to measure the surface temperature, and a Eurotherm temperature controller is used to control the surface temperature by radiative heating. Surface chemistry experiments such as water dosing and $\mathrm{Ar}^{+}$ion exposure are conducted in the same experimental setup without breaking vacuum.

The chamber is equipped with RAIRS and Temperature Programmed Desorption (TPD) spectroscopy. ${ }^{25}$ RAIRS spectra are measured at grazing incidence using a Fourier Transform Infrared (FTIR) spectrometer (Bruker Vertex 70V), which is equipped with a liquid $\mathrm{N}_{2}$ cooled detector. Each IR spectrum is summed over 256 scans with a resolution of $4 \mathrm{~cm}^{-1}$, with background and sample scans recorded at the lowest possible stable surface temperature $(\sim 85 \mathrm{~K})$. The sample is placed $\sim 1 \mathrm{~mm}$ away from the aperture of a Hiden Analytical 3F/PIC quadruple mass spectrometer to obtain TPD spectra. Deionized water is dosed on the surface using a retractable quartz tube connected via a pinhole. Surface coverage is calibrated against reference TPD spectra obtained from a clean $\mathrm{Ru}(0001)$ surface $^{26,27}$.

The chamber is also attached to a Xe plasma discharge Extreme Ultraviolet source (Philips EUV Alpha Source 2) with a repetition rate of $500 \mathrm{~Hz}$. EUV light is filtered from the source using a Mo/Si reflective mirror (55\% reflectivity at $13.5 \mathrm{~nm}$ ) and transmission through a $\mathrm{Si} / \mathrm{Mo} / \mathrm{Zr}$ membrane $(35 \% \text { transmission at } 13.5 \mathrm{~nm})^{11,13}$. This results in a total transmission of $19.25 \%$ at $13.5 \mathrm{~nm}$ with a FWHM of $0.2 \mathrm{~nm}$. The beam has a Gaussian profile $\left(F W H M=3 \mathrm{~mm}\right.$ ) with an intensity of $35-55 \mathrm{~mW} / \mathrm{cm}^{2}$, corresponding to a dose of $90-110 \mu \mathrm{J} / \mathrm{cm}^{2}$ per pulse.

The experimental procedure is, unless otherwise stated, as follows: a background IR spectrum at $85 \mathrm{~K}$ is recorded, the surface is doesd with with $0.75 \mathrm{ML}$ of water, and the surface exposed to EUV with different partial pressures of hydrogen (either $10^{-5}$ mbar or $10^{-4}$ mbar, unless otherwise stated). Further IR spectra are recorded at 10 minute 
intervals until the end of the 60 minutes of EUV $+\mathrm{H}_{2}$ exposure. Finally, TPD is performed by heating the surface to $450 \mathrm{~K}$ at a rate of $1 \mathrm{~K} / \mathrm{s}$.

X-ray Photoelectron Spectroscopy (XPS) measurements are performed ex-situ using monochromatic Al-Ka radiation, employing a ThermoFisher Theta Probe with a beam spot size of $1 \mathrm{~mm}$ in diameter. Scanning Electron Microscopy (also ex-situ) measurements are performed using a High resolution SEM (HR-SEM) using a voltage of $2 \mathrm{kV}$, with a point resolution of $1.2 \mathrm{~nm}$.

\subsection{Results and Discussion}

\subsubsection{As grown multi-layer graphene on Mo}

Previous results, mentioned in the introduction and reproduced in Figure 3.2(a), show the RAIRS data of a transferred single layer graphene when exposed to EUV, $\mathrm{H}_{2}$ $\left(10^{-5}\right.$ mbar) and $\mathrm{H}_{2} \mathrm{O}(0.75 \mathrm{ML})$ for 60 minutes. Apart from the water peaks $(\mathrm{O}-\mathrm{H}$ stretch, $\mathrm{O}-\mathrm{H}$ bend and libration), we see a peak at $\sim 2480 \mathrm{~cm}^{-1}$, corresponding to the formation of the enol form of 1,3 di-ketone. This indicates the oxidation of the graphene layer and degradation of its aromatic structure. ${ }^{28}$

For this work, an as-grown $\sim 6 \mathrm{~nm}$ thick multi-layer graphene sample is first dosed with 0.75 $\mathrm{ML}$ of $\mathrm{H}_{2} \mathrm{O}$ and then exposed to EUV at $\mathrm{H}_{2}$ partial pressures ranging from 10 ${ }^{5}$ to $10^{-3}$ mbar. Prior to exposure, a defect density (I(D)/I(G)) of 0.11 is measured using Raman spectroscopy, which corresponds to an inter-defect distance of $>24 \mathrm{~nm}$ ). ${ }^{29}$ As shown in Figure 3.2(b), with a partial pressure of $10^{-3} \mathrm{mbar}$ of $\mathrm{H}_{2}$, there is no increase in region indicative for keto-enol formation, even after 60 minutes of exposure. Indeed, this would mean that as-grown multi-layer graphene is more resistant to oxidation compared to transferred single-layer graphene.

The absence of the expected formation of a keto-enol peak on as-grown multi-layer graphene might be explained by a lower defect density for the multi-layer graphene sample. Previously investigated single layer graphene samples had an $I(D) / I(G)$ ratio 
on the order of 0.7 and an inter-defect distance of $20 \mathrm{~nm}$. To test this hypothesis, a graphene layer with a higher initial defect density is exposed to identical exposure conditions. In this experiment, we used as-grown multilayer graphene stack, $\sim 6 \mathrm{~nm}$ thick, with a higher defect ratio of $\mathrm{I}(\mathrm{D}) / \mathrm{I}(\mathrm{G})=0.31$. Again, RAIRS shows that there is no formation of a keto-enol peak when the water dosed surface (0.75 ML) is exposed to EUV at a relatively high partial pressure of $\mathrm{H}_{2}$ at $10^{-3}$ mbar. The RAIRS spectra indicate, therefore, that no oxidation is taking place in the MLG structure. This is supported by XPS measurements, which showed no increase in the C-O group contribution to the $\mathrm{C} 1 \mathrm{~s}$, nor any significant change in the O1s signal. Furthermore, no changes in $\mathrm{C} 1 \mathrm{sp}^{2}$ to $\mathrm{sp}^{3}$ ratio are observed, while changes in the C1s are previously shown to change the $\mathrm{sp}^{2}$ to $\mathrm{sp}^{3}$ ratio and the $\mathrm{C}$-O group contribution for transferred single-layer graphene under these exposure conditions. ${ }^{30}$

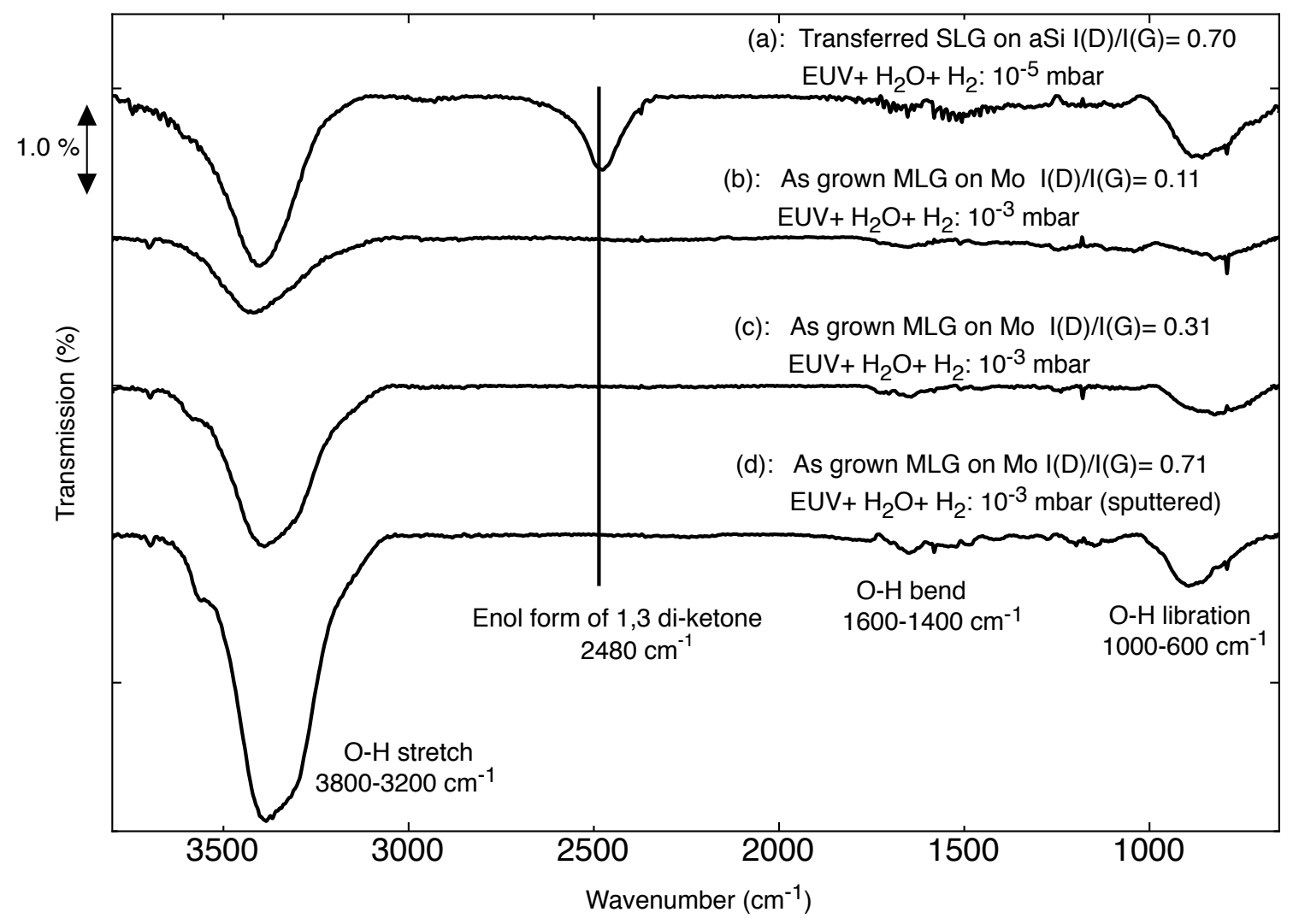

Figure 3.2. RAIRS spectra after 60 minutes of exposure to $\mathrm{H}_{2} \mathrm{O}$, EUV and $\mathrm{H}_{2}$ that show damaging of SLG at lower $\mathrm{H}_{2}$ pressures in the form of enol formation (2480 $\mathrm{cm}^{-1}$ ) in contrast to MLG which does not show any enol formation even at higher 
pressures. The hydrogen pressures and I(D)/I(G) ratios are mentioned in the plot. The peaks present in the spectra correspond to different $\mathrm{O}-\mathrm{H}$ modes of adsorbed water $^{32}$ : stretch $\left(3200-3800 \mathrm{~cm}^{-1}\right)$, bend $\left(1400-1600 \mathrm{~cm}^{-1}\right)$ and libration $(600-100$ $\left.\mathrm{cm}^{-1}\right)$.

To confirm that defect density plays little role in oxidation, the defect ratio is modified during exposure using $\mathrm{Ar}^{+}$sputtering. The graphene surface is exposed to $\mathrm{Ar}$ ions with an energy of $2.8 \mathrm{KeV}$ for a cumulative of 35 minutes (7 times 5 minute sputtering, followed by $\mathrm{H}_{2} \mathrm{O}$ dosing and EUV exposure) $\left(813 \mu \mathrm{C} / \mathrm{cm}^{2}\right)$ which is enough to remove a monolayer of graphene, according to the Bohdansky-Yamamura ${ }^{31}$ model. Similar to earlier results, there is no evidence of keto-enol formation in RAIRS for asgrown MLG dosed with water and exposed to EUV and $\mathrm{H}_{2}$. Furthermore, while ex-situ experiments such as Raman spectra showed an increase in the percentage $I(D) / I(G)$ ratio from 0.31 to 0.71 after sputtering and exposure, this did not correspond to noticeable changes in the overall $\mathrm{sp}^{2}$ to $\mathrm{sp}^{3}$ ratio after exposure or change in the C-O peak, which would reflect an oxidized MLG (Figure 3.2(d)).

\subsubsection{Transferred multi-layer graphene onto amorphous $\mathrm{Si}$}

Exposures are also performed for multi-layer graphene which is transferred $(\mathrm{I}(\mathrm{D}) / \mathrm{I}(\mathrm{G})=0.31$, after transfer) from the Mo thin film that acted as growth substrate to an amorphous Si layer. As described earlier, the surface is dosed with 0.75 ML of water, and exposed to EUV with different partial pressures of hydrogen. As shown in Figure 3.3, a keto-enol peak ${ }^{33}\left(2300-2700 \mathrm{~cm}^{-1}\right)$ forms when the water dosed $(0.75$ ML) surface is exposed to EUV at a partial pressure of $10^{-4} \mathrm{mbar} \mathrm{f}_{2}$. Similar to the case for SLG, the keto-enol peak $\left(2484 \mathrm{~cm}^{-1}\right)$ is visible after 10 mins of exposure to $\mathrm{H}_{2} \mathrm{O}$, EUV and $\mathrm{H}_{2}$.

The increasing peak intensity suggests that 1,3 -diketone continues to form during exposure, likely at the edges of graphene grain boundaries, which are relatively more hydrophilic than mid-grain points on the graphene layer ${ }^{34}$. 


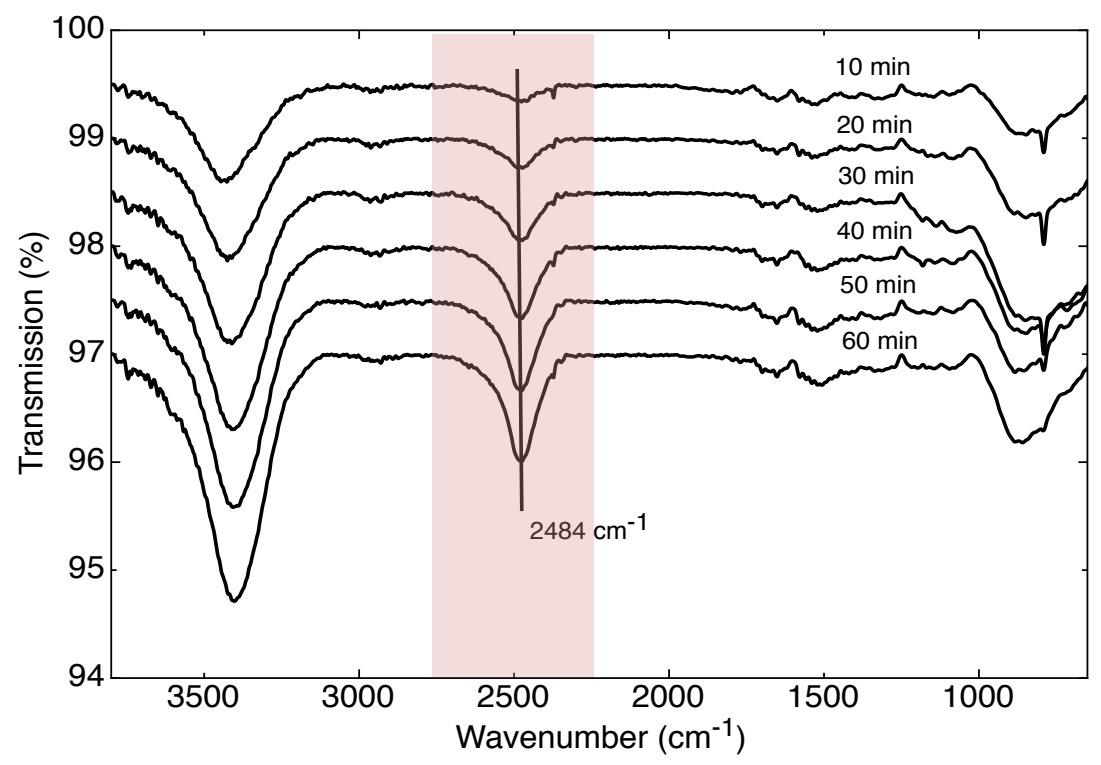

Figure 3.3. Keto-enol formation $\left(2300-2700 \mathrm{~cm}^{-1}\right)$ seen in transferred multi-layer graphene dosed with water $(0.75 \mathrm{ML})$ and exposed to EUV with a partial pressure of $10^{-4}$ mbar of $\mathrm{H}_{2}$. The other peaks shown correspond to different $\mathrm{O}-\mathrm{H}$ modes of adsorbed water ${ }^{35}$ : stretch $\left(3200-3800 \mathrm{~cm}^{-1}\right)$, bend $\left(1400-1600 \mathrm{~cm}^{-1}\right)$ and libration $\left(600-100 \mathrm{~cm}^{-1}\right)$.

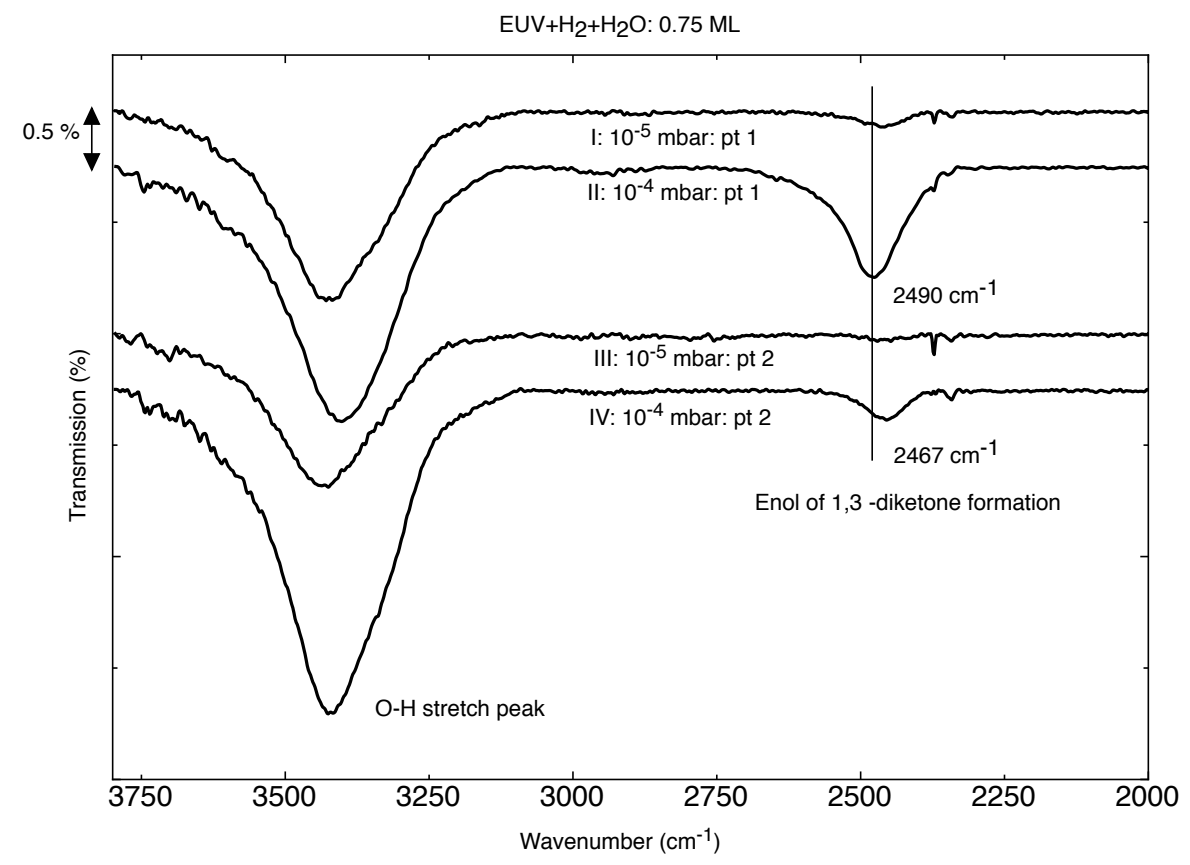

Figure 3.4. Formation of keto-enol peak in a transferred MLG stack on aSi seen around $\sim 2400-2500 \mathrm{~cm}^{-1}$, with EUV and $\mathrm{H}_{2} \mathrm{O}$ at different partial pressures of $\mathrm{H}_{2}$, 
after 60 minutes of exposure. Also, O-H stretches of adsorbed water (3200-3400 $\mathrm{cm}^{-1}$ ) are seen. The experiments are done sequentially from I to IV, with a new background taken before every experiment.

The formation of this peak is seen in more detail in Figure 3.4, curve I, where we see that the keto-enol peak first shows up when the $\mathrm{H}_{2}$ partial pressure is at $10^{-5}$ mbar. Firstly, the peak continues to grow over 60 minutes with peak intensity at $2467 \mathrm{~cm}^{-1}$. Secondly, after increasing the partial pressure of $\mathrm{H}_{2}$ to $10^{-4}$ mbar (curve II), the ketoenol peak is shown to grow faster, and the peak intensity shifts to $2490 \mathrm{~cm}^{-1}$. Thirdly, in curve III, as the experiment is repeated at $10^{-5}$ mbar, we see that the growth rate of the keto-enol peak reduces compared to the experiment seen in curve I. Finally, as the experiment conditions from curve II are repeated again, curve IV shows that the rise in peak intensity is lower compared to curve II.

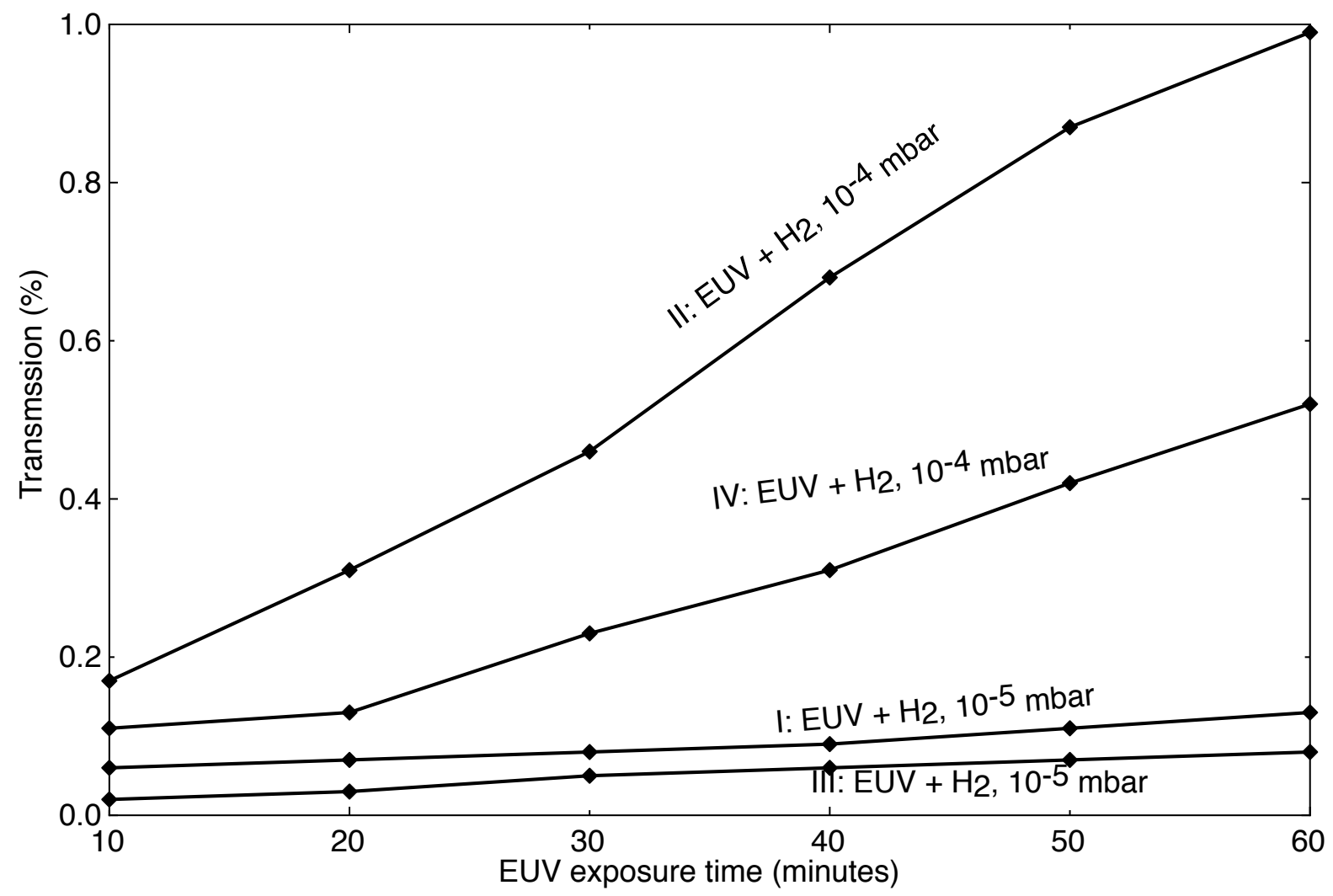

Figure 3.5. Keto-enol peak intensity plotted against EUV and $\mathrm{H}_{2}$ exposure time for subsequent exposures at different hydrogen partial pressures for a transferred 
MLG stack on aSi. Exposures are conducted in the order from I to IV at indicated $\mathrm{H}_{2}$ partial pressures.

A comparison of the growth of the keto-enol peak intensity for these different experiments is displayed in Figure 3.5, where the peak intensity has been plotted against EUV exposure time. From Figure 3.5 it is observed that the growth of the ketoenol peak for curve I (EUV $+\mathrm{H}_{2}$ at $10^{-5} \mathrm{mbar}$ ) starts at $0.002 \% / \mathrm{min}$, while the rate of keto-enol growth increases to $0.014 \% / \mathrm{min}$ when the hydrogen partial pressure is increased to $10^{-4}$ mbar (curve II). Finally, repeating/continuing the exposure experiments results in curve III and IV, with growth rates of $0.001 \% / \mathrm{min}$ and 0.006 $\% /$ min respectively, indicating the fact that the growth rate of keto-enol formation is indeed decreasing with exposure time.

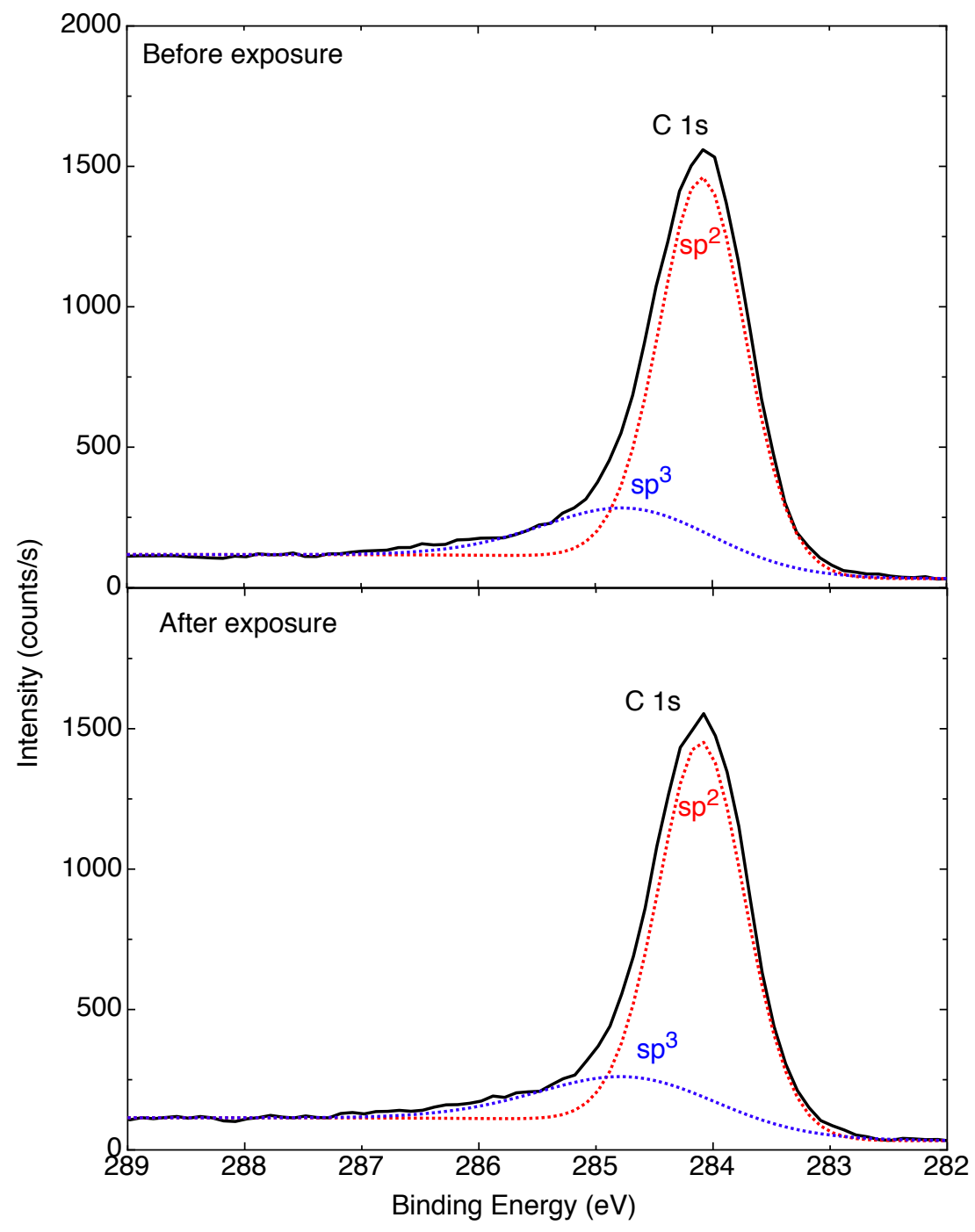


Figure 3.6. The C1s peak in XPS for transferred multi-layer graphene before and after exposures (Figures 3.4-3.5) to EUV.

Table 3.1. Atomic concentrations of spectral components of $C 1 s$ peak (C1s $O, s^{2}$ and $\mathrm{sp}^{3}, \mathrm{sp}^{2} \mathrm{FWHM}$ ), $\mathrm{O}$ 1s peak, Si $2 \mathrm{p}$ and oxidized Si $2 \mathrm{p}$ before and after exposure to multiple doses of EUV, $\mathrm{H}_{2} \mathrm{O}$ and $\mathrm{H}_{2}$.

\begin{tabular}{|l|l|l|}
\hline Name & $\begin{array}{l}\text { Unexposed graphene } \\
\text { (at \%) }\end{array}$ & Exposed graphene (at \%) \\
\hline C 1s O/ tail sp ${ }^{2}$ carbon & $2.4 \pm 0.2$ & $1.21 \pm 0.1$ \\
\hline C1s sp & & $76 \pm 7.5$ \\
\hline C1s sp & $76 \pm 7.5$ & $19.9 \pm 2.0$ \\
\hline O1s & $18.7 \pm 2.0$ & $1.45 \pm 0.2$ \\
\hline Si2p ox & $2.0 \pm 0.2$ & $0.47 \pm 0.1$ \\
\hline Si2p elemental & $1.02 \pm 0.1$ & $0.95 \pm 0.1$ \\
\hline C1s sp ${ }^{2}$ FWHM (eV) & $0.90 \pm 0.1$ & 0.1 \\
\hline
\end{tabular}

XPS data for a photoelectron take off angle of $34^{\circ}$ (with respect to the surface normal) has been compared for transferred unexposed graphene and graphene after EUV and $\mathrm{H}_{2}$ exposure in Figure 3.6. Table 3.1 quantifies the spectral components seen in the XPS data. The $\mathrm{C} 1 \mathrm{~s} \mathrm{sp}^{2}$ and $\mathrm{sp}^{3}$ peak percentages before and after exposure fall within margins of error of each other, indicating that the graphene layer has remained 
unchanged after EUV exposure up to the penetration depth of XPS, which is about $5 \mathrm{~nm}$ for carbon. ${ }^{36,37}$ Also, a Si 2 p percentage around $1 \%$ is detected before and after exposure. The silicon signal may be due to the Si substrate, which is on the edge of detection by the XPS, because the graphene layer is almost as thick $(\sim 5-8 \mathrm{~nm})$ as the penetration depth of the XPS. Furthermore, due to manufacturing defects, the graphene layer has holes that account for $2-3 \%$ of the total surface area, giving photoelectrons from the Si substrate an escape route to the detector so that the substrate is detected. This is further discussed in the section below.

In our previous work on single layer graphene exposed to $\mathrm{H}_{2} \mathrm{O}$, EUV and $\mathrm{H}_{2}$, changes in the $\mathrm{sp}^{2}$ and $\mathrm{sp}^{3}$ peaks are easily observable by eye. ${ }^{38}$ In the case of multilayer graphene, possible chemical changes in the topmost monolayers are expected to be less visible due to the background signal from the graphene layers below. We also confirmed that no detectable changes in the $\mathrm{C} 1 \mathrm{~s}$ peak are observed for a more grazing angle of $72^{\circ}$ with respect to the sample normal. If di-ketone formation occurred at the upper-most surface, a similar (absolute) increase in $\mathrm{sp}^{3}$ peak area of the C1s peak of at least 11\% (assuming the graphene layers below the top layer remained undamaged) would be expected, as previously observed for EUV exposed single-layer graphene. Detailed analysis of the peak fitting indicates that the same increase in $\mathrm{sp}^{3}$ peak area as observed for damage SLG would be detectable, also when deeper graphene layers are not damaged. Moreover, it should be noted that no increase in the concentration of oxygen (based on the $\mathrm{O} 1 \mathrm{~s}$ peak) is observed, which is an additional indication that no oxidation of the graphene is detectable within the information depth of XPS.

Therefore, this indicates that the keto-enol oxidation we see in RAIRS is most likely happening at the interface between the graphene and the $\mathrm{Si}$, which cannot be characterized by XPS. 

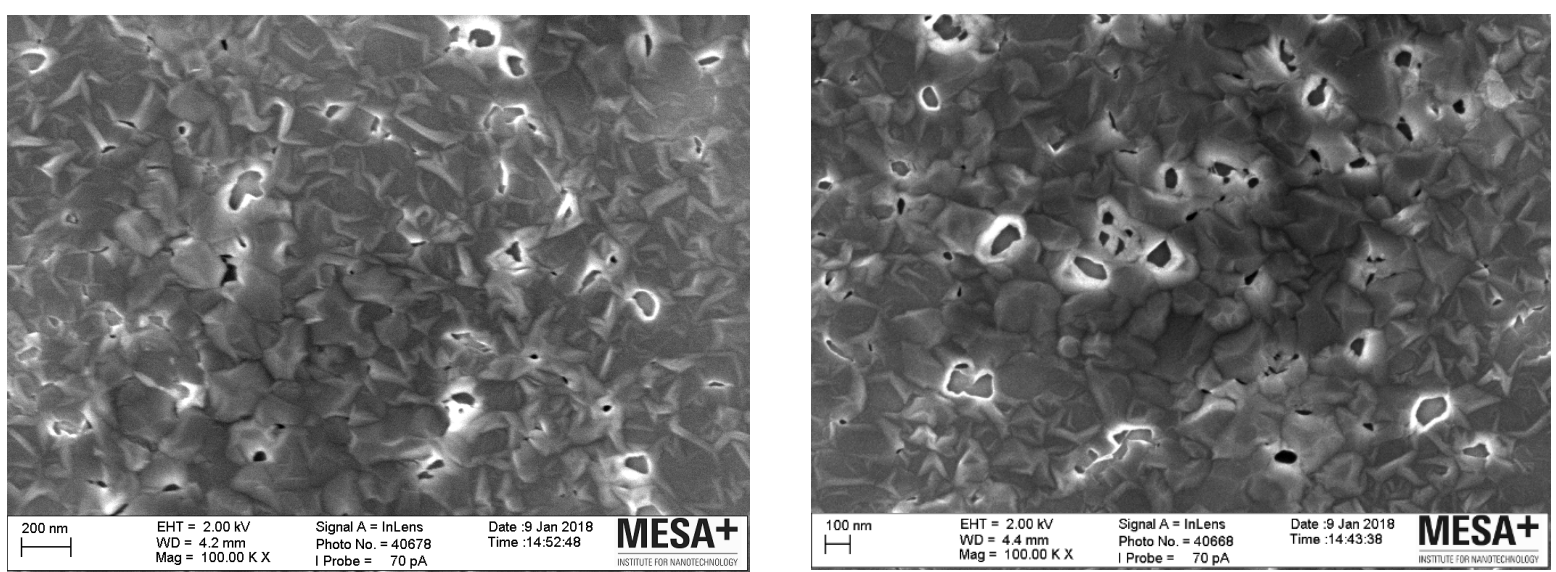

Figure 3.7. SEM micrographs of transferred multi-layer graphene (a) unexposed and (b) exposed to EUV and $\mathrm{H}_{2}$.

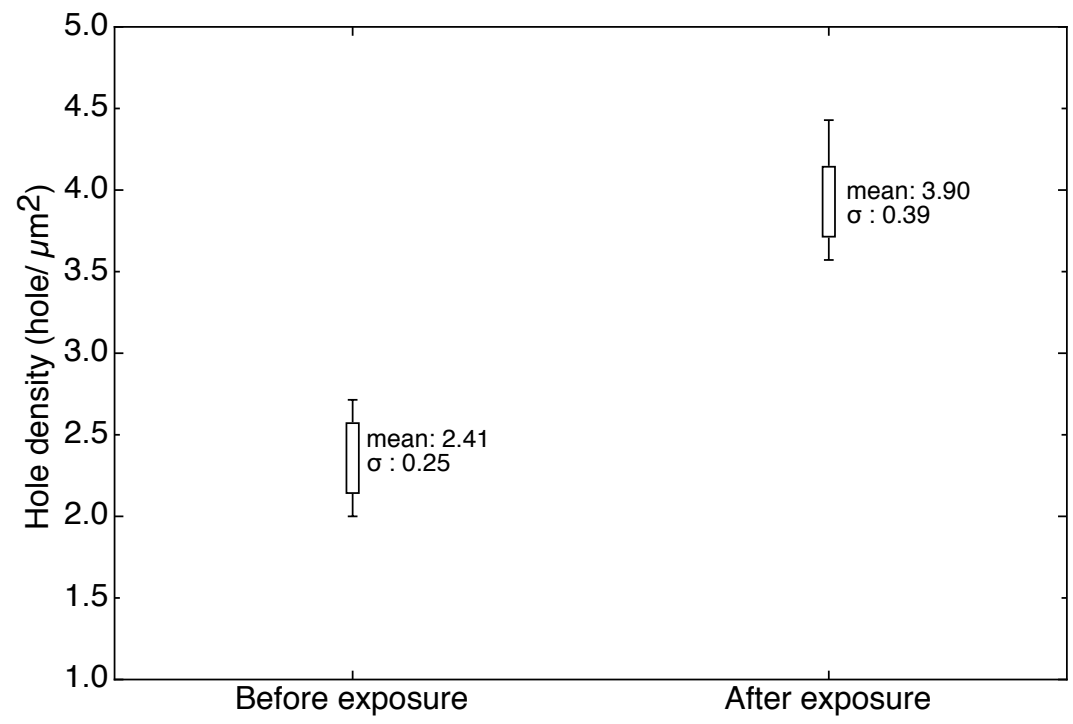

Figure 3.8. Comparison of the density of holes less than $50 \mathrm{~nm}$ in diameter seen in transferred MLG (in field-of-view $=3 \times 2.5 \mu \mathrm{m}^{2}$ ) in a set of 10 images before and after exposure to EUV and $\mathrm{H}_{2}$.

SEM images for the transferred multi-layer graphene before and after exposure are shown in Figure 3.7. As seen in the pictures, multiple holes are visible in the graphene layer. These holes are mostly around $\sim 100 \mathrm{~nm}$ in diameter, with largest holes being $\sim 300 \mathrm{~nm}$ in diameter. The smaller hole sizes $(<50 \mathrm{~nm})$ are quantified in Figure 3.8. Furthermore, the holes are through the depth of the graphene layer, exposing the $\mathrm{Si}$ 
substrate to the environment above the graphene layer, which is confirmed after looking at a cross section of a graphene layer in the SEM, as seen in Figure 3.9.

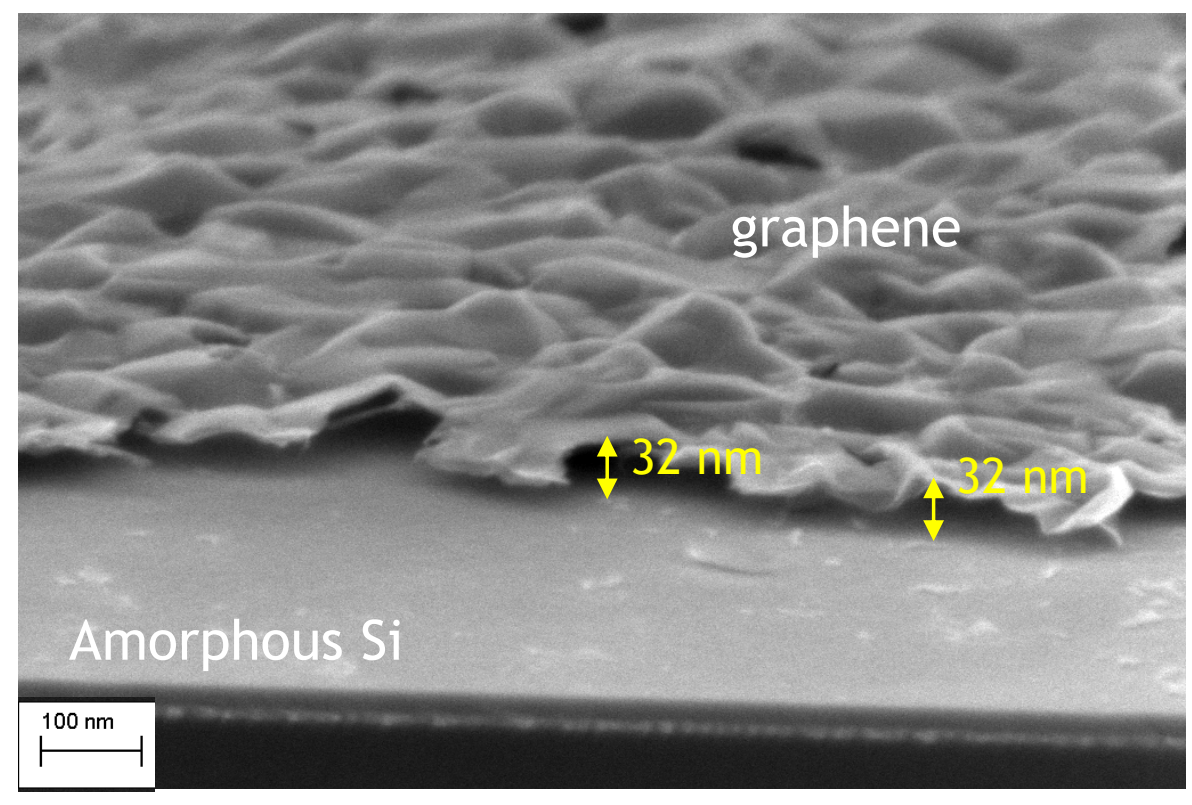

Figure 3.9. Cross-section of exposed transferred MLG on amorphous Si, displaying the morphology of graphene on the transferred surface. The distance between the graphene layer and aSi surface is also indicated.

Comparing a set of 10 images taken before and after exposure to EUV and $\mathrm{H}_{2}$, we find that the number of holes less than $50 \mathrm{~nm}$ in diameter increases after exposure. We see a significant difference in the number of holes less than $50 \mathrm{~nm}$ in size before and after exposure, whereas larger holes ( $>50 \mathrm{~nm}$ ) remain largely unaffected due to EUV exposure. This has been quantified in Figure 3.8, where we see that the average hole density for MLG before exposure is $\sim 2.41$ holes $/ \mu \mathrm{m}^{2}$ ( $\sigma=0.25$ ) in an image with fieldof-view of $3 \times 2.5 \mu \mathrm{m}^{2}$ ), which increases to $\sim 3.90 \mathrm{holes} / \mu \mathrm{m}^{2}(\sigma=0.39)$ after exposure. Furthermore, we see a slight increase in hole percentage to total graphene area (as pictured in Figure 3.7) from $2.21 \%$ before exposure to $2.68 \%$ after exposure. This increase in holes most likely corresponds to the oxidation of MLG and the breakdown of the graphene layer ${ }^{39}$. Furthermore, Figure 3.9 shows the cross-section of transferred multi-layer graphene where one could observe that it retains the rough grain structure 
of the surface it is grown on, in this case Mo, and therefore rests on aSi with an irregular waviness of approximately $32 \mathrm{~nm}$ peak-valley.

Indeed, this waviness could result in water being physisorbed between the MLG and aSi surface during the transfer process, with further water being introduced during dosing and exposures. As a result, large amounts of water can remain trapped between the graphene layer and the substrate, which dissociate into reactive species such as $\mathrm{OH}^{-}$ and $\mathrm{H}^{+}$during EUV exposure. ${ }^{40,41}$ This could support the fact that EUV photons react with water molecules, resulting in a trapped energy high enough to break $\mathrm{C}=\mathrm{C}$ bonds and form small holes in the graphene layer.

Finally, the difference in EUV-induced secondary electron yield between graphene and the aSi substrate can contribute to the different reactivity of as-grown and transferred multilayer graphene. Carbon has a reasonably low secondary electron yield $\delta$ at $92 \mathrm{eV}(13.5 \mathrm{~nm})(\delta=0.37)$ as compared to the underlying substrate such as $\mathrm{Si}$ $(\delta=0.74)$ or Mo $(\delta=0.87) .{ }^{42}$ This means that water trapped between graphene and the a-Si substrate has a higher probability to be dissociated, resulting in production of $\mathrm{O}$ radical species, compared to water adsorbed onto the graphene surface. ${ }^{5}$

\subsection{Conclusions}

Previously it has been shown that single layer graphene sheets, as-grown or transferred, are likely to oxidize and form defects when introduced to an EUV environment in the presence of water and hydrogen. ${ }^{43}$ In this work, we show that as grown multi-layer graphene is resistant to oxidation via $\mathrm{H}_{2} \mathrm{O}$, under EUV radiation and the presence of up to $10^{-3}$ mbar of partial pressure of $\mathrm{H}_{2}$. This is most likely due to the fact that multi-layer graphene conforms to the grain boundaries of the Mo substrate (on which it is grown), so the only way for water and EUV photons to break down the graphene layer is to access it from the topmost layers of the graphene. In addition, the lower EUV-induced secondary electron yield of carbon (graphene) reduces the generation of reactive $O$ species from water adsorbed on MLG. Indeed, the thickness of MLG is larger than the secondary electron mean free path (typically a few nm). Thus, 
secondary electrons generated in the Mo substrate cannot reach adsorbed water on the graphene surface, contrary to the case for single-layer graphene on a substrate with a relatively high $\mathrm{SE}$ yield. In the latter case, SE electrons from the substrate can reach the adsorbed water through the single graphene layer. ${ }^{44}$ This factor likely contributes to the absence of detectable defects formed in as-grown MLG exposed to EUV, $\mathrm{H}_{2} \mathrm{O}$ and $\mathrm{H}_{2}$.

On the other hand, transferred graphene has been shown in RAIRS to oxidize and form keto-enol groups. Since this transfer process is polymer free, we conclude this keto-enol formation does not occur due to polymer residues such as PMMA. Also, XPS data shows that this oxidation does not occur at the top surface of the graphene layer, but at the interface between the graphene and the aSi. Furthermore, this interface is studied in SEM, which indicates that the graphene is not conformal with the surface, and could result in water being trapped during dosing, which could oxidize the graphene when irradiated by EUV photons. Water trapped at the graphene-substrate interface is exposed to the relatively higher flux of secondary electrons from the substrate and thereby more likely to initiate oxidation. Indeed, this has been shown to result in the formation of additional small holes ( $<50 \mathrm{~nm}$ in diameter) when graphene has been exposed to EUV in the presence of hydrogen.

In summary, the results of this work show that transferred multi-layer graphene is susceptible to oxidation by formation of enols of 1,3-diketone compared to nontransferred.

\subsection{References}

(1) Geim, A. K.; Novoselov, K. S. The Rise of Graphene. Nature materials 2007, 6 (3), 183-191.

(2) Geim, A. K. Graphene: Status and Prospects. Science 2009, 324 (5934), 15301534.

(3) Hu, S.; Lozada-Hidalgo, M.; Wang, F. C.; Mishchenko, A.; Schedin, F.; Nair, R. R.; Hill, E. W.; Boukhvalov, D. W.; Katsnelson, M. I.; Dryfe, R. A. W.; et al. 
Proton Transport Through One-Atom-Thick Crystals. Nature 2014, advance online publication.

(4) Novoselov, K. S.; Jiang, D.; Schedin, F.; Booth, T. J.; Khotkevich, V. V.; Morozov, S. V.; Geim, A. K. Two-Dimensional Atomic Crystals. Proceedings of the National Academy of Sciences of the United States of America 2005, 102 (30), 10451-10453.

(5) Lee, C.; Wei, X.; Kysar, J. W.; Hone, J. Measurement of the Elastic Properties and Intrinsic Strength of Monolayer Graphene. Science 2008, 321 (5887), 385388.

(6) Han, M.; Özyilmaz, B.; Zhang, Y.; Kim, P. Energy Band-Gap Engineering of Graphene Nanoribbons. Phys. Rev. Lett. 2007, 98 (20).

(7) Avouris, P. Graphene: Electronic and Photonic Properties and Devices. Nano letters 2010.

(8) Bolotin, K. I.; Sikes, K. J.; Jiang, Z.; Klima, M.; Fudenberg, G.; Hone, J.; Kim, P.; Stormer, H. L. Ultrahigh Electron Mobility in Suspended Graphene. Solid State Communications 2008, 146 (9-10), 351-355.

(9) Berry, V. Impermeability of Graphene and Its Applications. Carbon 2013, 62 (0), 1-10.

(10) Bunch, J. S.; Verbridge, S. S.; Alden, J. S.; van der Zande, A. M.; Parpia, J. M.; Craighead, H. G.; McEuen, P. L. Impermeable Atomic Membranes From Graphene Sheets. Nano letters 2008, 8 (8), 2458-2462.

(11) Joshi, R. K.; Carbone, P.; Wang, F. C.; Kravets, V. G.; Su, Y.; Grigorieva, I. V.; Wu, H. A.; Geim, A. K.; Nair, R. R. Precise and Ultrafast Molecular Sieving Through Graphene Oxide Membranes. Science 2014, 343 (6172), 752-754.

(12) Achtyl, J. L.; Unocic, R. R.; Xu, L.; Cai, Y.; Raju, M.; Zhang, W.; Sacci, R. L.; Vlassiouk, I. V.; Fulvio, P. F.; Ganesh, P.; et al. Aqueous Proton Transfer Across Single-Layer Graphene. Nat Commun 2015, 6 (1), 54.

(13) Homaeigohar, S.; Elbahri, M. Graphene Membranes for Water Desalination. NPG Asia Mater 2017, 9 (8), e427.

(14) Mishra, N.; Boeckl, J.; Motta, N.; Iacopi, F. Graphene Growth on Silicon Carbide: a Review. Phys. Status Solidi A 2016, 213 (9), 2277-2289. 
(15) Yong, V.; Hahn, H. T. Graphene Growth with Giant Domains Using Chemical Vapor Deposition. CrystEngComm 2011, 13 (23), 6933-6936.

(16) Bae, S.; Kim, H.; Lee, Y.; Xu, X.; Park, J.-S.; Zheng, Y.; Balakrishnan, J.; Lei, T.; Ri Kim, H.; Song, Y. I.; et al. Roll-to-Roll Production of 30-Inch Graphene Films for Transparent Electrodes. Nature nanotechnology 5, 2010, 574-578.

(17) Zande, A. M. V. D.; Barton, R. A.; Alden, J. S.; Ruiz-Vargas, C. S.; Whitney, W. S.; Pham, P. H. Q.; Park, J.; Parpia, J. M.; Craighead, H. G.; McEuen, P. L. LargeScale Arrays of Single-Layer Graphene Resonators. Nano letters 2010, 10 (12), 4869-4873.

(18) Van Lam, D.; Kim, S. M.; Cho, Y.; Kim, J. H.; Lee, H. J.; Yang, J. M.; Lee, S. M. Healing Defective CVD-Graphene Through Vapor Phase Treatment. Nanoscale 2014, 6 (11), 5639-5644.

(19) Lee, J. U.; Yoon, D.; Cheong, H. Estimation of Young's Modulus of Graphene by Raman Spectroscopy. Nano letters 2012, 12 (9), 4444-4448.

(20) Zhou, L.; Wang, Y.; Cao, G. Estimating the Elastic Properties of Few-Layer Graphene From the Free-Standing Indentation Response. J. Phys.: Condens. Matter 2013, 25 (47), 475301.

(21) Wortman, J. J.; Evans, R. A. Young“S Modulus, Shear Modulus, and Poisson"S Ratio in Silicon and Germanium. J. Appl. Phys. 1965, 36 (1), 153-156.

(22) Henke, B. L.; Gullikson, E. M.; Davis, J. C. X-Ray Interactions: Photoabsorption, Scattering, Transmission, and Reflection at $\mathrm{E}=50-30,000 \mathrm{eV}, \mathrm{Z}=1-92$. Atomic Data and Nuclear Data Tables 1993, 54 (2), 181-342.

(23) Nair, R. R.; Blake, P.; Grigorenko, A. N.; Novoselov, K. S.; Booth, T. J.; Stauber, T.; Peres, N. M. R.; Geim, A. K. Fine Structure Constant Defines Visual Transparency of Graphene. Science 2008, 320 (5881), 1308-1308.

(24) Kim, H.; Ahn, J.-H. Graphene for Flexible and Wearable Device Applications. Carbon 2017, 120, 244-257.

(25) Reddy, D.; Register, L.F.; Carpenter, G.D.; Banerjee, S.K.; Graphene Field-Effect Transistors. J. Phys. D: Appl. Phys. 2011, 44 (31), 313001.

(26) Novoselov, K. S.; Geim, A. K.; Morozov, S. V.; Jiang, D.; Zhang, Y.; Dubonos, S. V.; Grigorieva, I. V.; Firsov, A. A. Electric Field Effect in Atomically Thin Carbon Films. Science 2004, 306 (5696), 666-669. 
(27) Standley, B.; Mendez, A.; Schmidgall, E.; Bockrath, M. Graphene-Graphite Oxide Field-Effect Transistors. Nano letters 2012, 12 (3), 1165-1169.

(28) Koenig, S. P.; Wang, L.; Pellegrino, J.; Bunch, J. S. Selective Molecular Sieving Through Porous Graphene. Nature nanotechnology 2012, 7 (11), 728-732.

(29) Ke, Q.; Wang, J. Graphene-Based Materials for Supercapacitor Electrodes - a Review. Journal of Materiomics 2016, 2 (1), 37-54.

(30) Shang, J.; Ma, L.; Li, J.; Ai W; Yu T.; Gurzadyan G.G. Femtosecond Pump-Probe Spectroscopy of Graphene Oxide in Water. J. Phys. D: Appl. Phys. 2014, 47 (9), 094008.

(31) Nemanich, R. J.; Solin, S. A. First- and Second-Order Raman Scattering From Finite-Size Crystals of Graphite. Phys. Rev. B 1979, 20 (2), 392-401.

(32) Ferrari, A. C.; Basko, D. M. Raman Spectroscopy as a Versatile Tool for Studying the Properties of Graphene. Nature nanotechnology 2013, 8 (4), 235-246.

(33) Wang, Y. Y.; Ni, Z. H.; Yu, T.; Shen, Z. X.; Wang, H. M.; Wu, Y. H.; Chen, W.; Shen Wee, A. T. Raman Studies of Monolayer Graphene: the Substrate Effect. J. Phys. Chem. C 2008, 112 (29), 10637-10640.

(34) Cancado, L. G.; Jorio, A.; Ferreira, E. H.; Stavale, F.; Achete, C. A.; Capaz, R. B.; Moutinho, M. V.; Lombardo, A.; Kulmala, T. S.; Ferrari, A. C. Quantifying Defects in Graphene via Raman Spectroscopy at Different Excitation Energies. Nano letters 2011, 11 (8), 3190-3196.

(35) Greenler, R. G. Infrared Study of Adsorbed Molecules on Metal Surfaces by Reflection Techniques. J. Chem. Phys. 1966, 44 (1), 310-315.

(36) Greenler, R. G. Design of a Reflection-Absorption Experiment for Studying the Ir Spectrum of Molecules Adsorbed on a Metal Surface. Journal of Vacuum Science and Technology 1975, 12 (6), 1410-1417.

(37) Greenler, R. G.; Snider, D. R.; Witt, D.; Sorbello, R. S. The Metal-Surface Selection Rule for Infrared Spectra of Molecules Adsorbed on Small Metal Particles. Surface Science 1982, 118 (3), 415-428.

(38) Uspenskii, Y. A.; Seely, J. F.; Kjornrattanawanich, B.; Windt, D. L.; Bugayev, Y. A.; Kondratenko, V. V.; Artyukov, I. A.; Titov, A. A.; Kulatov, E. T.; Vinogradov, 
A. V. Determination of the Optical Constants of Amorphous Carbon in the EUV Spectral Region 40-450 eV; 2006; Vol. 6317.

(39) Sturm, J. M.; Lee, C. J.; Bijkerk, F. Reactions of Ethanol on Ru(0001). Surface Science 2013, 612, 42-47.

(40) Liu, F.; Sturm, J.; Lee, C.; Bijkerk, F. Coexistence of Ice Clusters and Liquid-Like Water Clusters on Ru (0001) Surface. Physical chemistry chemical physics : PCCP 2017, 19 (12), 8288-8299.

(41) Liu, F.; Sturm, J. M.; Lee, C. J.; Bijkerk, F. Extreme UV Induced Dissociation of Amorphous Solid Water and Crystalline Water Bilayers on Ru(0001). Surface Science 2016, 646, 101-107.

(42) Lee, J.; Zheng, X.; Roberts, R. C.; Feng, P. X. L. Scanning Electron Microscopy Characterization of Structural Features in Suspended and Non-Suspended Graphene by Customized CVD Growth. Diamond and Related Materials 2015, 54, 64-73.

(43) Díaz, J.; Paolicelli, G.; Ferrer, S.; Comin, F. Separation of the Sp3 and Sp2 Components in the C1s Photoemission Spectra of Amorphous Carbon Films. Phys. Rev. B 1996, 54 (11), 8064-8069.

(44) Lee, D. W.; Seo, J. W. Sp 2/Sp 3Carbon Ratio in Graphite Oxide with Different Preparation Times. J. Phys. Chem. C 2011, 115 (6), 2705-2708. 


\section{Chapter 4: Atomic H diffusion and C etching in multi-layer graphene monitored using a Y based optical sensor}

In this work we expose transferred multi-layer graphene on a yttrium based hydrogen sensor. Using spectroscopic ellipsometry, we show that graphene, as well as amorphous carbon reference films, reduce diffusion of hydrogen to the underlying $\mathrm{Y}$ layer. Graphene and $\mathrm{C}$ are both etched due to exposure to atomic $\mathrm{H}$, eventually leading to hydrogenation of the $\mathrm{Y}$ to $\mathrm{YH}_{2}$ and $\mathrm{YH}_{3}$. Multi-layer graphene, even with defects originating from manufacturing and transfer, showed a higher resistance against atomic $\mathrm{H}$ etching compared to amorphous carbon films of similar thickness.

\subsection{Introduction}

Graphene, a hexagonally bound 2D network of carbon atoms, is shown to possess a number of unique physical, electronic and chemical properties. ${ }^{1-8}$ Multi-layer graphene as a membrane has been introduced as a potential candidate for inexpensive water desalination ${ }^{9}$, memory cells ${ }^{10}$ and gas separation. ${ }^{11}$ Further broadening its aspects for application and manufacturability in various thin-film systems, graphene growth has been demonstrated on transition metals such as Ir and $\mathrm{Ru}$, after which it can be transferred onto flat or arbitrary substrates. ${ }^{12,13}$

Graphene has been known as an impermeable membrane with fascinating properties. Bunch et al. ${ }^{12}$ have shown that by applying a pressure across single-layer graphene, a separation barrier for even helium is created that is only atomic layer thick. Other research has shown graphene oxide sheets can act as selective barrier for elements with atomic radii larger than $0.45 \mathrm{~nm} .{ }^{13}$ Defect-free graphene especially shows prospects as 
an impermeable membrane, as indicated by Density Functional Theory (DFT) calculations. $^{14}$

Earlier experiments have shown that yttrium is known to form two stable hydrides: $\mathrm{YH}_{2}$ and $\mathrm{YH}_{3}$, depending on the application of a protective capping layer and the hydrogen desorption properties of this capping layer. ${ }^{15,16}$ Both hydrides have clearly different optical properties from Y metal, which allows probing of the hydrogenation state with spectroscopic techniques, such as optical transmission measurements ${ }^{17}$ and ellipsometry. ${ }^{18}$ The stability of $\mathrm{YH}_{3}$ is investigated in the context of using $\mathrm{Y}$ as a hydrogen sensor to measure the hydrogen adsorption of and diffusion through a metal capping layer on $\mathrm{Y}^{18}$ In this work, we present our findings on hydrogen diffusion through multi-layer graphene, placed on top of a metal capped Y film. Spectroscopic ellipsometry is performed in-situ to monitor the hydrogen permeation in the Y layer. Ex-situ measurements such as X-ray photoelectron spectroscopy (XPS) and X-ray diffraction (XRD) measurements are used to characterize spectral components and yttrium hydride peaks respectively.

\subsection{Experimental}

Thin film samples are deposited by DC magnetron sputtering, taking place in a chamber with a base pressure of $10^{-8}$ mbar with targets including $99.95 \%$ yttrium and ruthenium and $99.999 \%$ C. A layer of $70 \mathrm{~nm}$ of Y is coated on pre-cut $15 \mathrm{~mm} \times 15 \mathrm{~mm}$ $\mathrm{Si}(100)$ wafer pieces, and then capped with $6 \mathrm{~nm}$ of Ru and/or $5 \mathrm{~nm}$ C. These capping layers protect the Y film against oxidation, as checked by XPS, which is essential for proper functioning of the $\mathrm{Y}$ film as hydrogen sensor. Next, the crystallinity and thickness of the coatings are measured using X-ray reflectivity (XRR) and XRD (Panalytical Empyrean).

Multi-layer graphene (MLG) is grown by chemical vapour deposition (VG Scienta system at the NanoLab facilities at the University of Twente) on a $70 \mathrm{~nm}$ Mo thin film, sputter deposited on a $\mathrm{SiO}_{2}$-on-Si substrate (300 nm oxide thickness). MLG is grown using a partial pressure of 8 mbar each of $\mathrm{Ar}, \mathrm{H}_{2}$ and $\mathrm{CH}_{4}$. The resultant graphene layer 
(5 - $8 \mathrm{~nm}$ thick, determined using a Scanning Electron Microscope; Raman I(D)/I(G)= 0.11 , which translates to an inter-defect distance of $20 \mathrm{~nm})^{19}$ is then removed from the growth surface and transferred on a Ru capped Y sample, using $\mathrm{H}_{2} \mathrm{O}_{2}$ as an etchant. After transfer, the resulting sample is cut to size to ensure the graphene covered the entire sample surface, i.e. edges not covered by graphene are removed.

Hydrogenation experiments are performed in a vacuum chamber with a base pressure of $1 \times 10^{-7}$ mbar and a hydrogen pressure of $1.3 \times 10^{-2}$ mbar. A constant hydrogen flow of $115 \mathrm{sccm}$ is introduced along a W filament heated to $2000{ }^{\circ} \mathrm{C}$, placed $5 \mathrm{~cm}$ away from the surface of the sample. The filament temperature is read out using an infra-red temperature sensor (Raytek, RayMR1SCCF). The atomic hydrogen flux incident on the sample surface is estimated to be in the order of $10^{18} \mathrm{at} \cdot \mathrm{cm}^{-2} \cdot \mathrm{s}^{-1}$, based on calibration of the etch rate of a carbon thin film sample. ${ }^{20} \mathrm{~A}$ K-type thermocouple is used to monitor the sample temperature, which is maintained at $30-40{ }^{\circ} \mathrm{C}$ using water cooling.

In-situ spectroscopic ellipsometry (Woollam M-2000XI) at an angle of incidence of $75^{\circ}$ and a spectral range of $240-1600 \mathrm{~nm}$ is used to monitor hydrogenation of the $\mathrm{Y}$ film and etching of the $\mathrm{C}$ film.

X-ray Photoelectron Spectroscopy (XPS) measurements are performed ex-situ using monochromatic Al-Ka radiation, employing a ThermoFisher Theta Probe with a beam spot size of typically $1 \mathrm{~mm}$ in diameter.

Heating experiments to promote hydrogen release from samples are performed by heating the sample in protective nitrogen atmosphere to $350{ }^{\circ} \mathrm{C}$. This is completed by increasing the surface temperature in 10 degree steps and measuring the XRD peaks with a scan time of 5 minutes for a $2 \theta$ range of $20^{\circ}$ to $80^{\circ}$. If no change is detected in Yttrium XRD peaks, the temperature is increased by $10{ }^{\circ} \mathrm{C}$, and a new scan is taken. However, if a change in $\mathrm{Y}$ peak intensities is detected, a new measurement is consequently recorded until the peak intensities stabilized. Once stabilized, the temperature is again increased by $10{ }^{\circ} \mathrm{C}$, followed by another measurement. A parafocusing geometry with a $0.2 \mathrm{~mm}$ fixed divergence slit through a Ni filter for the 
incident beam is used for XRD measurements. Furthermore, a scanning line detector is used to obtain a higher diffracted intensity and increased signal-to-noise ratio.

\subsection{Results and Discussion}

Previous studies have shown amorphous $\mathrm{C}$ removal by atomic hydrogen and it is used as a reference for graphene removal in this study as well. ${ }^{20-22}$ Therefore, to provide an appropriate comparison of hydrogen diffusion through carbon and graphene, four different samples are made, as shown in Figure 4.1. Also, transfer of graphene onto a hydrogen sensing thin film stack involves exposure of the sensor sample to atmosphere. This will lead to native oxide formation on the Ru cap layer, which is expected to have a retarding effect on the diffusion of hydrogen into the Y film. Type-I samples had multi-layer graphene which is transferred on a Ru-Y surface. For this sample type the $\mathrm{Ru}$ layer is exposed to atmosphere, leading to growth of typically $0.8 \mathrm{~nm}$ native ruthenium oxide, as evidenced by XPS. For type II samples, after Ru is grown on the Y film, amorphous carbon is sputtered in-vacuo on top of the Ru layer, so as to not induce any oxidation of Ru. For Type III samples, amorphous carbon is sputtered after exposing Ru-Y samples to atmosphere (for 24 hours) to initiate Ru oxidation which will provide a comparison to Type I samples. Lastly, a sample of ruthenium sputtered on yttrium (without carbon or graphene) is produced to be used as a reference (type IV).

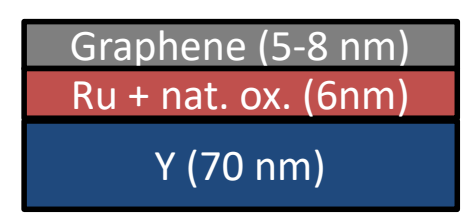

Type I

Carbon $(5 \mathrm{~nm})$ $\mathrm{Ru}+$ nat. ox. $(6 \mathrm{~nm})$

$\mathrm{Y}(70 \mathrm{~nm})$

Type III

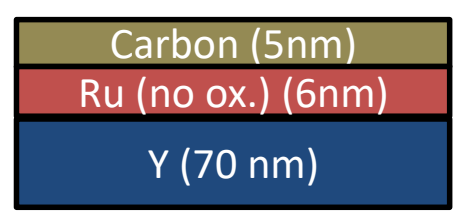

Type II

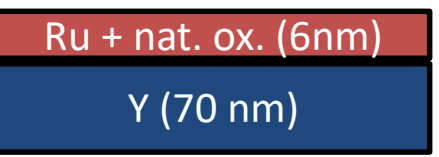

Type IV 
Figure 4.1. Four types of samples made with multi-layer graphene (Type I) and carbon (no oxide (II) and with Ru native oxide (III)) on Ru-Y surface and uncovered ruthenium capped yttrium film (IV).

Ellipsometry measures the reflectance ratio $(\rho)$ of the thin film system the light is incident upon, and is parametrized by amplitude ratio upon reflection $\Psi$ and phase shift $\Delta .{ }^{23}$ Therefore, a change in the reflectance of the perpendicular $\left(r_{s}\right)$ and parallel components $\left(r_{p}\right)$ of polarized incident light is reflected as a change in the dielectric properties of the system. This is described in the equation shown below:

$$
\rho=\frac{r_{p}}{r_{s}}=\tan (\psi) e^{i \Delta}
$$

When measuring a system composed of isotropic, homogeneous thin films with known optical constants, $\Psi$ and $\Delta$ can be used to create a layer model to extract thicknesses of individual layers. In a complex multi-layer system, such as in our present study, optical constants, thickness, possible inhomogeneous composition of films and roughness would need to be taken into account for constructing a layer model. However, since the multi-layer graphene used here has a variable thickness, with varying surface morphology, ${ }^{24}$ realizing an accurate layer model is challenging. In addition the polycrystalline Y layer will change its crystal structure upon hydrogenation and may form various mixtures of hydrogenation states. For this reason we only look to the $\Psi$ and $\Delta$ values as finger prints for changes in hydrogenation state. ${ }^{28}$

\subsubsection{Hydrogenation of graphene on $\mathrm{Ru} / \mathrm{Y}$ sensor}

We expose a multi-layer graphene on Ru-Y (Type I) sample to atomic hydrogen until no further change is observed in the ellipsometric angles of $\Psi$ and $\Delta$, which in this case turned out be after $\sim 1450$ minutes exposure. The $\Psi$ values as compared with time are 
shown in Figure 4.2. We see for the first 500 minutes, there is no significant change in $\Psi$, as $\mathrm{H}$ radicals are most likely involved in the removal of the graphene layer on the sample. Beyond 500 minutes, as $\mathrm{H}$ radicals get closer to the surface after etching away graphene, we see $\Psi$ at all wavelengths decreasing in intensity, except for $1689.6 \mathrm{~nm}$ and $245.2 \mathrm{~nm}$ for which $\Psi$ is increasing between 500 and 850 minutes. Next, for the wavelengths $1689.6 \mathrm{~nm}$ and $1108.5 \mathrm{~nm}$, we see a peak in $\Psi$ at 1003 minutes. Experiments conducted by Soroka et al. ${ }^{18,28}$ show that this peak corresponds to a $\mathrm{YH}_{2}$ phase formation, therefore indicating that all $\mathrm{Y}$ has reacted with $\mathrm{H}$. Prolonged exposure to atomic hydrogen further decreases the $\Psi$ intensity for all wavelengths, except 245.2 $\mathrm{nm}$, below its initial state and we see $\Psi$ values saturating after $\sim 1400$ minutes exposure. Soroka et al. ${ }^{18}$ contribute this decrease in $\Psi$ to the transition of $\mathrm{YH}_{2}$ to $\mathrm{YH}_{3}$ and complete formation of $\mathrm{YH}_{3}$ is seen at $\sim 1400$ minutes when no change is seen for further atomic $\mathrm{H}$ exposure.

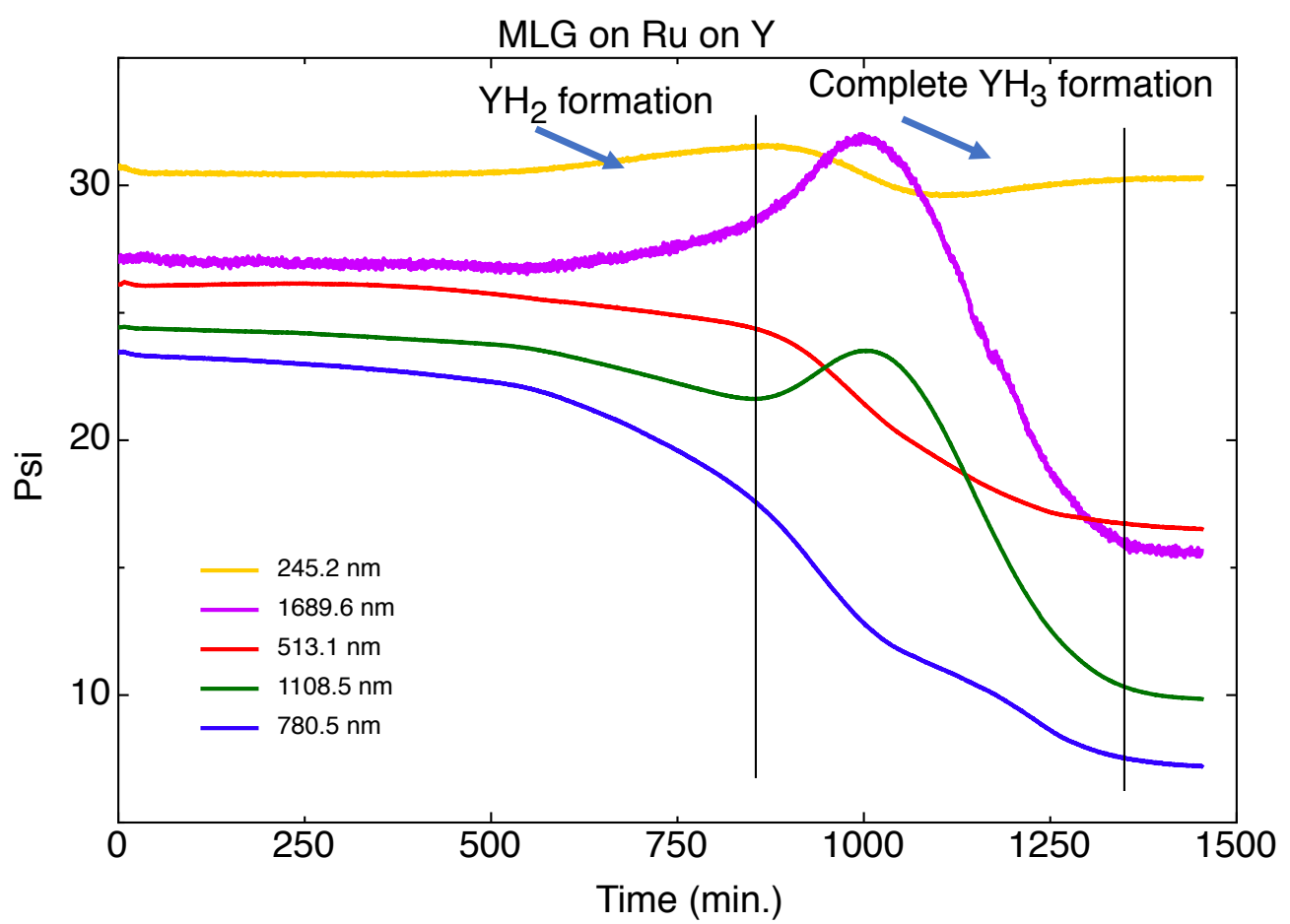

Figure 4.2. Ellipsometry $\Psi$ values of multi-layer graphene on a ruthenium capped yttrium substrate (Type I) exposed to atomic $\mathrm{H}$, indicating hydrogenation of $\mathrm{Y}$, through formation of $\mathrm{YH}_{2}$ and $\mathrm{YH}_{3}$. 
Figure 4.3 shows the $\Psi$ and $\Delta$ values of all four types of samples which have been exposed to $\mathrm{H}$ radicals until there is no change noticed in $\Psi$. Characteristic peaks in $\Psi$ values for 1108.5 and $1689.6 \mathrm{~nm}$ occur for all sample types at 257, 489, 693 and 1004 minutes exposure for Types IV, III, II and I samples respectively. As discussed earlier, this is attributed to the transition of $\mathrm{Y}$ to $\mathrm{YH}_{2}$, indicating that the samples hydrogenate in same order as these peaks appear. Thus, the sample with graphene transferred onto a hydrogen sensing stack shows the highest resistance to hydrogenation, followed by samples with amorphous $\mathrm{C}$ on oxide free $\mathrm{Ru}$ and amorphous $\mathrm{C}$ on $\mathrm{Ru}$ with native oxide. The reference sample of $\mathrm{Ru}$ capped $\mathrm{Y}$ (with $\mathrm{Ru}$ native oxide) without carbon or graphene shows the fastest hydrogenation.

For $\Delta$ values, we see corresponding troughs to the peaks seen in $\Psi$ values. Noticeably, both amorphous carbon capped samples (Types II and III) show an initial linear increase in $\Delta$ by about $10^{\circ}$, due to carbon etching off of the surface ${ }^{21}$ For sample type III (amorphous C on Ru with native oxide), we see an additional, but slower increase in $\Delta$ of about $4^{\circ}$, most likely due to the etching of native oxide present on the Ru surface ${ }^{25,26}$ once carbon is removed. A similar increase in $\Delta$ is also observed in the initial stage of exposure of the reference Ru capped Y film (with Ru native oxide), albeit that the increase in $\Delta$ is much faster ( $6^{\circ}$ in 157 minutes). ${ }^{25}$ Possibly, residual carbon in the case of samples type III slows down the etching of Ru oxide, but based on ellipsometry only it is not possible to obtain further details on a possible interplay between the etching mechanisms of carbon and native oxide. Both samples with amorphous carbon show that hydrogenation of the Y only takes place after the carbon film (and where applicable Ru oxide) is removed. The carbon films thus act as barrier against penetration of atomic $\mathrm{H}$, regardless of the presence of $\mathrm{Ru}$ oxide. The hydrogenation of the C-on- $\mathrm{Ru}$ sample (without native oxide) is considerably slower than that of the sample with native Ru oxide. We speculate that this may be caused by formation of a $\mathrm{Ru}$ carbide layer for $\mathrm{C}$ on oxygen free $\mathrm{Ru}$, that is more resistant to carbon etching and penetration of atomic $\mathrm{H}$. In contrast, the graphene capped Ru-Y surface behaves differently, as we see a monotonic increase in $\Delta$ of about $25^{\circ}$ for more than 800 minutes before we encounter the trough. The more gradual slope of $\Delta$ could be due to the fact that the graphene 
layer is transferred onto the surface, and does not adhere to the surface as a sputtered amorphous carbon layer would. ${ }^{18,24}$ Also, we do not see any distinct linear increase that would be indicative of etching of Ru native oxide. As a result, graphene etching is seen to be more gradual than etching of amorphous carbon. During part of the first 900 min of $\mathrm{H}$ exposure, graphene and native $\mathrm{Ru}$ oxide are probably etched simultaneously, due to lateral thickness variations of the graphene and holes that expose the underlying $\mathrm{Ru}$ layer.

Multi-layer graphene which has been used for this experiment is known to contain holes due to artifacts in synthesis. From secondary electron microscopy pictures, these holes are known to be around 40-50 $\mathrm{nm}$ in diameter on average with the largest holes being $~ 120 \mathrm{~nm}$ in size. Also, holes are known to account for $2-3 \%$ of the total sample area. ${ }^{24}$ As such, in the frame of this experiment, one would expect these holes to form a direct way for hydrogen to access the underlying Ru-Y layers. On the other hand, as we see from the results shown in Figure 4.3, the holes do not result in rapid hydrogenation of graphene covered $H$ sensing samples, since the $\Psi$ value at $\lambda=1698.6$ $\mathrm{nm}$ only starts to increase after 600 minutes of hydrogen exposure. On the contrary, graphene proves to be a better barrier to hydrogenation as compared to sputtered amorphous carbon. This at first sight unexpected result may be explained by redeposition of amorphous carbon from volatile hydrocarbon species on the Ru surface exposed by holes in the graphene. Atomic $\mathrm{H}$ etching of graphene takes place through formation of volatile hydrocarbons. ${ }^{20,22}$ Previous experimental and theoretical results have shown that on clean $\mathrm{Ru}$, dissociation of hydrocarbons to amorphous carbon or adsorbed $\mathrm{C}_{\mathrm{x}} \mathrm{H}_{\mathrm{y}}$ species is more effective than formation of volatile hydrocarbons. ${ }^{27}$ Therefore, while most of the surface is still covered with graphene, it is likely that amorphous carbon will efficiently redeposit on exposed $\mathrm{Ru}$ in holes and thereby prevent direct hydrogenation of the underlying $\mathrm{Ru} / \mathrm{Y}$ stack through these holes. 


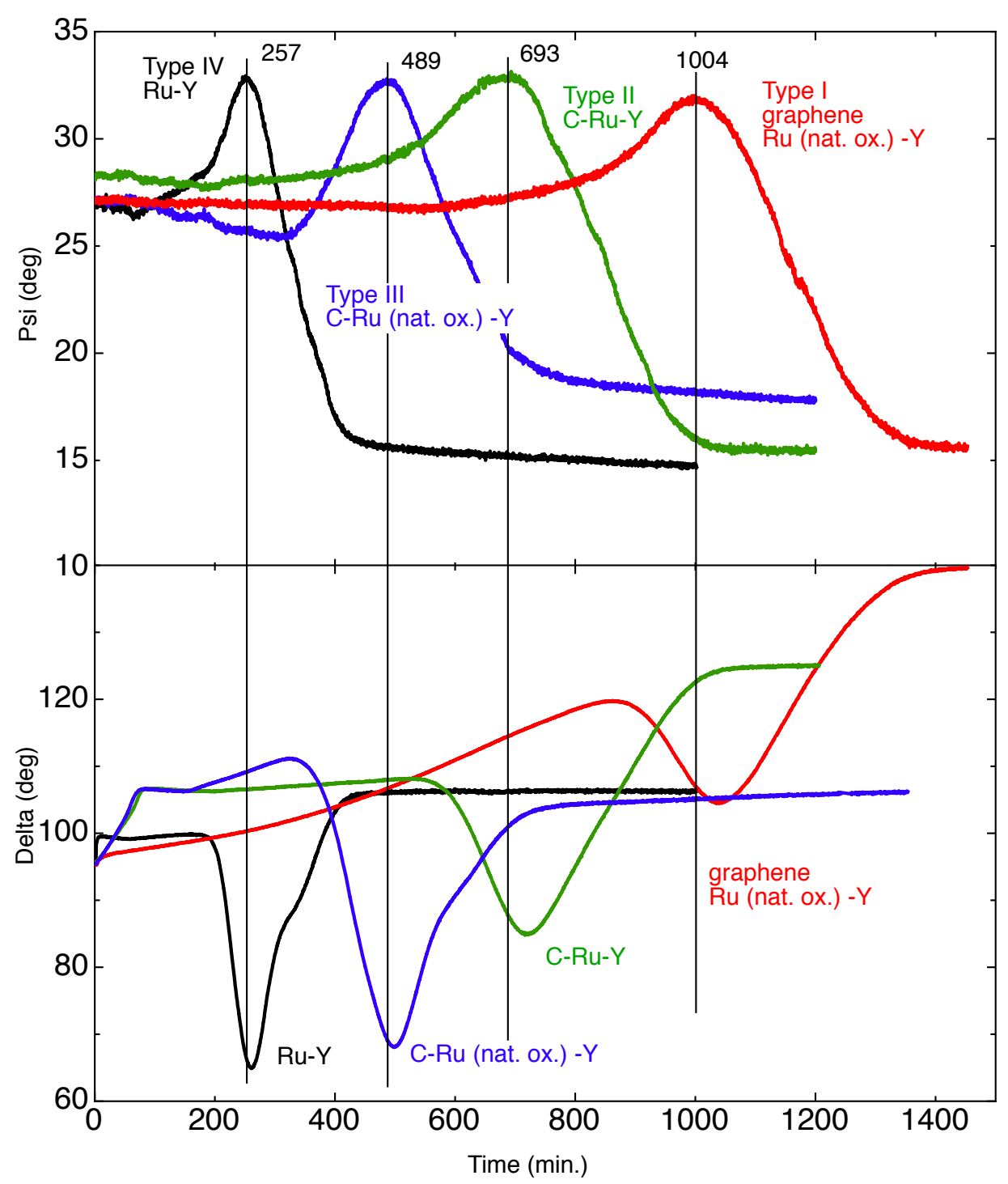

Figure 4.3. $\Psi$ values $(\lambda=1698.6 \mathrm{~nm})$ of different samples when hydrogenated by atomic $\mathrm{H}$ exposure. The four samples shown (in the order of hydrogenation speed) are Ru (with native oxide) on Y (black, Type IV), $5 \mathrm{~nm}$ carbon on Ru and Y (blue, Type III), $5 \mathrm{~nm}$ of carbon on Ru (with native oxide) (green, Type II) and $\mathrm{Y}$, and graphene on Ru (with native oxide) and Y (red, Type I). 


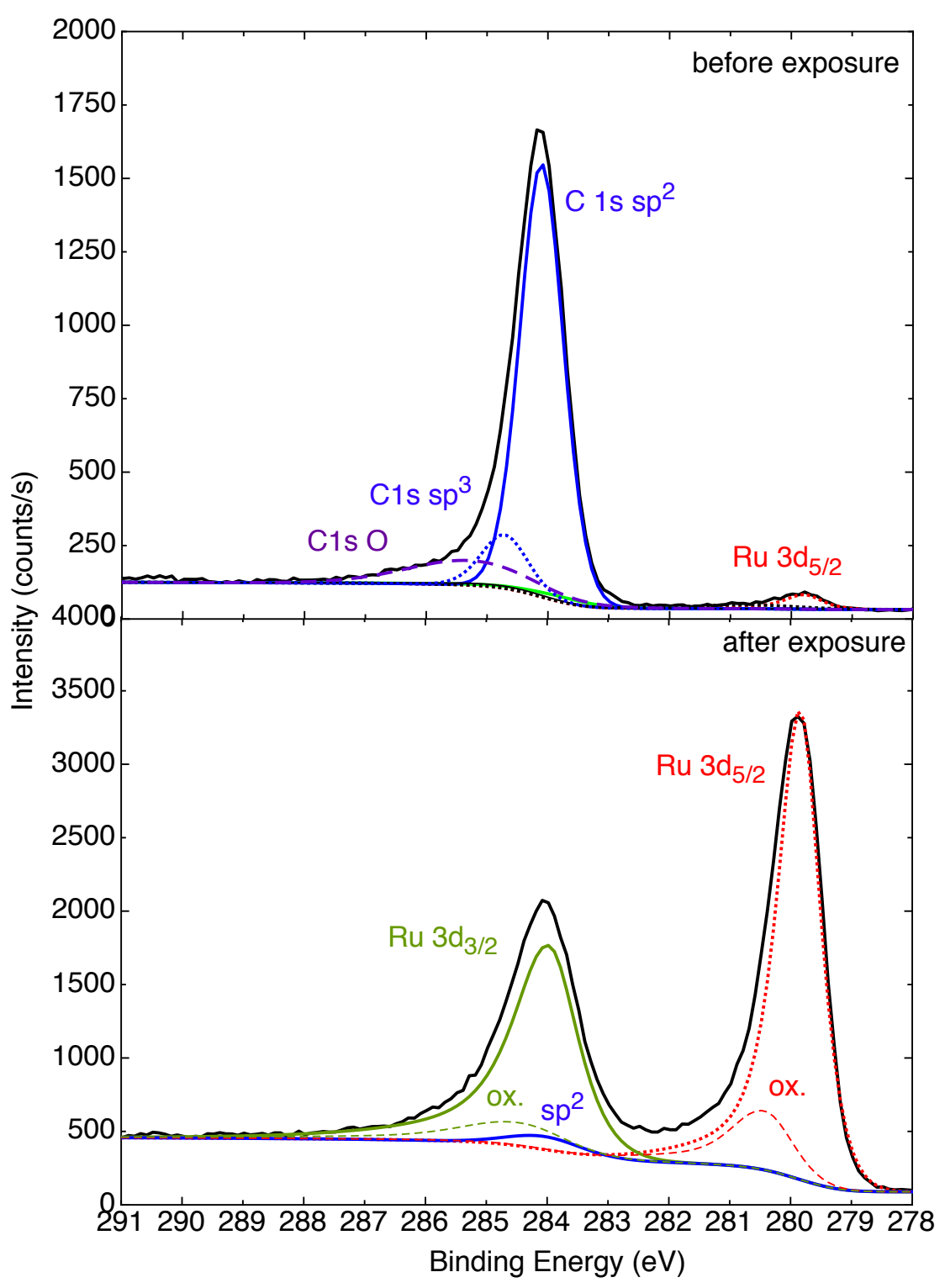

Figure 4.4. XPS data for a Type I sample (graphene on Ru (with native oxide)/Y) before and after exposure to atomic $\mathrm{H}$ for $\mathbf{1 4 5 0}$ minutes. The peaks seen here are for $\mathrm{C} 1 \mathrm{~s}$ ( $\mathrm{sp}^{2}$ and $\mathrm{sp}^{3}$ components), $\mathrm{C} 1 \mathrm{~s} \mathrm{O}, \mathrm{Ru} 3 \mathrm{~d}_{5 / 2}$ and $\mathrm{Ru} 3 \mathrm{~d}_{3 / 2}$ and $\mathrm{Ru}$ oxides. 
Table 4.1. Atomic concentrations derived from spectra from Figure 4.4 (graphene on $\mathrm{Ru}-\mathrm{Y}$ ) before and after exposure to atomic hydrogen for 1450 minutes. The contribution from possible oxidised C species overlaps with the tail due to asymmetry of the $\mathrm{C} 1 \mathrm{~s}$ peak of $\mathrm{sp}^{2}$ carbon and thus presents and overestimate of possible oxidised $\mathrm{C}$ species. After exposure the signal of remaining carbon is dominated by Ru, therefore no fit of different $\mathrm{C}$ species can be reliably obtained.

\begin{tabular}{|c|c|c|}
\hline Name & Unexposed Atomic \% & Exposed At \% \\
\hline $\mathrm{C} 1 \mathrm{~s} \mathrm{O} / \mathrm{sp}^{2}$ tail & 12.2 & \multirow{3}{*}{15.3} \\
\hline $\mathrm{C} 1 \mathrm{~s} \mathrm{sp}^{2}$ & 75.2 & \\
\hline C1s sp ${ }^{3}$ & 9.9 & \\
\hline O1s & 2.1 & 25.0 \\
\hline Ru3d $_{5 / 2}$ elemental & 0.4 & 42.5 \\
\hline 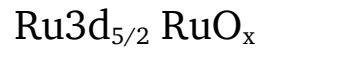 & 0.2 & 8.2 \\
\hline
\end{tabular}

XPS data has been compared for multi-layer graphene on Ru-Y (Type I) before and after atomic $\mathrm{H}$ exposure in Figure 4.4 and Table 4.1. Firstly, the sum of the $\mathrm{C} 1 \mathrm{~s}$ atomic percentage is shown to decrease from $97.3 \%$ before exposure to $15.3 \%$ after exposure to atomic hydrogen. This confirms that atomic hydrogen etches graphene from the surface, similarly as the amorphous carbon films are found to be etched, based on ellipsometry results from Figure 4.3. The C 1s signal remaining after exposure is typical for $\mathrm{C}$ contamination due to sample storage and handling. Thus, this supports the fact that there is no more graphene left on the surface after atomic hydrogen exposure. 
Secondly, as a result of this reduction of carbon on the surface uncovering the underlying $\mathrm{Ru}$ layer, the elemental $\mathrm{Ru}$ concentration is shown to increase from $0.4 \%$ before exposure to $42.5 \%$ after exposure. Additionally, we see an increase in oxidized $\mathrm{Ru}(0.2 \%$ to $8.2 \%)$, which can be explained because the Ru surface is reintroduced into ambient pressure after atomic hydrogen exposure.

\subsubsection{Dehydrogenation of $Y$ through graphene}

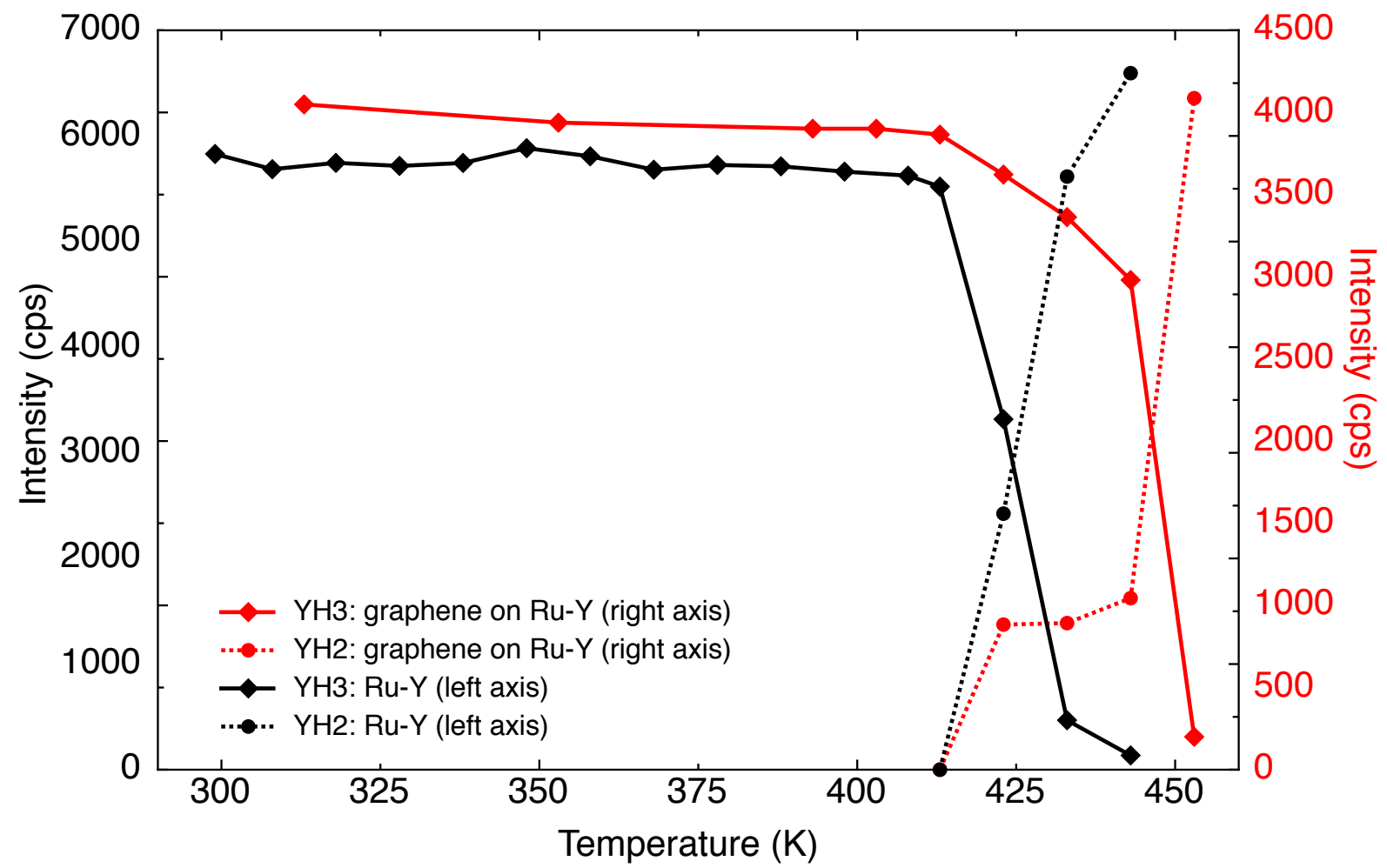

Fig 4.5. Intensity of diffraction peaks $\mathrm{YH}_{3}$ (002) and $\mathrm{YH}_{2}$ (111) for both a hydrogenated Ru-Y sample (black left Y-axis) and a graphene covered prehydrogenated Ru-Y sample (right red Y-axis) during in-situ heating. ${ }^{28}$

The in-situ ellipsometry data measured during atomic $\mathrm{H}$ exposure shows that hydrogenation of the Y sensing layer only proceeds after (most of) the carbon and/or graphene layer is etched away. This suggests that carbon and graphene in principle could form effective barriers against diffusion of hydrogen, as long as their surfaces are protected against direct exposure to $\mathrm{H}$ radicals. To check whether graphene provides an effective barrier for hydrogen, without exposing the graphene surface to $\mathrm{H}$ radicals, 
a multi-layer graphene sheet is transferred on a previously completely hydrogenated $\mathrm{Ru}-\mathrm{Y}$ sample, where all $\mathrm{Y}$ is consumed for forming stable $\mathrm{YH}_{3}$. Previous experiments ${ }^{18}$ showed that when such a fully hydrogenated $\mathrm{Ru} / \mathrm{YH}_{3}$ sample is heated above $420 \mathrm{~K}$, hydrogen diffuses back through the $\mathrm{Ru}$ film and desorbs as $\mathrm{H}_{2}$ at the surface, until all $\mathrm{YH}_{3}$ is converted to $\mathrm{YH}_{2} \cdot{ }^{18}$ Possible changes in dehydrogenation of a pre-saturated sensing sample covered by graphene, might thus be used to check whether graphene acts as diffusion barrier, without directly exposing the graphene to atomic H. Figure 4.5 compares the evolution of $\mathrm{YH}_{3}$ and $\mathrm{YH}_{2} \mathrm{XRD}$ peaks as function of temperature for a reference pre-hydrogenated $\mathrm{Ru} / \mathrm{YH}_{3}$ sample and a $\mathrm{Ru} / \mathrm{YH}_{3}$ sample covered by graphene. We observe that $\mathrm{YH}_{3}$ starts to dehydrogenate in both samples at $423 \mathrm{~K}$ (Figure 4.5). We see, however, that in the case of graphene/ $\mathrm{Ru} / \mathrm{YH}_{3}$ the decrease of $\mathrm{YH}_{3}$ occurs at an about 2.5 times slower rate as compared to the $\mathrm{Ru} / \mathrm{YH}_{3}$ reference sample. Consequently, reformation of $\mathrm{YH}_{2}$ also happens more gradually in the case of a graphene covered sample compared to the reference sample. This would indicate that graphene does not delay the initiation of dehydrogenation but can slow the hydrogen transport process.

As discussed in previous work, the graphene film retains the texture of the rough molybdenum carbide film that forms during graphene growth after transfer onto a flat sample. ${ }^{24,29}$ The graphene film thus only adheres to a limited surface area of the $\mathrm{Ru} / \mathrm{YH}_{3}$ sample, leaving room for hydrogen to desorb from the Ru surface, but stay trapped below the graphene. This possibly explains why the onset for dehydrogenation is identical to the reference $\mathrm{Ru} / \mathrm{YH}_{3}$ sample. Moreover, holes in the graphene will allow hydrogen desorbing from the Ru cap to escape. Unfortunately, these effects make it impossible to use this experiment as a proper check how well graphene blocks diffusion of hydrogen.

As mentioned earlier in section 4.3, multi-layer graphene, being highly ordered, ${ }^{24}$ resists hydrogenation better when compared to sputtered carbon. Despite manufacturing defects such as holes seen in multi-layer graphene, and additional access points for hydrogen created during the transfer process, graphene still provides 
more resistance to etching than amorphous carbon and as a result delayed complete hydrogenation of a Y based sensor.

\subsection{Conclusions}

In this work, we investigated the ability of multi-layer graphene to serve as a barrier to the diffusion of atomic hydrogen and compared that with amorphous carbon of a similar thickness. Using spectroscopic ellipsometry to probe hydrogenation of an underlying $\mathrm{Ru} / \mathrm{Y}$ stack, we do indeed see that multi-layer graphene is shown to delay hydrogenation of the $\mathrm{Y}$ sensor when compared to an uncovered and amorphous carbon capped Y sensor. This is due to the fact that transferred multi-layer graphene is shown to have a slower etch rate than amorphous carbon. The presence of small holes in the graphene is not found to lead to direct hydrogenation of the underlying film, which is attributed to redeposition of carbon from volatile hydrocarbon species created during graphene etching.

Dehydrogenation of yttrium hydride is also investigated where we see that in both cases of graphene covered and a bare Ru capped $\mathrm{Y}$ sensor, $\mathrm{YH}_{3}$ starts to dissociate at the same temperature of $423 \mathrm{~K}$. This would indicate that graphene does not delay initial $\mathrm{YH}_{3}$ dissociation but instead delays the release of hydrogen, evidenced by the slower formation of $\mathrm{YH}_{2}$ measured using XRD. This might be attributed to trapping of hydrogen in the voids between the $\mathrm{Ru}$ cap and the rough graphene layer, followed by slower escape of hydrogen through holes in the graphene.

This work shows that graphene and carbon can in principle be used as barrier against diffusion of atomic hydrogen, provided that the outermost surface is protected against direct exposure to atomic hydrogen. Several metal or metal oxide layers may be suitable for that purpose, although it will be a challenge to grow a closed layer on top of carbon and graphene, because of intermixing and intercalation effects, respectively. 30,31 


\subsection{References}

(1) Geim, A. K.; Novoselov, K. S. The Rise of Graphene. Nature materials 2007, 6 (3), 183-191.

(2) Geim, A. K. Graphene: Status and Prospects. Science 2009, 324 (5934), 1530-1534.

(3) Hu, S.; Lozada-Hidalgo, M.; Wang, F. C.; Mishchenko, A.; Schedin, F.; Nair, R. R.; Hill, E. W.; Boukhvalov, D. W.; Katsnelson, M. I.; Dryfe, R. A. W.; et al. Proton Transport Through One-Atom-Thick Crystals. Nature 2014, 516, 227-230.

(4) Novoselov, K. S.; Jiang, D.; Schedin, F.; Booth, T. J.; Khotkevich, V. V.; Morozov, S. V.; Geim, A. K. Two-Dimensional Atomic Crystals. Proceedings of the National Academy of Sciences of the United States of America 2005, 102 (30), 10451-10453.

(5) Lee, C.; Wei, X.; Kysar, J. W.; Hone, J. Measurement of the Elastic Properties and Intrinsic Strength of Monolayer Graphene. Science 2008, 321 (5887), 385-388.

(6) Han, M.; Özyilmaz, B.; Zhang, Y.; Kim, P. Energy Band-Gap Engineering of Graphene Nanoribbons. Phys. Rev. Lett. 2007, 98 (20).

(7) Avouris, P. Graphene: Electronic and Photonic Properties and Devices. Nano letters 2010, 11, 4285-4294.

(8) Bolotin, K. I.; Sikes, K. J.; Jiang, Z.; Klima, M.; Fudenberg, G.; Hone, J.; Kim, P.; Stormer, H. L. Ultrahigh Electron Mobility in Suspended Graphene. Solid State Communications 2008, 146 (9-10), 351-355.

(9) Homaeigohar, S.; Elbahri, M. Graphene Membranes for Water Desalination. Npg Asia Materials 9, e427.

(10) Siahlo, A. I.; Popov, A. M.; Poklonski, N. A.; Lozovik, Y. E.; Vyrko, S. A.; Ratkevich, S. V. Multi-Layer Graphene Membrane Based Memory Cell. Physica E: Low-dimensional Systems and Nanostructures 2016, 84, 348-353.

(11) Yoo, B. M.; Shin, J. E.; Lee, H. D.; Park, H. B. Graphene and Graphene Oxide Membranes for Gas Separation Applications. Nanotechnology / Separation Engineering 2017, 16, 39-47. 
Bunch, J. S.; Verbridge, S. S.; Alden, J. S.; van der Zande, A. M.; Parpia, J. M.; Craighead, H. G.; McEuen, P. L. Impermeable Atomic Membranes From Graphene Sheets. Nano letters 2008, 8 (8), 2458-2462.

Joshi, R. K.; Carbone, P.; Wang, F. C.; Kravets, V. G.; Su, Y.; Grigorieva, I. V.; Wu, H. A.; Geim, A. K.; Nair, R. R. Precise and Ultrafast Molecular Sieving Through Graphene Oxide Membranes. Science 2014, 343 (6172), 752-754.

Tsetseris, L.; Pantelides, S. T. Hydrogen Uptake by Graphene and Nucleation of Graphane. Journal of Materials Science 2012, 47 (21), 7571-7579.

Flotow, H. E.; Osborne, D. W.; Otto, K.; Abraham, B. M. YH 3and YD 3: Heat Capacities and Thermodynamic Functions From $15^{\circ}$ to $350^{\circ} \mathrm{K}$ and Infrared Absorption Spectra. J. Chem. Phys. 1963, 38 (11), 2620-2626.

Flotow, H. E.; Osborne, D. W.; Otto, K. Heat Capacities and Thermodynamic Functions of $\mathrm{YH} 2$ and $\mathrm{YD} 2$ from $5^{\circ}$ to $350^{\circ} \mathrm{K}$ and the Hydrogen Vibration Frequencies. J. Chem. Phys. 1962, 36 (4), 866-872.

Astakhov, D. I.; Goedheer, W. J.; Lee, C. J.; Ivanov, V. V.; Krivtsun, V. M.; Koshelev, K. N.; Lopaev, D. V.; van der Horst, R. M.; Beckers, J.; Osorio, E. A.; et al. Exploring the Electron Density in Plasma Induced by EUV Radiation: II. Numerical Studies in Argon and Hydrogen. J. Phys. D: Appl. Phys. 2016, 49 (29), 295204.

Soroka, O.; Sturm, J. M.; van de Kruijs, R. W. E.; Lee, C. J.; Bijkerk, F. Control of YH3 Formation and Stability via Hydrogen Surface Adsorption and Desorption. Applied Surface Science 2018, 455, 70-74.

Cancado, L. G.; Jorio, A.; Ferreira, E. H.; Stavale, F.; Achete, C. A.; Capaz, R. B.; Moutinho, M. V.; Lombardo, A.; Kulmala, T. S.; Ferrari, A. C. Quantifying Defects in Graphene via Raman Spectroscopy at Different Excitation Energies. Nano letters 2011, 11 (8), 3190-3196.

Braginsky, O. V.; Kovalev, A. S.; Lopaev, D. V.; Malykhin, E. M.; Rakhimova, T. V.; Rakhimov, A. T.; Vasilieva, A. N.; Zyryanov, S. M.; Koshelev, K. N.; Krivtsun, V. M.; et al. Removal of Amorphous C and Sn on Mo:Si Multilayer Mirror Surface in Hydrogen Plasma and Afterglow. J. Appl. Phys. 2012, 111 (9), 093304.

Chen, J.; Louis, E.; Lee, C. J.; Wormeester, H.; Kunze, R.; Schmidt, H.; Schneider, D.; Moors, R.; van Schaik, W.; Lubomska, M.; et al. Detection 
and Characterization of Carbon Contamination on EUV Multilayer Mirrors. Opt. Express 2009, 17 (19), 16969-16979.

(22) Chen, J.; Louis, E.; Harmsen, R.; Tsarfati, T.; Wormeester, H.; van Kampen, M.; van Schaik, W.; van de Kruijs, R.; Bijkerk, F. In Situ Ellipsometry Study of Atomic Hydrogen Etching of Extreme Ultraviolet Induced Carbon Layers. Applied Surface Science 2011, 258 (1), 7-12.

(23) Vedam, K. Spectroscopic Ellipsometry: a Historical Overview. Thin Solid Films 1998, 313-314, 1-9.

(24) Mund, B. K.; Sturm, J. M.; Lee, C. J.; Bijkerk, F. Etching Processes of Transferred and Non-Transferred Multi-Layer Graphene in the Presence of Extreme UV, $\mathrm{H} 2 \mathrm{O}$ and $\mathrm{H} 2$, to be published.

(25) Ugur, D.; Storm, A. J.; Verberk, R.; Brouwer, J. C.; Sloof, W. G. Kinetics of Reduction of a RuO 2(110) Film on Ru(0001) by H 2. J. Phys. Chem. C 2012, 116 (51), 26822-26828.

(26) Nishiyama, I.; Oizumi, H.; Motai, K.; Izumi, A.; Ueno, T.; Akiyama, H.; Namiki, A. Reduction of Oxide Layer on Ru Surface by Atomic-Hydrogen Treatment. J. Vac. Sci. Technol. B 2005, 23 (6), 3129.

(27) Mund, B. K.; Sturm, J. M.; Lee, C. J.; Bijkerk, F. Formation of H2O on a CO2 Dosed Ru(0 00 1) Surface Under Extreme Ultraviolet Light and H2. Applied Surface Science 456 IS -, 538-544.

(28) Soroka, O.; Sturm, J. M.; Bijkerk, F. 2018, In Preparation.

(29) Suk, J. W.; Kitt, A.; Magnuson, C. W.; Hao, Y.; Ahmed, S.; An, J.; Swan, A. K.; Goldberg, B. B.; Ruoff, R. S. Transfer of CVD-Grown Monolayer Graphene Onto Arbitrary Substrates. ACS Nano 2011, 5 (9), 6916-6924.

(30) Kovtyukhova, N. I.; Wang, Y.; Berkdemir, A.; Cruz-Silva, R.; Terrones, M.; Crespi, V. H.; Mallouk, T. E. Non-Oxidative Intercalation and Exfoliation of Graphite by Brønsted Acids. Nature chemistry 2014, 6, 957-963.

(31) Voloshina, E.; Dedkov, Y. Graphene on Metallic Surfaces: Problems and Perspectives. Physical chemistry chemical physics : PCCP 2012, 14 (39), 13502-13514. 


\section{Chapter 5: Formation of $\mathrm{H}_{2} \mathrm{O}$ on a $\mathrm{CO}_{2}$ dosed Ru(0001) surface under Extreme Ultraviolet Light and $\mathrm{H}_{2}$}

In this work, we study the reaction of the dissociation products of carbon dioxide on a $\mathrm{Ru}(0001)$ surface under Extreme Ultraviolet (EUV) light with a partial pressure of hydrogen. Our results show that both amorphous carbon and $\mathrm{H}_{2} \mathrm{O}$ are the end products of the $\mathrm{CO}_{2}$ dissociation at the $\mathrm{Ru}$ surface, and these are produced only in the presence EUV and $\mathrm{H}_{2}$. Partial dissociation of $\mathrm{CO}_{2}$ on the Ru surface is an intermediate step in the overall reaction. Using Reflection Absorption Infrared spectroscopy (RAIRS) and Temperature Programmed Desorption (TPD), only water is detected as molecular reaction product. We further show that this reaction deactivates the Ru surface due to the formation of an amorphous carbon layer, thereby confirming the catalytic role of $\mathrm{Ru}$ in the total reaction.

\subsection{Introduction}

$\mathrm{CO}_{2}$ has been shown to dissociate when in contact with metal surfaces, such as $\mathrm{Fe}^{1,2}$, $\mathrm{Ni}^{1,2}, \mathrm{~W}^{3}, \mathrm{Re}^{4}$ and $\mathrm{Al}^{5}$, into $\mathrm{CO}$ and $\mathrm{O} .^{6}$ In the chemical industry, transition metals are widely studied as catalysts, ${ }^{7}$ due to their high efficiency to convert carbon dioxide to methane and methanol. Thus, to understand the transition metal driven catalytic conversion of $\mathrm{CO}_{2}$ to other compounds, the interaction of $\mathrm{CO}_{2}$ with metal surfaces needs to be studied. ${ }^{8}$

Besides its relevance for catalysis, $\mathrm{Ru}$ is also employed as a protective cap for optics for Extreme Ultraviolet (EUV) light. EUV optics must operate in a moderate vacuum where there may be a complex balance between, on the one side photochemical reactions of residual hydrocarbons and water on the cap, and on the other side, cleaning by hydrogen radicals. One option to control reaction pathways is to deliberately introduce additional species into the vacuum to consume reactive species. 
For instance, a balance between ruthenium oxidation and reduction is achieved by controlling the partial pressure of either hydrogen or water. ${ }^{9}$

The dissociation products of $\mathrm{CO}_{2}$ reacting with hydrogen to form hydrocarbons on the optics surfaces to prevent oxidation and consume excess reactive hydrogen is an attractive prospect in highly reactive environments, such as in the case of Extreme Ultraviolet (EUV) Lithography. However, to prevent oxidation and consume hydrogen via this pathway, a reverse water gas shift reaction needs to take place. ${ }^{10}$ Ruthenium surfaces have previously been used as catalyzing agents for reverse water gas shift reactions, but ruthenium's interaction with $\mathrm{CO}_{2}$ has not been fully investigated. ${ }^{8,11}$ Furthermore, this catalyzing behavior is shown in Density Functional Theory (DFT) calculations as well, where $\mathrm{CO}_{2}$ adsorption and dissociation is seen on a Ru surface, hydrogenating to form $\mathrm{CH}_{\mathrm{x}}$ species. ${ }^{12,13}$

Prior experiments ${ }^{14}$ have shown that $\mathrm{CO}_{2}$ adsorption on a $\mathrm{Ru}(0001)$ surface results in partial dissociation, shown by the existence of both $\mathrm{CO}_{2}$ and $\mathrm{CO}$ species on the surface. Furthermore, this dissociation is observed to saturate with increasing $\mathrm{CO}_{2}$ coverage. Additionally, no evidence is found for oxygen desorption, indicating that the oxygen is consumed by forming additional $\mathrm{CO}$ and/or $\mathrm{H}_{2} \mathrm{O}$ via reactions with residual carbon and/or hydrogen on the crystal surface.

However, these experiments are not extended to more realistic scenarios, involving the presence of hydrogen and EUV. Thus, it is unknown if the partial dissociation of $\mathrm{CO}_{2}$ is sufficient to induce further reactions with excess hydrogen. In order to understand the preferred reaction pathways under more realistic conditions for EUV optics, the reactions of $\mathrm{CO}_{2}$ on the $\mathrm{Ru}(0001)$ surface, in the presence of EUV light and $\mathrm{H}_{2}$ are studied in more detail in this work.

For this work, the surface is characterized, in-situ, using Reflection Absorption Infrared Spectroscopy (RAIRS) and Temperature Programmed Desorption (TPD) spectroscopy. RAIRS measurements are sensitive to study the changes in adsorbed 
molecular groups, their orientation, density, and surrounding environment via changes in vibrational modes.

\subsection{Experimental}

For this work, a ruthenium (0001) single crystal, $11 \mathrm{~mm}$ in diameter and $\sim 3 \mathrm{~mm}$ in thickness, prepared by Surface Preparation Laboratories, The Netherlands, is used. The crystal is mounted on a 3-axis positioning manipulator in Ultra-High Vacuum (UHV) conditions and maintained at a base pressure of $10^{-10}$ mbar. A K-type thermocouple is spot welded to the side of the crystal to measure the surface temperature. A Eurotherm temperature controller is used to control the temperature of the surface.

All surface chemistry experiments are performed in the same experimental setup, sequentially without breaking vacuum. The crystal surface is treated with a cleaning process involving oxidation, annealing and argon ion sputtering. Firstly, oxidation is performed to remove carbon from the surface, by increasing the surface temperature to $1300 \mathrm{~K}$, with a partial pressure of $1 \times 10^{-7}$ mbar of $\mathrm{O}_{2}$ in the chamber. Secondly, ion sputtering is conducted. Finally, the surface is annealed at $1300 \mathrm{~K}$ for 30 minutes and flashed to $1580 \mathrm{~K}$. Repeated sputtering and annealing is performed until a reference TPD spectrum from water and $\mathrm{CO}$ on clean $\mathrm{Ru}(0001)$ could be reproduced. ${ }^{15}$

The experimental chamber is also equipped with RAIRS and TPD spectroscopy, and is attached to an EUV source ${ }^{16,17}$. RAIRS spectra are measured at grazing incidence using a Fourier Transform Infrared Spectrometer (Bruker vertex $70 \mathrm{~V}$ ), equipped with a liquid $\mathrm{N}_{2}$ cooled mercury-cadmium-telluride (MCT) detector. Each IR spectrum is accumulated over 256 scans with a resolution of $4 \mathrm{~cm}^{-1}$, with background and measurement scans recorded at $85 \mathrm{~K}$. To obtain TPD spectra, the surface is placed $\sim 1$ $\mathrm{mm}$ away from the entrance aperture of a Hiden Analytical 3F/PIC quadrupole mass spectrometer (QMS), housed in a differential pumped system, to ensure the signal is dominated by surface desorption. 
Carbon dioxide (99.998\% purity; residuals: $\mathrm{O}_{2} 2$ ppm, $\mathrm{N}_{2} 8 \mathrm{ppm}$, hydrocarbon 3 ppm, $\mathrm{H}_{2} \mathrm{O} 1 \mathrm{ppm}, \mathrm{CO} 1 \mathrm{ppm}$ ) is dosed on the surface at a temperature of $85 \mathrm{~K}$. This is done using a retractable quartz dosing tube, placed $1 \mathrm{~cm}$ away from the surface. $\mathrm{CO}_{2}$ is delivered via a pinhole mounted between the gas supply and doser, to maintain an effective pressure in the $10^{-8}$ mbar range near the crystal surface. Calibration of $\mathrm{CO}_{2}$ dose is performed by comparing the amount detected via TPD against reference water TPD spectra. ${ }^{14,17}$

The chamber is attached to a Xe plasma discharge EUV source (Philips EUV Alpha Source) with a repetition rate of $500 \mathrm{~Hz}$. The light from the source is filtered via reflection from a Mo/Si multilayer mirror (55\% reflectivity at $13.5 \mathrm{~nm}$ ) and via transmission through a Si/Mo/Zr membrane $(35 \% \text { transmission at } 13.5 \mathrm{~nm})^{18}$, resulting in a peak transmission of $19 \%$ at $13.5 \mathrm{~nm}$ with a FWHM of $0.2 \mathrm{~nm}$ and an additional transmission of $9 \%$ at $21.5 \mathrm{~nm}$ with a FWHM of $3.1 \mathrm{~nm} .{ }^{1920} 21$ The average intensity of the EUV beam, with a Gaussian profile (FWHM $=3 \mathrm{~mm}$ ) is $35-55$ $\mathrm{mW} / \mathrm{cm}^{2}$, which corresponds to an EUV pulse fluence of $90-110 \mu \mathrm{J} / \mathrm{cm}^{2}$.

The experimental procedure begins with dosing the cleaned (unless otherwise noted) $\mathrm{Ru}(0001)$ surface with $0.2 \mathrm{ML}$ of $\mathrm{CO}_{2}$, followed by exposing the surface to EUV with a partial pressure of $\mathrm{H}_{2}$. A RAIRS background spectrum is recorded before dosing, and further spectra are recorded after dosing, and for every 5 minutes of EUV or $\mathrm{H}_{2}$ exposure. TPD measurements are performed by heating the crystal to $600 \mathrm{~K}$ from $80 \mathrm{~K}$ at a rate of $2 \mathrm{~K} / \mathrm{s}$, followed by further heating to $1580 \mathrm{~K}$ at $10 \mathrm{~K} / \mathrm{s}$.

\subsection{Results and Discussion}

To investigate the dissociation of $\mathrm{CO}_{2}$ and its end product formation, experiments are first performed with an $\mathrm{H}_{2}$ partial pressure of $1 \times 10^{-7}$ mbar under EUV illumination. In this case, characterization techniques such as RAIRS and TPD are unable to detect the formation of $\mathrm{H}_{2} \mathrm{O}$ and simple hydrocarbons (such as methane, ethylene, formic acid, and methanol). Also, changing the $\mathrm{H}_{2}$ partial pressure to $1 \times 10^{-6} \mathrm{mbar}$, while keeping all the other parameters $\left(\mathrm{CO}_{2}, \mathrm{EUV}\right)$ the same, did not result in any change in RAIRS 
$\mathrm{OH}$ signals (to detect water) or TPD mass spectra. Therefore, the partial pressure of $\mathrm{H}_{2}$ is further increased to $1 \times 10^{-5}$ mbar (keeping the parameters for $\mathrm{EUV}$ and $\mathrm{CO}_{2}$ the same), for which the results are detailed below.

\subsubsection{EUV induced surface water formation}

a) $\mathrm{H}_{2}: 10^{-5}$ mbar

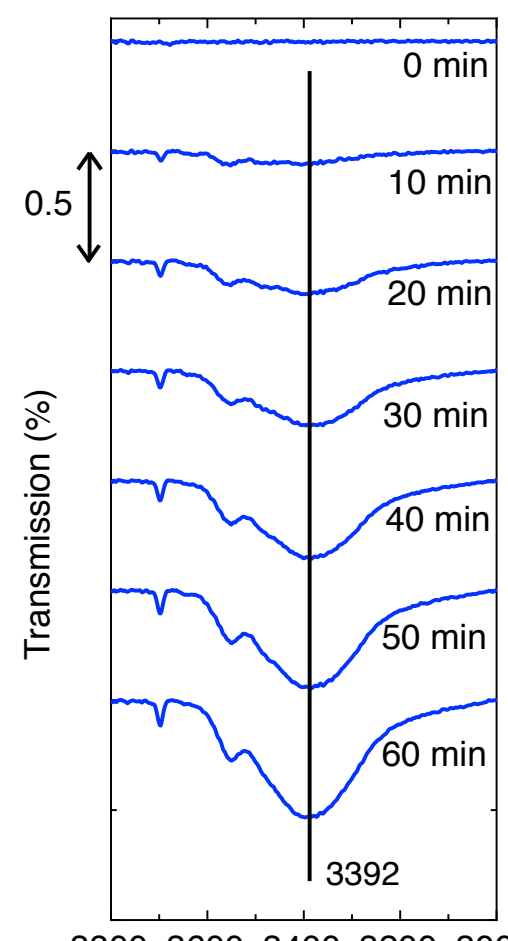

38003600340032003000 b) $\mathrm{CO}_{2}+\mathrm{H}_{2}: 10^{-5} \mathrm{mbar}$

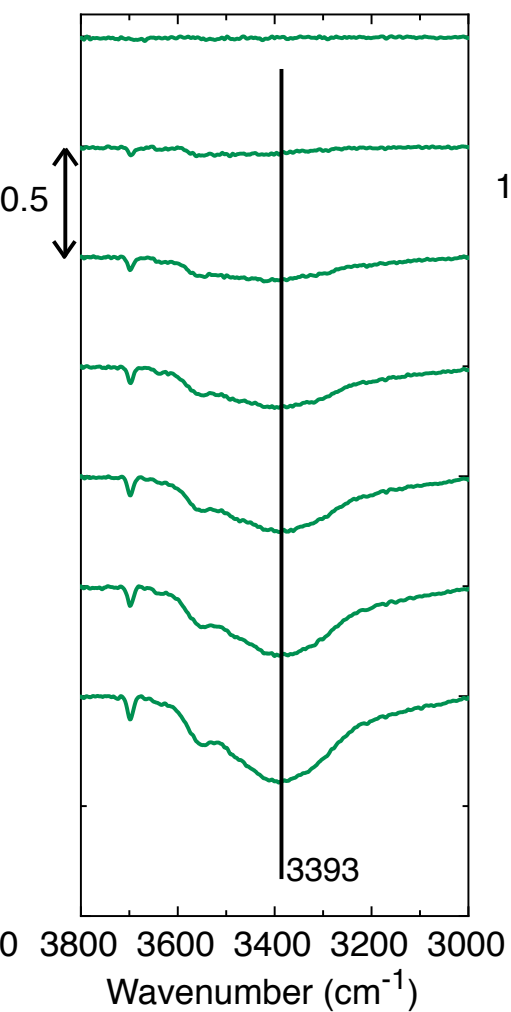

c) $\mathrm{EUV}+\mathrm{CO}_{2}+\mathrm{H}_{2}: 10^{-5} \mathrm{mbar}$

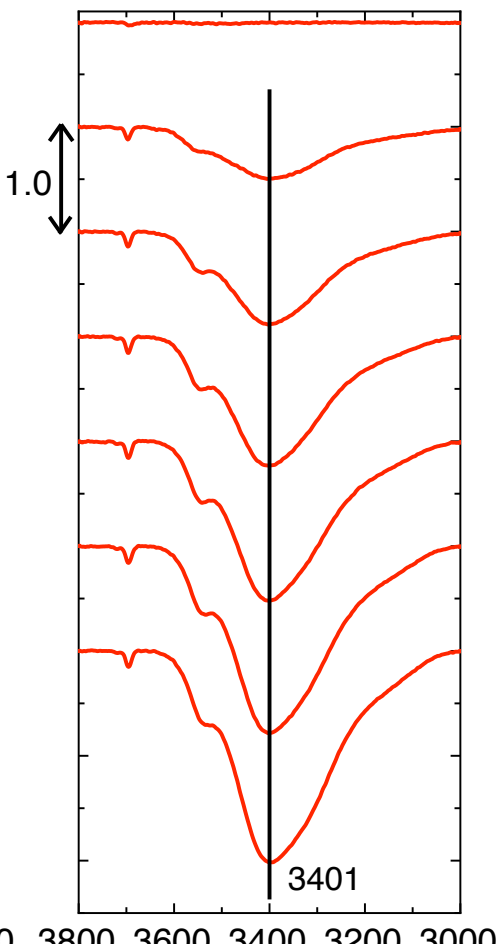

Figure 5.1. RAIRS spectra of the $\mathrm{OH}$ peak $(3000-3800 \mathrm{~cm}-1)$ with (a) $1 \times 10^{-5}$ mbar $\mathrm{H}_{2}$ background pressure, (b) adsorbed $\mathrm{CO}_{2}+\mathrm{H}_{2}$ background and (c) adsorbed $\mathrm{CO}_{2}$ and $\mathrm{H}_{2}$ background under EUV irradiation. Spectra are shown in 10minute exposure increments from top to bottom.

Figure 5.1 shows the difference in RAIRS OH vibration peak size, which is sensitive for adsorption of molecular $\mathrm{H}_{2} \mathrm{O}$ on the surface, for different exposure conditions. As seen in Figure 5.1(a), the peak intensity increases with $\mathrm{H}_{2}$ exposure time for a clean $\mathrm{Ru}(0001)$ surface, indicating increasing water deposition. This water is due to an increased residual $\mathrm{H}_{2} \mathrm{O}$ gas pressure from the $\mathrm{H}_{2}$ gas line. ${ }^{22}$ Similarly, an increase in 
$\mathrm{OH}$ peak intensity is seen in Figure 5.1(b) for $\mathrm{H}_{2}$ exposure of a $\mathrm{Ru}(0001)$ surface with adsorbed $\mathrm{CO}_{2}$. However, the $\mathrm{OH}$ intensity is lower than it is in the plot shown in Figure 5.1(a). This is due to $\mathrm{CO}_{2}$ (or its partial dissociation products) occupying sites on the surface which prevent $\mathrm{H}_{2} \mathrm{O}$ from adsorbing. In contrast, when $\mathrm{Ru}(0001)$ is dosed with $\mathrm{CO}_{2}$ and exposed to $\mathrm{H}_{2}$ and EUV radiation (Figure 5.1(c)), the $\mathrm{OH}$ peak intensity is significantly higher than for the other two conditions, with the only difference being the introduction of EUV. This indicates that more water is formed on the $\mathrm{CO}_{2}$ covered $\mathrm{Ru}(0001)$ surface when exposed to EUV in the presence of hydrogen. Figure 5.2 shows the rate of $\mathrm{OH}$ peak formation.

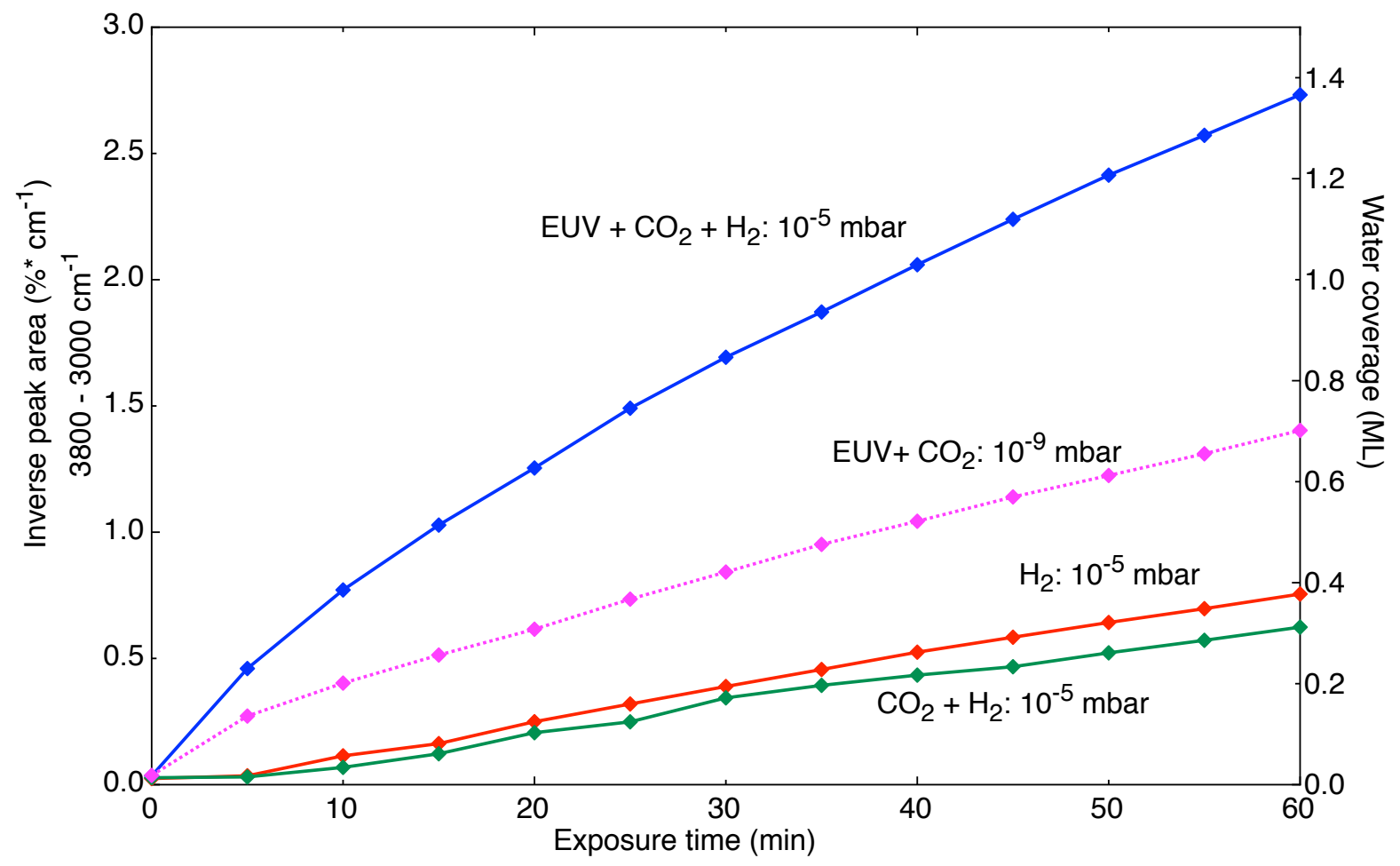

Figure 5.2. Comparison of the $\mathrm{OH}$ peak area growth over the course of 60 minutes for a $\mathrm{CO}_{2}$ dosed $\mathrm{Ru}(0001)$ surface exposed to EUV with $\mathrm{H}_{2}$ at $1 \times 10^{-5} \mathrm{mbar}$. The $\mathrm{Y}$ axis on the left shows the area under the inverse IR peak $\left(3800-3000 \mathrm{~cm}^{-1}\right)$, while the $\mathrm{Y}$ axis on the right shows the corresponding indicative water coverage.

Figure 5.2 compares the growth rate of the $\mathrm{OH}$ peak for the three exposure conditions shown in Figure 5.1. Water coverage is expressed in terms of both peak area and water coverage. It should be noted that RAIRS is in general not quantitative. However, based 
on a calibration of RAIRS versus TPD results on $\mathrm{Ru}(0001)$ in the same experimental set-up, an indicative water coverage can be provided based on comparison of the peak height in the transmission plots. ${ }^{16}$ We see that water coverage increases on the surface over 60 minutes for all three cases: $0.33 \mathrm{ML}$ for $\mathrm{CO}_{2}+\mathrm{H}_{2}, 0.37 \mathrm{ML}$ for $\mathrm{H}_{2}$, and $1.36 \mathrm{ML}$ for EUV $+\mathrm{CO}_{2}+\mathrm{H}_{2}$. When a clean $\mathrm{Ru}(0001)$ surface is dosed with $\mathrm{CO}_{2}$ and exposed to EUV without introducing $\mathrm{H}_{2}$, the deposition of water from residual gas amounts to 0.70 $\mathrm{ML}$ in 60 minutes. Furthermore, water deposited in the presence of EUV without $\mathrm{CO}_{2}$ and $\mathrm{H}_{2}$ is shown to be less than 0.1 ML. The difference in final water coverage between $\mathrm{EUV}+\mathrm{CO}_{2}+\mathrm{H}_{2}$ compared to $\mathrm{CO}_{2}+\mathrm{H}_{2}$ without EUV is thus $1.03 \mathrm{ML}$. The individual contributions due to EUV $+\mathrm{CO}_{2}$ and $\mathrm{CO}_{2}+\mathrm{H}_{2}$ added together would amount to $1.03 \mathrm{ML}$, which is also less compared to exposure to $\mathrm{EUV}+\mathrm{CO}_{2}+\mathrm{H}_{2}$. The clearly higher water coverage after $\mathrm{EUV}+\mathrm{H}_{2}$ exposure of a $\mathrm{CO}_{2}$ dosed $\mathrm{Ru}(0001)$ surface in comparison with all reference cases indicates that water is produced by an EUV-induced reaction of $\mathrm{CO}_{2}$ and $\mathrm{H}_{2}$ or its partial dissociation products.

The formation of water can be attributed to the overall reaction equation (FischerTropsch type reaction):

$$
\mathrm{CO}_{2}+(2+n) \mathrm{H}_{2} \stackrel{\mathrm{EUV}}{\longrightarrow} \mathrm{CH}_{2 n}+2 \mathrm{H}_{2} \mathrm{O}
$$

Although equation 5.1 could be a direct process, previous experiments ${ }^{14}$ have shown that $\mathrm{CO}_{2}$ partially dissociates on $\mathrm{Ru}(0001)$ without EUV exposure, therefore a second reaction path is also possible:

$$
\begin{aligned}
& \mathrm{CO}_{2} \rightarrow \mathrm{CO}+\mathrm{O} \text { (adsorbed) } \\
& \mathrm{CO}+\mathrm{O} \text { (adsorbed) }+(2+n) \mathrm{H}_{2} \stackrel{\mathrm{EUV}}{\longrightarrow} \mathrm{CH}_{2 n}+2 \mathrm{H}_{2} \mathrm{O}
\end{aligned}
$$

In what follows, we show that the formation of water, under reaction conditions investigated here, proceeds only via the second path.

Equation 5.1 and 5.3 show that molecular hydrogen cracks into atomic hydrogen in the presence of EUV, ${ }^{20}$ Both equations 5.1 and 5.3 lead to the formation of 
hydrocarbons $\left(\mathrm{CH}_{\mathrm{x}}\right)$ and water as products. Since we do not see the formation of volatile hydrocarbons, the value of $n$ can be 0 , indicating the formation of amorphous carbon. Also, equation 5.2 can only occur on the surface of $\operatorname{Ru}(0001),{ }^{14}$ this means equation 3 is limited by the formation of $\mathrm{CO}$.

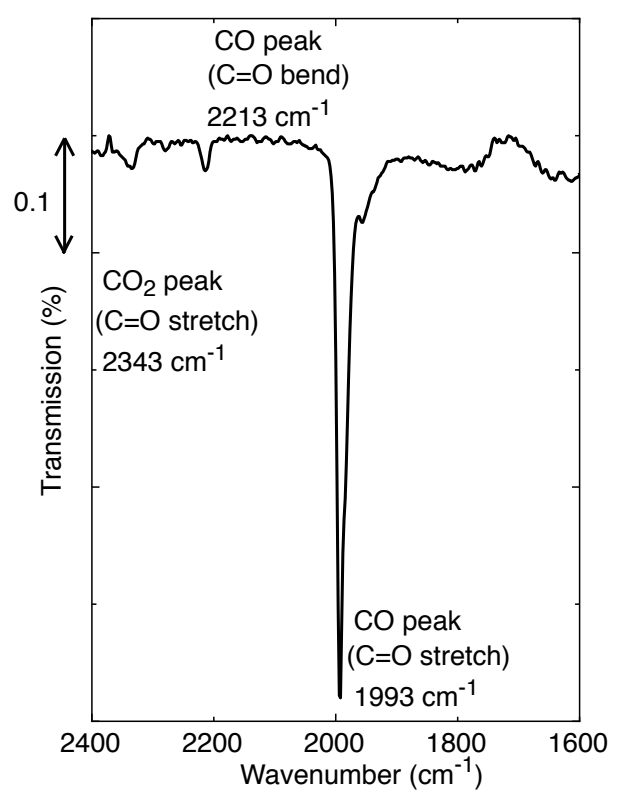

Figure 5.3. RAIRS spectra of a $\mathrm{CO}_{2}$ dosed $\mathrm{Ru}(0001)$ surface before exposure to EUV and $\mathrm{H}_{2}$. The surface has been dosed with $0.2 \mathrm{ML}$ of $\mathrm{CO}_{2}$, and maintained at $85 \mathrm{~K}$.

Figure 5.3 shows the RAIRS spectra of a clean $\mathrm{CO}_{2}$ dosed $\mathrm{Ru}(0001)$ surface before any EUV and $\mathrm{H}_{2}$ experiments have taken place. Three distinct peaks are visible, one for $\mathrm{CO}_{2}$ at $2343 \mathrm{~cm}^{-1}$ corresponding to a $\left(v_{3}\right) \mathrm{C}=\mathrm{O}$ stretch $^{23}$, and two for $\mathrm{CO}$ at $2213 \mathrm{~cm}^{-1}$ and $1993 \mathrm{~cm}^{-1}$ corresponding to a $\mathrm{C}=\mathrm{O}$ bend and a $\mathrm{C}=\mathrm{O}$ stretch, respectively ${ }^{24}$. This result shows that for the $\mathrm{CO}_{2}$ dose used in this study, most of the dosed $\mathrm{CO}_{2}$ partially dissociates to CO before the RAIRS spectrum is acquired.

In Figure 5.4, the $\mathrm{C}=\mathrm{O}$ stretch for $\mathrm{CO}$ is visible when $\mathrm{CO}_{2}$ is first dosed on the surface, followed by exposure to EUV. Figure 5.4(a) shows spectra for a reference experiment where a $\mathrm{CO}_{2}$ dosed $\mathrm{Ru}(0001)$ surface is exposed to EUV without presence of $\mathrm{H}_{2}$ (other than residual gas) during exposure. In this case the CO peak intensity increases over 
30 minutes of exposure, most likely due to adsorption of $\mathrm{CO}$ from residual gas. $\mathrm{As}_{2}$ is introduced at pressures of $1 \times 10^{-7} \mathrm{mbar}$ and $1 \times 10^{-5} \mathrm{mbar}$ in Figures 5.4(b) and 5.4(c), respectively, we see that the $\mathrm{CO}$ peak intensity actually decreases over time, indicating dissociation of $\mathrm{CO}$ by a reaction that only proceeds under EUV irradiation in $\mathrm{H}_{2}$ background. Additionally, we observe that there is no corresponding increase in the $\mathrm{OH}$ peak from adsorbed water at $1 \times 10^{-7} \mathrm{mbar}_{2}$, while adsorbed water is produced at an $\mathrm{H}_{2}$ pressure of $1 \times 10^{-5}$ mbar (see Figures 5.1 and 5.2).

While the sharp CO peak decreases under exposure to EUV and $\mathrm{H}_{2}$, the formation and increase of a broad peak around $1983 \mathrm{~cm}^{-1}$ is observed, which might correspond to the vibrational frequencies of several simple hydrocarbons (methane, ethylene and propadiene). ${ }^{23}$ However, since no other desorbing species than $\mathrm{H}_{2} \mathrm{O}, \mathrm{H}_{2}, \mathrm{CO}_{2}$ and $\mathrm{CO}$ are detected by TPD, this indicates that amorphous $\mathrm{C}$ and/or $\mathrm{C}_{\mathrm{x}} \mathrm{H}_{\mathrm{y}}$ species stay bound to the surface. Furthermore, the broad peak may be caused by $\mathrm{CO}$ molecules that have a different binding strength to the surface due to a change in coverage and the presence of co-adsorbed molecules or $\mathrm{C}_{\mathrm{x}} \mathrm{H}_{\mathrm{y}}$ species ${ }^{25}$.

This comparison of EUV exposure at different $\mathrm{H}_{2}$ pressures thus shows that the dissociation of $\mathrm{CO}$ is not a pure photochemical reaction. Only in the presence of $\mathrm{H}_{2}$ and/or $\mathrm{H}$ radicals produced by EUV radiation, EUV exposure leads to dissociation of $\mathrm{CO}$ into amorphous (hydro)carbon and oxygen adsorbed on the Ru surface. At an $\mathrm{H}_{2}$ pressure of $1 \times 10^{-7}$ mbar, no significant formation of $\mathrm{H}_{2} \mathrm{O}$ by reactions of adsorbed $\mathrm{O}$ with $\mathrm{H}$ radicals is observed. Only at a pressure of $1 \times 10^{-5} \mathrm{mbar}_{2}$, water is produced by (EUV induced) reactions of $\mathrm{H}_{2}$ and adsorbed oxygen originating from (partial) dissociation of $\mathrm{CO}_{2}$. 
(a): $\mathrm{EUV}+\mathrm{CO}_{2}$, no $\mathrm{H}_{2}$

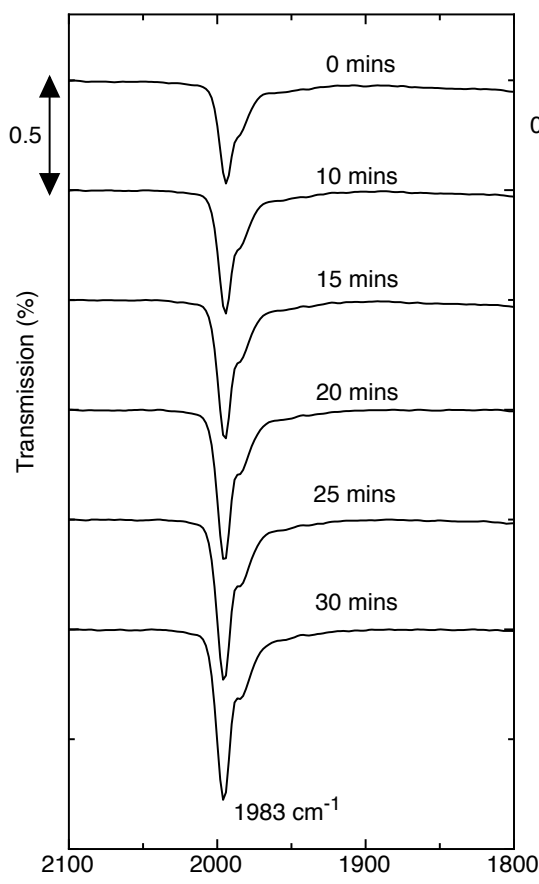

(b): $\mathrm{EUV}+\mathrm{CO}_{2}+\mathrm{H}_{2}$

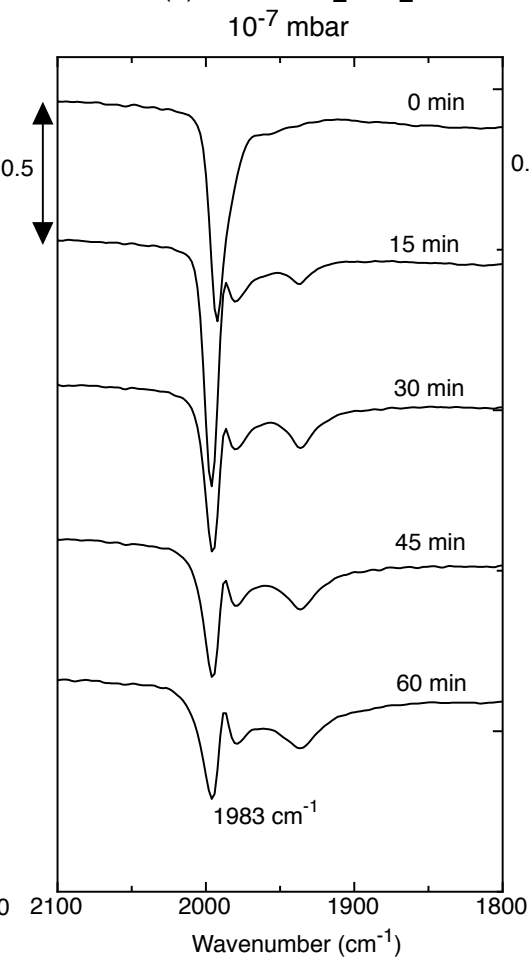

(c): $\mathrm{EUV}+\mathrm{CO}_{2}+\mathrm{H}_{2}$ $10^{-5} \mathrm{mbar}$

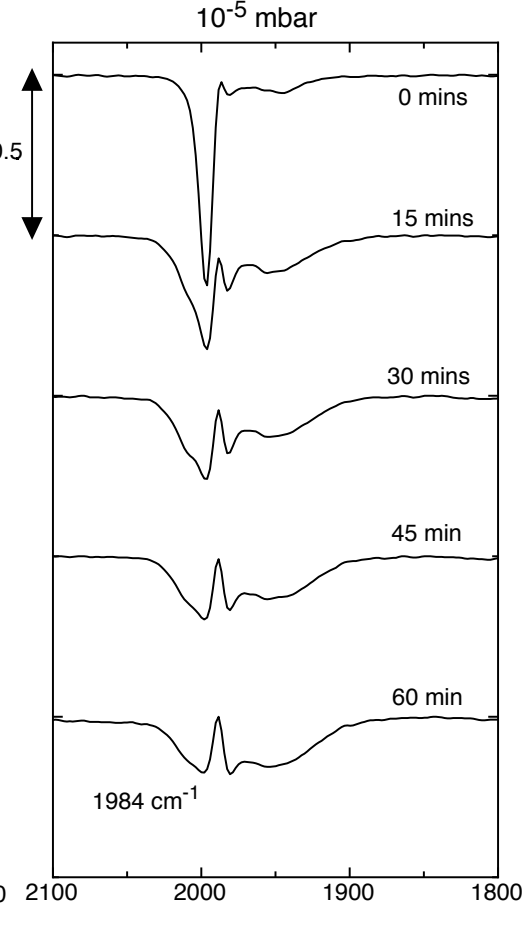

Figure 5.4. RAIRS spectra of the $\mathrm{CO}$ peak when $\mathrm{Ru}(0001)$ is dosed with $\mathrm{CO}_{2}$ and exposed to EUV in the (a) absence and presence of $\mathrm{H}_{2}$ at (b) $1 \times 10^{-7} \mathrm{mbar}$ and (c) $1 \times 10^{-5}$ mbar. The EUV exposure time is indicated on each plot.

More evidence for the formation of water due to the presence of $\mathrm{CO}_{2}$, EUV and $\mathrm{H}_{2}$ is presented in Figure 5.5. Under EUV, $\mathrm{CO}_{2}$ and $\mathrm{H}_{2}$, the amount of water on the surface is measured to increase by a factor of 3.7 and 4.1 when compared to water coverage of a surface only exposed to $\mathrm{H}_{2}$ and $\mathrm{CO}_{2}+\mathrm{H}_{2}$ respectively, while only EUV and $\mathrm{CO}_{2}$ produce 0.70 ML of water, a factor 0.5 as compared to the surface exposed to EUV, $\mathrm{CO}_{2}$ and $\mathrm{H}_{2}$.

Furthermore, TPD spectra showed us that the other products desorbing from the surface are $\mathrm{CO}_{2}, \mathrm{CO}$ and $\mathrm{H}_{2}$. Simple hydrocarbons, such as methane (mass 16), ethylene (mass 28), methanol (mass 31), ethanol and formic acid (both mass 46), and formate (desorption of $\mathrm{CO}_{2}$ and $\mathrm{H}_{2}$ at the same temperature) ${ }^{26}$, are not detected. Therefore, it is highly likely that non-volatile reaction products, such as (hydrogenated) amorphous carbon are formed on the surface, although it cannot be fully excluded that small molecules undergo EUV induced desorption. 


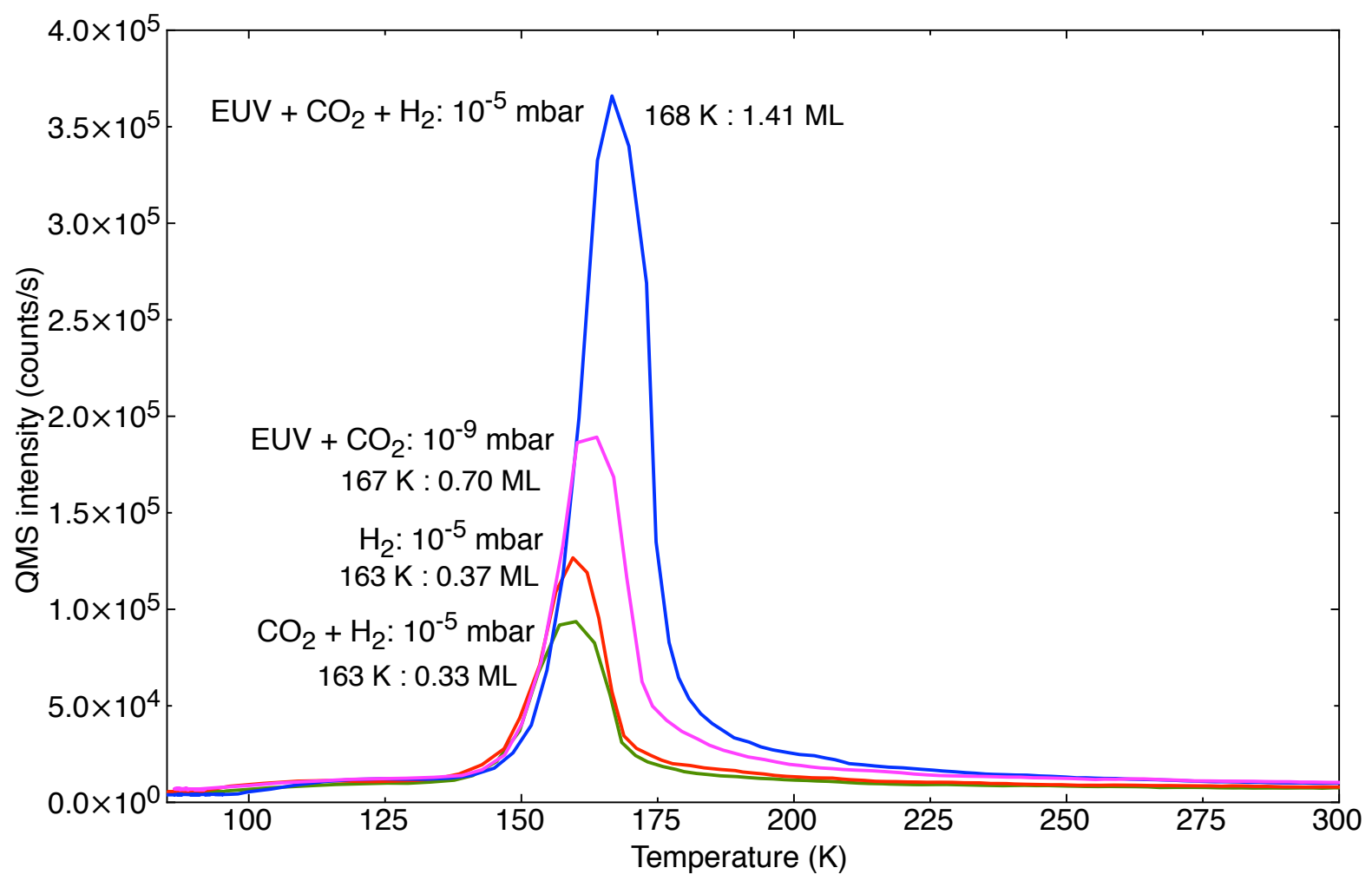

Figure 5.5. TPD spectra of $\mathrm{H}_{2} \mathrm{O}$ (mass 18) for different exposure conditions after 60 minutes: $\mathrm{H}_{2}, \mathrm{CO}_{2}+\mathrm{H}_{2}, \mathrm{EUV}+\mathrm{CO}_{2}+\mathrm{H}_{2}$ at $1 \times 10^{-5}$ mbar and $\mathrm{EUV}+\mathrm{CO}_{2}$ at $10^{-9}$ mbar. The plot indicates the peak desorption temperature and water coverage on the surface after 60 minutes in monolayers (ML), as compared to TPD peak areas on clean $\operatorname{Ru}(0001){ }^{14,16}$ The spectra have been smoothed over 4 values over temperature.

\subsubsection{Coverage of $\mathrm{Ru}(0001)$ surface with amorphous carbon/hydrocarbons}

If the formation of water requires partial dissociation of $\mathrm{CO}_{2}$ to $\mathrm{CO}$ as a first step, then water formation could be limited by the availability of catalytic sites on the Ru surface. The formation of amorphous carbon implies that Ru sites are gradually covered with amorphous carbon/hydrocarbons. In order to find out whether the EUV-induced reaction of $\mathrm{CO}_{2}$ and $\mathrm{H}_{2}$ indeed leads to amorphous carbon formation on Ru surface sites, and to confirm that the Ru surface has a catalytic role in the $\mathrm{CO}_{2}$ dissociation 


\section{surfaces}

reaction, the de-activation of the $\mathrm{CO}_{2}$ dissociation reaction is studied using multiple reaction cycles.

An, initially clean, surface is exposed to 5 consecutive cycles (or iterations) consisting of $\mathrm{CO}_{2}$ dosing, followed by 60 minutes exposure to EUV and $\mathrm{H}_{2}$ without sputtering or high temperature annealing the surface in between the cycles. After each cycle, the surface temperature is only increased to $600 \mathrm{~K}$ for a TPD spectrum. This ensures that any amorphous carbon formed on the surface stays adsorbed on the surface. For each cycle, the same amount of $\mathrm{CO}_{2}(0.2 \mathrm{ML})$ is dosed on the surface at $85 \mathrm{~K}$.

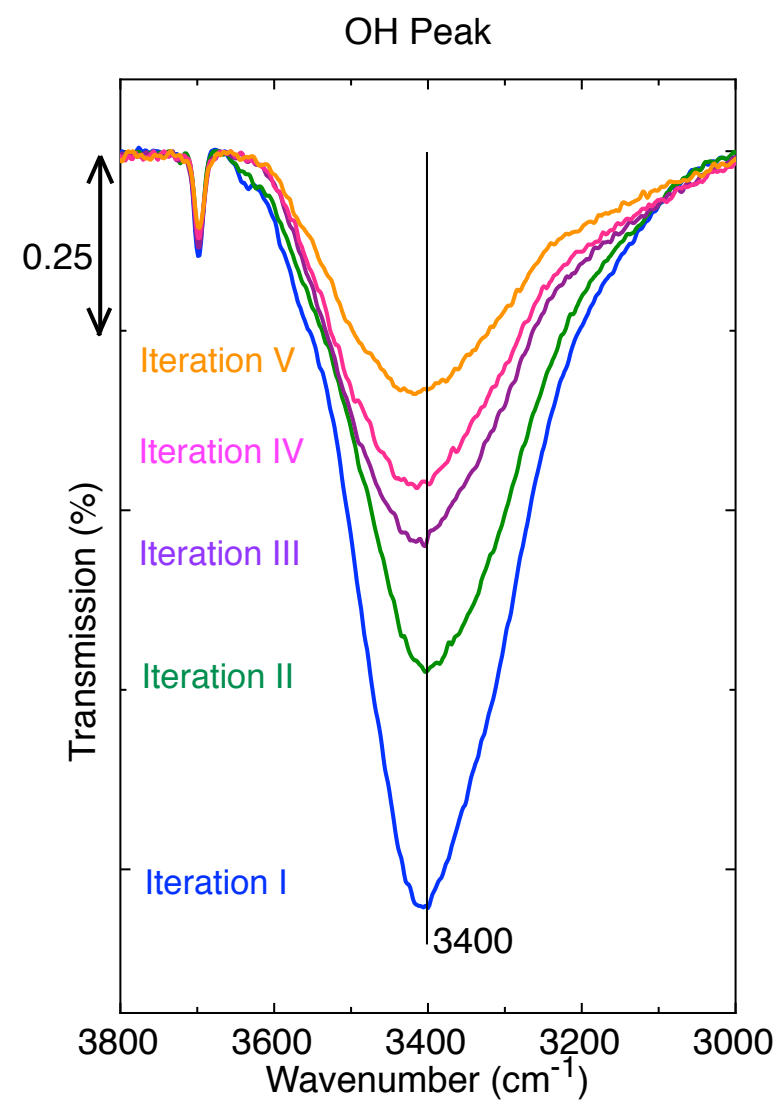

Figure 5.6. RAIRS spectra of $\mathrm{OH}$ peak for cycles of $\mathrm{CO}_{2}$ dosed $\mathrm{Ru}(0001)$ after exposure to EUV and $\mathrm{H}_{2}$ for 60 minutes. After each exposure the sample is heated to $600 \mathrm{~K}$, after which new $\mathrm{CO}_{2}$ is adsorbed at $85 \mathrm{~K}$. A new background is taken for each iteration, just before $\mathrm{CO}_{2}$ dosing. 
Figure 5.6 shows that the intensity of the $\mathrm{OH}$ peak reduces with repeated exposures of EUV and $\mathrm{H}_{2}$ on a $\mathrm{CO}_{2}$ dosed $\mathrm{Ru}$ surface, with the intensity for iteration $\mathrm{V}$ being reduced by a factor of 4 compared to the intensity for iteration I. This indicates that water generation on the surface is reduced with each cycle.

Figure 5.7 shows the water TPD spectra corresponding to the RAIRS experiment from Figure 5.6, with an indication of the water coverage reached after 60 minutes of EUV exposure time, based on reference experiments of water on clean $\mathrm{Ru}(0001) .{ }^{16,17}$ The intensity of the $\mathrm{OH}$ peak decreases with each iteration EUV and $\mathrm{H}_{2}$ exposure. These results confirm that the water produced by the EUV-induced reaction of $\mathrm{CO}_{2}$ and $\mathrm{H}_{2}$ decreases for an increasing number of iterations. The final water coverage in the fifth reaction cycle is reduced by a factor of 2 compared to the first reaction cycle. We attribute the reduction to a lower availability of Ru surface sites as they are covered with amorphous carbon.

Water on the surface is shown to come from two sources: the $\mathrm{H}_{2}$ line or exchange reactions on walls ${ }^{15}$ and hydrogen reacting with CO. As mentioned before, after 60 minutes, 0.33 ML is attributed to the water deposited on the surface from the $\mathrm{H}_{2}$ line for a reference measurement of $\mathrm{CO}_{2}+\mathrm{H}_{2}$ without EUV, while $\mathrm{CO} 2$ reacting with EUV produces 0.70 ML. We speculate that the production of water in the latter case is due to reactions of $\mathrm{CO}_{2}$ with residual hydrogen on surfaces in the system exposed to EUV. Assuming that water adsorbs on the surface at the same rate for a clean and carbon contaminated surface, we can say that about $1.36-(0.70+0.33)=0.33 \mathrm{ML}$ of the water adsorbed at the end of the reaction cycle is from $\mathrm{H}_{2}$ reacting with $\mathrm{CO}$ on the $\mathrm{Ru}$ crystal in the presence of EUV. It should be noted that such a quantitative comparison is not straightforward in view the long reaction times that inevitably lead to adsorption of residual water. However, this quantification of the amount of water formed from reactions on the $\mathrm{Ru}(0001)$ surface seems reasonably in line with the initial dose of $\sim 0.2 \mathrm{ML} \mathrm{CO}_{2}$ and the stoichiometry from reaction (1)-(3), when taking into account that some $\mathrm{CO}$ is left on the surface at the end of the reaction cycle. 


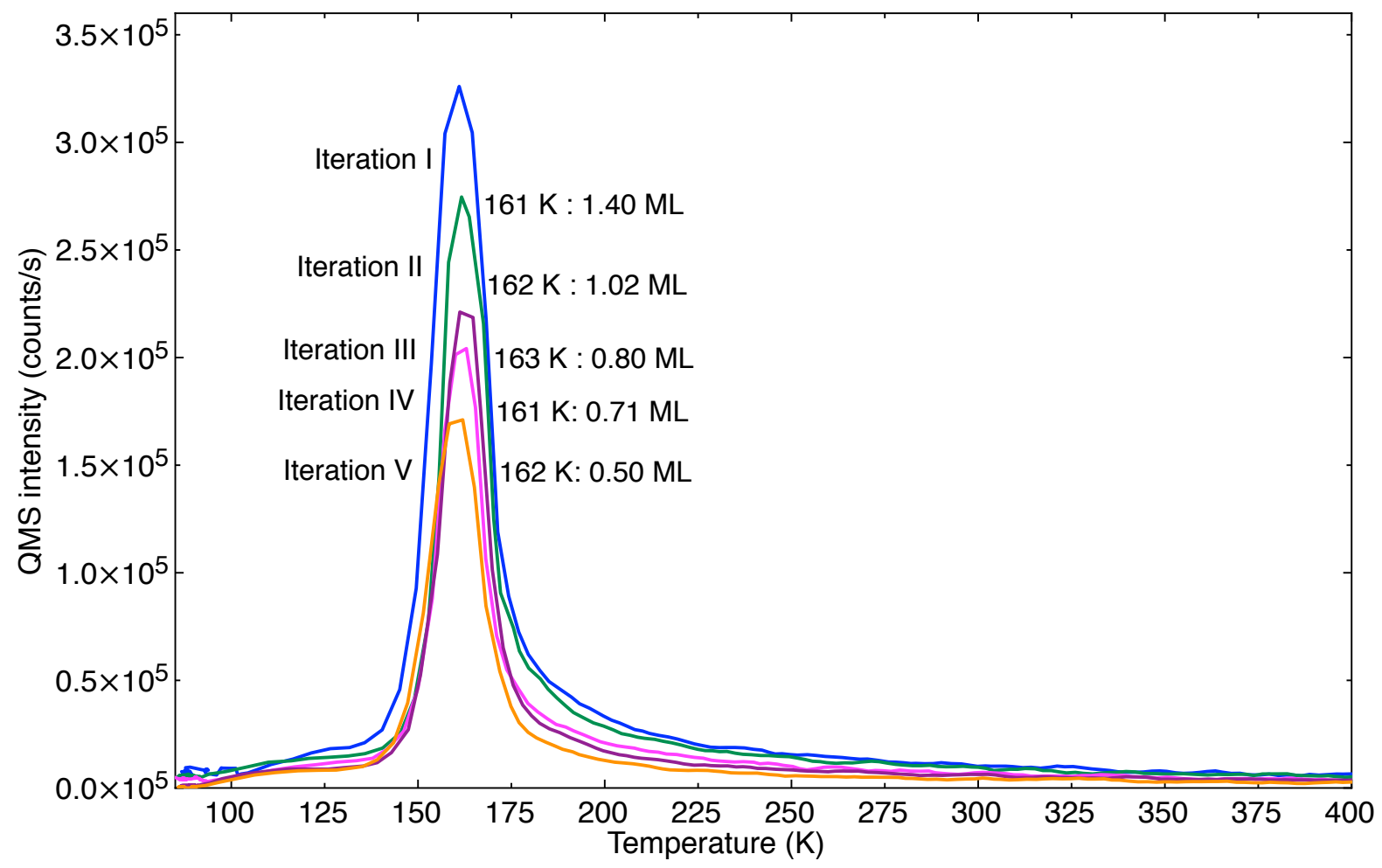

Figure 5.7. TPD spectra of water (mass 18) for 5 cycle experiment on $\mathrm{CO}_{2}$ dosed $\mathrm{Ru}(0001)$ in the presence of EUV and $\mathrm{H}_{2}$. The plot indicates the peak desorption temperature and water coverage on the surface after 60 minutes exposure in monolayers (ML). The spectra has been smoothed over 4 values.

TPD measurements (Figure 5.8) further show that the peak desorption temperature of the unreacted CO, remaining after the EUV exposure, is $469 \mathrm{~K}$ for the first iteration. This measurement corresponds to the peak desorption temperature from other experiments done at the same and lower partial pressures of hydrogen $\left(10^{-7} \mathrm{mbar}\right)$, corresponding to $\mathrm{CO}$ desorption from a mostly clean surface. For subsequent cycles of $\mathrm{EUV}+\mathrm{H}_{2}$ exposure, we see that the peak desorption temperature of $\mathrm{CO}$ drops to $418 \mathrm{~K}$, and remains unchanged thereafter. This indicates that the bonding of $\mathrm{CO}$ to the surface weakens due to the formation of amorphous carbon on the surface. 


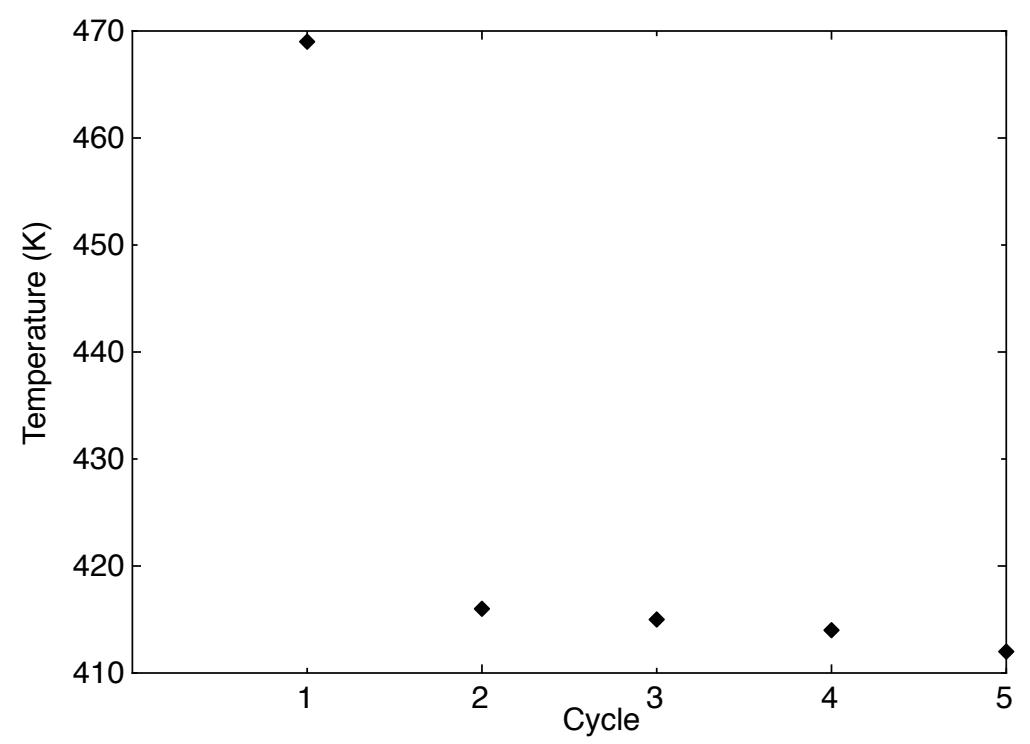

Figure 5.8. Peak desorption temperature of $\mathrm{CO}$ at the end of each cycle of EUV and $\mathrm{H}_{2}$ exposure to a $\mathrm{CO}_{2}$ dosed $\mathrm{Ru}(0001)$ surface.

\subsection{Conclusions}

This study shows the formation of $\mathrm{H}_{2} \mathrm{O}$ and amorphous carbon when a $\mathrm{CO}_{2}$ dosed $\mathrm{Ru}(0001)$ surface is exposed to EUV with a partial $\mathrm{H}_{2}$ pressure of at least $1 \times 10^{-5} \mathrm{mbar}$. We have shown that the reaction pathway proceeds via the partial dissociation of $\mathrm{CO}_{2}$ into $\mathrm{CO}$ and $\mathrm{O}$. This dissociation is not driven by photo-induced processes, but is due to catalytic activity at the Ru surface. The overall photo-induced reaction of $\mathrm{CO}_{2}$ and $\mathrm{H}_{2}$ forms water and an amorphous carbon layer, which may be partially hydrogenated. For the reaction conditions and initial $\mathrm{CO}_{2}$ coverages investigated in this study, the catalytic conversion of $\mathrm{CO}_{2}$ to $\mathrm{CO}$ is rapid compared to photo-induced processes, therefore there is practically no intact $\mathrm{CO}_{2}$ left at the start of the EUV exposure. The possibility of direct EUV-induced $\mathrm{CO}_{2}$ dissociation therefore could not be investigated. When exposing a $\mathrm{CO}_{2}$ dosed surface to EUV photons without $\mathrm{H}_{2}$ present in the background, only catalytic partial dissociation of $\mathrm{CO}_{2}$ into $\mathrm{CO}$ and $\mathrm{O}$ is observed. Photodissociation of the formed $\mathrm{CO}$ is only observed for simultaneous presence of EUV and $\mathrm{H}_{2}$. For hydrogen pressures below $1 \times 10^{-5}$ mbar, no photo-induced formation of water is observed, even though $\mathrm{CO}$ is dissociated. Only at $1 \times 10^{-5} \mathrm{mbar}_{2}$, formation of water from EUV-induced reactions of hydrogen and oxygen are observed. This indicates that 
the EUV-induced generation of hydrogen radical species is most likely the rate-limiting step for the overall reaction. Cycles of $\mathrm{CO}_{2}$ dosing without cleaning show that the carbon layer covers the Ru surface, reducing the partial dissociation of $\mathrm{CO}_{2}$ and slowing the production of water in later cycles. This confirms that EUV-induced $\mathrm{CO}_{2}$ dissociation is either negligible, or does not lead to any detectable reaction products.

These results can be understood in view of previously reported research on EUVinduced and thermal reactions of hydrocarbons, $\mathrm{CO}_{2}$ and hydrogen on $\mathrm{Ru}$ surfaces. Experimental and theoretical results on $\mathrm{CH}_{4}$ adsorption on $\mathrm{Ru}(0001)$ showed that dissociative $\mathrm{CH}_{4}$ adsorption results in $\mathrm{CH}_{2}$ groups and surface hydrogen, which further dissociate to $\mathrm{CH}+\mathrm{H}$ after annealing to $273 \mathrm{~K} .{ }^{27}$ Theoretical results in that work show that hydrogenation of carbon species would require significantly higher pressures (in the bar range) than used in this study, which explains our finding that no hydrocarbons or alcohols are found as reaction products. Instead dissociation and surface carbon formation dominates. Similarly, reported theoretical ${ }^{28}$ and experimental ${ }^{29}$ results on hydrogenation of $\mathrm{CO}_{2}$ by $\mathrm{H}_{2}$ on $\mathrm{Ru}$ refer to hydrogen pressures in the range of 1 bar. EUV irradiation in hydrogen background leads to formation of hydrogen radicals, which are able to clean surface oxygen by $\mathrm{H}_{2} \mathrm{O}$ formation ${ }^{30}$ and surface carbon by formation of volatile $\mathrm{CH}_{\mathrm{x}}$ species. ${ }^{15,31,32}$ The results of this work show that $\mathrm{H}_{2} \mathrm{O}$ formation from surface $O$ is already effective at a hydrogen pressure of $1 \times 10^{-5}$ mbar and a sample temperature below $90 \mathrm{~K}$, while for removal of surface $\mathrm{C}$ requires higher hydrogen pressure and/or sample temperatures, in line with the results mentioned in Chen et al. ${ }^{33}$

\subsection{References}

(1) Benziger, J. B.; Madix, R. J. The Decomposition of Formic Acid on Ni(100). Surface Science 1979, 79 (2), 394-412.

(2) McCarty, J.; Falconer, J.; Madix, R. J. Decomposition of Formic Acid on $\mathrm{Ni}(110)$. Journal of Catalysis 1973, 30 (2), 235-249. 
(3) Chen, H.-T.; Musaev, D. G.; Lin, M. C. Adsorption and Dissociation of CO X( $\mathrm{X}=1,2)$ on W(111) Surface : a Computational Study. J. Phys. Chem. C 2008, 112 (9), 3341-3348.

(4) Asscher, M.; Kao, C. T.; Somorjai, G. A. High-Resolution Electron Energy Loss Spectroscopic Study of Carbon Dioxide Adsorbed on Rhenium(0001). J. Phys. Chem. 1988, 92 (10), 2711-2714.

(5) Carley, A. F.; Gallagher, D. E.; Roberts, M. W. Activation of Carbon Dioxide at Low Temperatures at Aluminium Surfaces. Surface Science 1987, 183 (1), L263-L268.

(6) Solymosi, F. The Bonding, Structure and Reactions of CO2 Adsorbed on Clean and Promoted Metal Surfaces. Journal of Molecular Catalysis 1991, 65 (3), 337358.

(7) Kuhl, K. P.; Hatsukade, T.; Cave, E. R.; Abram, D. N.; Kibsgaard, J.; Jaramillo, T. F. Electrocatalytic Conversion of Carbon Dioxide to Methane and Methanol on Transition Metal Surfaces. J. Am. Chem. Soc. 2014, 136 (40), 14107-14113.

(8) Bricker, J. C.; Nagel, C. C.; Shore, S. G. Reactivities of Ruthenium Cluster Anions: Implications for Catalysis of the Water-Gas Shift Reaction. J. Am. Chem. Soc. 1982, 104 (5), 1444-1445.

(9) Sturm, J. M.; Lee, C. J.; Bijkerk, F. Reactions of Ethanol on Ru(0001). Surface Science 2013, 612, 42-47.

(10) Utaka, T.; Okanishi, T.; Takeguchi, T.; Kikuchi, R.; Eguchi, K. Water Gas Shift Reaction of Reformed Fuel Over Supported Ru Catalysts. Applied Catalysis A: General 2003, 245 (2), 343-351.

(11) Liu, N.; Guo, L.; Cao, Z.; Li, W.; Zheng, X.; Shi, Y.; Guo, J.; Xi, Y. Mechanisms of the Water-Gas Shift Reaction Catalyzed by Ruthenium Carbonyl Complexes. J. Phys. Chem. A 2016, 120 (15), 2408-2419.

(12) Zhao, P.; He, Y.; Liu, S.; Cao, D.-B.; Wen, X.; Xiang, H.; Li, Y.-W.; Jiao, H. Adsorption and Dissociation of $\mathrm{H} 2 \mathrm{O}$ and $\mathrm{CO} 2$ on the Clean and O-Pre-Covered $\mathrm{Ru}(0001)$ Surface. Applied Catalysis A: General 2017, 540, 31-36.

(13) Zhang, S.-T.; Yan, H.; Wei, M.; Evans, D. G.; Duan, X. Hydrogenation Mechanism of Carbon Dioxide and Carbon Monoxide on Ru(0001) Surface: a Density Functional Theory Study. RSC Adv. 2014, 4 (57), 30241-30249. 
(14) Pachecka, M.; Sturm, J. M.; Lee, C. J.; Bijkerk, F. Adsorption and Dissociation of CO 2on Ru(0001). J. Phys. Chem. C 2017, 121 (12), 6729-6735.

(15) Madey, T. E.; Faradzhev, N. S.; Yakshinskiy, B. V.; Edwards, N. V. Surface Phenomena Related to Mirror Degradation in Extreme Ultraviolet (EUV) Lithography. Applied Surface Science 2006, 253 (4), 1691-1708.

(16) Liu, F.; Sturm, J.; Lee, C.; Bijkerk, F. Coexistence of Ice Clusters and Liquid-Like Water Clusters on Ru (0001) Surface. Physical chemistry chemical physics : PCCP 2017.

(17) Liu, F.; Sturm, J. M.; Lee, C. J.; Bijkerk, F. Extreme UV Induced Dissociation of Amorphous Solid Water and Crystalline Water Bilayers on Ru(0001). Surface Science 2016, 646, 101-107.

(18) Soer, W. A.; Jak, M. J. J.; Yakunin, A. M.; van Herpen, M. M. J. W.; Banine, V. Y. Grid Spectral Purity Filters for Suppression of Infrared Radiation in LaserProduced Plasma EUV Sources; Schellenberg, F. M., La Fontaine, B. M., Eds.; SPIE, 2009; Vol. 7271Y.

(19) Henke, B. L.; Gullikson, E. M.; Davis, J. C. X-Ray Interactions: Photoabsorption, Scattering, Transmission, and Reflection at $\mathrm{E}=50-30,000 \mathrm{eV}, \mathrm{Z}=1-92$. Atomic Data and Nuclear Data Tables 1993, 54 (2), 181-342.

(20) Astakhov, D. I.; Goedheer, W. J.; Lee, C. J.; Ivanov, V. V.; Krivtsun, V. M.; Koshelev, K. N.; Lopaev, D. V.; van der Horst, R. M.; Beckers, J.; Osorio, E. A.; et al. Exploring the Electron Density in Plasma Induced by EUV Radiation: II. Numerical Studies in Argon and Hydrogen. J. Phys. D: Appl. Phys. 2016, 49 (29), 295204.

(21) Kieft, E. R.; van der Mullen, J. J. A. M.; Kroesen, G. M. W.; Banine, V. TimeResolved Pinhole Camera Imaging and Extreme Ultraviolet Spectrometry on a Hollow Cathode Discharge in Xenon. Phys. Rev. E 2003, 68 (5), 056403.

(22) Mund, B. K.; Sturm, J. M.; Lee, C. J.; Bijkerk, F. Aromatic Structure Degradation of Single Layer Graphene on an Amorphous Silicon Substrate in the Presence of Water, Hydrogen and Extreme Ultraviolet Light. Applied Surface Science, 2018, 427(B), 1033-1040.

(23) Gerakines, P. A. Infrared Band Strengths: Laboratory Techniques and Applications to Astronomical Observations. Bulletin of the American Astronomical Society 2002, 34, 911. 
(24) Smith, A. L. The Coblentz Society Desk Book of Infrared Spectra, 2nd ed.; Carver, C. D., Ed.; The Coblentz Society, 1982; pp 1-24.

(25) Pfnür, H.; Menzel, D.; Hoffmann, F. M.; Ortega, A.; Bradshaw, A. M. High Resolution Vibrational Spectroscopy of $\mathrm{CO}$ on $\mathrm{Ru}(001)$ : the Importance of Lateral Interactions. Surface Science 1980, 93 (2), 431-452.

(26) Taylor, P. A.; Rasmussen, P. B.; Ovesen, C. V.; Stoltze, P.; Chorkendorff, I. Formate Synthesis on Cu(100). Surface Science 1992, 261 (1), 191-206.

(27) Kirsch, H.; Zhao, X.; Ren, Z.; Levchenko, S. V.; Wolf, M.; Campen, R. K. Controlling $\mathrm{CH} 2$ Dissociation on Ru(0001) Through Surface Site Blocking by Adsorbed Hydrogen. Journal of Catalysis 2014, 320 (Supplement C), 89-96.

(28) Avanesian, T.; Gusmão, G. S.; Christopher, P. Mechanism of CO2 Reduction by $\mathrm{H} 2$ on Ru(0 00 1) and General Selectivity Descriptors for Late-Transition Metal Catalysts. Journal of Catalysis 2016, 343 IS -, 86-96.

(29) Prairie, M. R.; Renken, A.; Highfield, J. G.; Ravindranathan Thampi, K.; Grätzel, M. A Fourier Transform Infrared Spectroscopic Study of C02 Methanation on Supported Ruthenium. Journal of Catalysis 1991, 129 (1), 130-144.

(30) Nishiyama, I.; Oizumi, H.; Motai, K.; Izumi, A.; Ueno, T.; Akiyama, H.; Namiki, A. Reduction of Oxide Layer on Ru Surface by Atomic-Hydrogen Treatment. $J$. Vac. Sci. Technol. B 2005, 23 (6), 3129-3131.

(31) Chen, J.; Louis, E.; Lee, C. J.; Wormeester, H.; Kunze, R.; Schmidt, H.; Schneider, D.; Moors, R.; van Schaik, W.; Lubomska, M.; et al. Detection and Characterization of Carbon Contamination on EUV Multilayer Mirrors. Opt. Express 2009, 17 (19), 16969-16979.

(32) Chen, J.; Louis, E.; Wormeester, H.; Harmsen, R.; van de Kruijs, R.; Lee, C. J.; van Schaik, W.; Bijkerk, F. Carbon-Induced Extreme Ultraviolet Reflectance Loss Characterized Using Visible-Light Ellipsometry. Measurement Science and Technology 2011, 22 (10), 105705.

(33) Chen, J.; Louis, E.; Harmsen, R.; Tsarfati, T.; Wormeester, H.; van Kampen, M.; van Schaik, W.; van de Kruijs, R.; Bijkerk, F. In Situ Ellipsometry Study of Atomic Hydrogen Etching of Extreme Ultraviolet Induced Carbon Layers. Applied Surface Science 2011, 258 (1), 7-12. 


\section{Summary}

Graphene, a covalently bound, hexagonal 2D network of carbon atoms, is generally reported to be a chemically inert material with a high mechanical strength. Due to its high optical transmission, graphene is a great candidate as an optical material in the EUV to soft X-ray wavelength range. In this thesis, the chemical and physical interactions of both single-layer and multi-layer graphene is experimentally investigated, in order to verify and corroborate graphene's viability for optical uses.

Firstly, oxidation studies on single-layer graphene (SLG) are done. SLG is transferred from the $\mathrm{Cu}$ surface on which the layer was grown, to an amorphous Si surface. SLG is shown to oxidize when dosed with $\mathrm{H}_{2} \mathrm{O}$ and exposed to EUV radiation in the presence of $\mathrm{H}_{2}$. This oxidation signifies degradation of the aromatic layer of graphene in the form of keto-enol groups, such as enol of forms of 1,3 di-ketone, most likely occurring at point defects and/or grain boundaries. Experimentally, this is noted by in-situ reflection-absorption infrared spectroscopy (RAIRS) which indicates that ring structure degradation occurs through graphene oxidation by reactive oxygen species. These are generated through interaction of EUV with adsorbed $\mathrm{H}_{2} \mathrm{O}$. Also, XPS shows an increase in the amount of $\mathrm{C}$ bound to oxygen and also an increase in formation of $\mathrm{sp}^{3}$ bonds, indeed confirming that the surface is oxidized, leading to graphene being more defective. Higher pressures of hydrogen enhance the oxidation of graphene, most likely by creation of defects by EUV generated $\mathrm{H}$ radicals, which subsequently can oxidize under exposure to EUV and $\mathrm{H}_{2} \mathrm{O}$. This study shows that a low defect density of SLG is paramount for optical use, as a balance between oxidation and reduction reactions on a defective graphene surface cannot be achieved.

Next, the oxidation of transferred and as-grown multi-layer graphene was investigated in the presence of EUV radiation and a $\mathrm{H}_{2}$ background. In this case, asgrown MLG is shown to be resistant to oxidation when dosed with $\mathrm{H}_{2} \mathrm{O}$ and exposed to EUV radiation in the presence of even up to $1 \times 10^{-3} \mathrm{mbar} \mathrm{H}_{2}$. Most likely, this is due 
to the morphology of MLG, which conforms to the grain boundaries of the surface it is grown on, which in this case is Mo. Additionally, secondary electrons generated in the underlying Mo substrate (which has a higher secondary electron yield than carbon) have a lower mean free path than the thickness of MLG, and therefore cannot reach the adsorbed water layer on top the MLG surface. Therefore, the only way for EUVinduced chemistry to take place would be through either EUV photons, or photoelectrons generated from graphene.

In contrast, transferred MLG (on an aSi surface) is shown to oxidize and form ketoenol groups (as observed for transferred SLG). However, XPS shows that this formation does not occur in the top-most layers of the graphene stack, and most likely takes place at the interface between the graphene stack and the surface onto which the graphene was transferred (aSi). SEM images show that graphene does not follow the morphology of the underlying aSi surface, but retains the morphology of the original Mo film. Consequently, during dosing water gets trapped between the aSi and the MLG, which most likely leads to graphene being oxidized when irradiated with EUV photons. Furthermore, SEM images show that MLG contains holes of $<200 \mathrm{~nm}$ diameter, and image analysis indicates that small holes $(<50 \mathrm{~nm}$ diameter) are shown to increase in number after exposure to EUV. As such, transferred MLG is shown to be more susceptible to oxidation by formation of keto-enol groups when compared to as-grown MLG.

Multi-layer graphene is further investigated as a diffusion barrier for atomic hydrogen and compared to sputter-deposited amorphous carbon of similar thickness. In this case, MLG was transferred onto a Ru capped Y film, and spectroscopic ellipsometry was used to probe hydrogenation of the $\mathrm{Y}$ film to $\mathrm{YH}_{2}$ and $\mathrm{YH}_{3}$. By comparing the in-situ ellipsometry measurements acquired during atomic $\mathrm{H}$ exposure of a reference $\mathrm{Ru} / \mathrm{Y}$ sample with carbon and graphene covered $\mathrm{Ru} / \mathrm{Y}$ samples, it was demonstrated that carbon and graphene both act as barrier against diffusion of hydrogen to underlying layers. However, since the exposure of graphene and carbon to atomic hydrogen leads to etching of carbon, eventually the carbon/graphene is removed, after which the $\mathrm{Y}$ film does hydrogenate. The experiments demonstrated that etching of graphene by 
atomic hydrogen is considerably slower than etching of an amorphous carbon film of similar thickness. This investigation shows that when the surface is protected against direct exposure to atomic hydrogen, MLG can be used as barrier against diffusion of atomic hydrogen.

As a final sub-study, Ru was investigated as a protective material with respect to photochemistry of carbon and oxygen containing molecules, notably $\mathrm{CO}_{2}$. A Ru(0001) surface was dosed with $\mathrm{CO}_{2}$ and exposed to EUV in the presence of $\mathrm{H}_{2}$. At an $\mathrm{H}_{2}$ background pressure of at least $1 \times 10^{-5}$ mbar, a combination of Ru-catalyzed and EUVinduced reactions of $\mathrm{CO}_{2}$ is shown to lead to the formation of $\mathrm{H}_{2} \mathrm{O}$ and amorphous carbon on the $\mathrm{Ru}(0001)$ surface. The reaction pathway is shown to proceed via partial dissociation of $\mathrm{CO}_{2}$ into $\mathrm{CO}$ and $\mathrm{O}$, due to the catalytic activity of the Ru surface, instead of by photo-chemical processes. Due to photochemical reactions and EUV-generated hydrogen radicals, $\mathrm{CO}$ is further dissociated to amorphous carbon and $\mathrm{H}_{2} \mathrm{O}$ is produced. The formation of amorphous carbon deactivates Ru surface sites and therefore reduces the partial dissociation of $\mathrm{CO}_{2}$. This was investigated by repetitive cycles of $\mathrm{CO}_{2}$ dosing on the Ru surface without cleaning the formed amorphous carbon. This $\mathrm{CO}_{2}$ dose cycle leads to a decrease in water formation, indicating that EUV-induced $\mathrm{CO}_{2}$ dissociation is either negligible or does not lead to any detectable reaction end-products. Furthermore, it was demonstrated that reduction of ruthenium oxide by EUV generated hydrogen radicals proceeds at relatively low pressure, where carbon cleaning is still not effective. 


\section{Samenvatting}

Grafeen, een 2D hexagonaal netwerk van covalent gebonden koolstofatomen, staat bekend als een chemisch inert en mechanisch sterk materiaal. Grafeen heeft bovendien een hoge optische transmissie voor zachte röntgenstraling, wat het een geschikte kandidaat maakt als optisch materiaal in dit golflengtegebied. Dit proefschrift beschrijft experimentele verificaties van optisch relevante chemische en fysische interacties van enkellaags- en multilaagsgrafeen, om de geschiktheid van grafeen voor deze toepassingen verder te onderzoeken.

Allereerst werd enkellaagsgrafeen, gegroeid op $\mathrm{Cu}$, overgezet op een amorf $\mathrm{Si}$ oppervlak. Wanneer nu water op de grafeenlaag geadsorbeerd wordt en het monster wordt blootgesteld aan extreem ultraviolet (EUV) in een achtergronddruk van waterstof, vindt oxidatie van het grafeen plaats. Oxidatie van grafeen door water resulteert in de vorming van keton-enol-groepen, wat de aromatische structuur van de grafeenlaag degradeert. Hoogstwaarschijnlijk vormen puntdefecten en/of korrelgrenzen de initiatiepunten voor deze degradatie. Experimenteel is deze degradatie bevestigd door in-situ reflectie-absorptie-infraroodspectroscopie (RAIRS), waarmee aangetoond is dat reactief zuurstof, gevormd door interactie van EUV-fotonen met water, grafeen kan oxideren. Röntgen-foto-elektronenspectroscopie (XPS) na blootstelling aan water, EUV en waterstof, laat een toename zien van koolstof gebonden met zuurstof en daarnaast een toename van $\mathrm{sp}^{3}$ gebonden koolstof, wat aangeeft dat $\mathrm{sp}^{2}$-bindingen van grafeen verbroken zijn om $\mathrm{sp}^{3}$-bindingen te vormen. Dit bevestigt de vorming van defecten in de grafeenlaag. Hogere waterstofdrukken tijdens de EUV-belichting vergroten de oxidatie van het grafeen. Dit geeft aan dat EUVgegenereerde waterstofradicalen defecten in de grafeenlaag produceren, die vervolgens oxideren door blootstelling aan EUV en water. Dit deel-onderzoek geeft aan dat een lage initiële defectdichtheid van enkellaagsgrafeen zeer belangrijk is, omdat er bij grafeen geen evenwicht tussen oxidatie- en reductiemechanismen bereikt kan worden. 
Vervolgens is de oxidatie van overgezet en niet-overgezet multilaagsgrafeen (MLG) onder blootstelling aan EUV en waterstof onderzocht. Op niet-overgezet MLG (op het oorspronkelijke Mo substraat) kon geen oxidatie vastgesteld worden na adsorptie van water en belichting met EUV met waterstofdrukken tot zelfs $1 \times 10^{-3}$ mbar. Eén van de mogelijke redenen hiervoor is dat de grafeenlaag de morfologie van het Mo substraat volgt. Daarnaast hebben secondaire elektronen die door EUV uit het Mo substraat vrijgemaakt worden een kortere vrije weglengte dan de dikte van de MLG-film, zodat deze de waterlaag bovenop het MLG niet kunnen bereiken. EUV-geïnduceerde chemische reacties kunnen daarom alleen plaatsvinden door secondaire elektronen uit grafeen (dat een lage secondaire elektronenproductie heeft in vergelijking met Mo) en door directe EUV-geïnduceerde processen.

MLG overgezet op een amorf Si oppervlak vertoont daarentegen gelijksoortige oxidatieverschijnselen als enkellaagsgrafeen, in de vorm van keto-enol-groepen. XPS laat echter zien dat deze oxidatie niet in de bovenste lagen van het grafeen plaatsvindt en dus hoogstwaarschijnlijk aan het grensvlak met amorf Si plaats moet vinden. Afbeeldingen gemaakt met secondaire-elektronenmicroscopie (SEM) laten zien dat de grafeenlaag niet de morfologie van het onderliggende amorf Si volgt, maar de morfologie van de oorspronkelijke Mo film behoudt. Als gevolg hiervan kan water opgesloten raken tussen MLG en Si, wat waarschijnlijk tot oxidatie leidt bij belichting met EUV-fotonen. SEM-foto's laten zien dat MLG gaten met diameter <200 nm bevat. Beeldanalyse toont aan dat het aantal kleine gaten $(<50 \mathrm{~nm}$ diameter) toeneemt na belichting door EUV. Overgezet MLG is dus gevoeliger voor oxidatie in de vorm van keton-enol-groepen, in vergelijking met MLG op het oorspronkelijke groeisubstraat.

MLG is daarnaast onderzocht als diffusiebarrière voor atomair waterstof, waarbij een vergelijking gemaakt is met een koolstoffilm van vergelijkbare dikte, gedeponeerd met sputterdepositie. Voor dit onderzoek is MLG overgezet op een Y film met een Ru beschermingslaag (cap), waarbij spectroscopische ellipsometrie gebruikt is om de hydrogenatie van de $\mathrm{Y}$ film tot $\mathrm{YH}_{2}$ en $\mathrm{YH}_{3}$ te meten. Door in-situ metingen met ellipsometrie op een $\mathrm{Ru} / \mathrm{Y}$ referentiefilm te vergelijken met metingen op $\mathrm{Ru} / \mathrm{Y}$ films 
bedekt met koolstof en grafeen, kon aangetoond worden dat koolstof en grafeen diffusie van waterstof naar de onderliggende lagen verhinderen. Echter, omdat blootstelling aan atomair waterstof leidt tot etsen van koolstof, wordt bij lange blootstelling het grafeen / de koolstoffilm verwijderd, waarna alsnog hydrogenatie van de Y film optreedt. Deze studie heeft aangetoond dat de etssnelheid van grafeen door atomair waterstof aanzienlijk lager is dan die van een gedeponeerde koolstoffilm van vergelijkbare dikte. MLG kan dus in principe gebruikt worden als diffusiebarrière voor atomair waterstof, mits het oppervlak beschermd wordt tegen directe blootstelling aan atomair waterstof.

In een laatste deelstudie is Ru onderzocht als een beschermend materiaal m.b.t. de fotochemie van een koolstof- en zuurstofhoudend molecule, m.n. $\mathrm{CO}_{2}$. Een $\mathrm{Ru}(0001)$ oppervlak is blootgesteld aan $\mathrm{CO}_{2}$ en belicht met EUV in een achtergronddruk van $\mathrm{H}_{2}$.

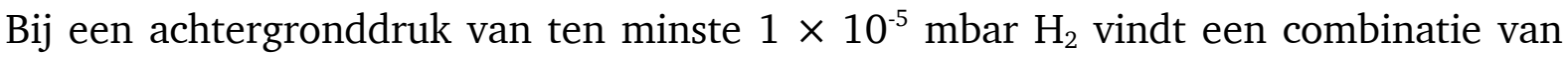
door $\mathrm{Ru}$ gekatalyseerde en EUV-geïnduceerde reacties plaats, waarbij $\mathrm{H}_{2} \mathrm{O}$ en amorf koolstof gevormd wordt op het $\mathrm{Ru}(0001)$ oppervlak. Deze reactie begint met partiële dissociatie van $\mathrm{CO}_{2}$ in $\mathrm{CO}$ en $\mathrm{O}$, door katalytische werking van het rutheniumoppervlak (en dus niet door een fotochemisch proces). Vervolgens zorgen fotochemische reacties en EUV-gegenereerde waterstofradicalen voor de verdere dissociatie van CO tot amorf koolstof, waarbij ook $\mathrm{H}_{2} \mathrm{O}$ geproduceerd wordt. De vorming van amorf koolstof deactiveert het rutheniumoppervlak, waardoor de partiële dissociatie van $\mathrm{CO}_{2}$ afneemt. Dit is bevestigd door herhaalde reactiecycli van adsorptie van $\mathrm{CO}_{2}$ en belichting te bestuderen, zonder het gevormde amorf koolstof te verwijderen. In iedere opvolgende reactiecyclus neemt de hoeveelheid gevormd water af, wat aantoont dat directe EUVgeïnduceerde dissociatie van $\mathrm{CO}_{2}$ verwaarloosbaar is, of niet tot detecteerbare eindproducten leidt. Tot slot laat dit onderzoek zien dat reductie van rutheniumoxide door EUV-gegenereerde waterstofradicalen al bij relatief lage waterstofdruk plaatsvindt, terwijl reiniging van koolstofvervuiling bij de gebruikte druk nog niet effectief is. 


\section{Acknowledgments}

Firstly, I would like to thank my promotor Fred Bijkerk, for giving me the opportunity for undertaking this Ph.D. project. Thank you for the encouraging and inspiring words which drove me to finish my Ph.D.

During my last year of my Ph.D. I was very fortunate to have Marko Sturm as my daily supervisor, who helped me with so much, such as measurements and their analyses, providing suggestions and ideas on how to move things forward, and last but not least going over countless drafts of my work, to name a few. Thank you for making the transition between supervisors easy during a difficult time.

I would like to thank Chris Lee for being my daily supervisor during the first three years of my Ph.D., without whom this thesis would not have been possible. Thank you for the endless hours of discussion about scientific questions, making complex concepts look easy for me, and for helping me to look for new ways to tackle problems. Your dedication and drive certainly trickled through to help me create the best quality work possible.

Additionally, thanks to Wesley van den Beld for providing me graphene samples with crucial support on how to work with them. Also, thanks to Meint de Boer for delivering beautiful SEM pictures of the graphene layer. In the XUV lab, I would like to thank Theo van Oijen for his help in sample preparation. Also, I would like to thank Carin Krijnen and Jacqueline Emmerich for taking care of all the administration issues.

I would also like to express my sincere gratitude to Wim van der Zande and Ageeth Bol for invaluable discussions during the bi-annual meetings.

At ASML, I am incredibly grateful to Luc Stevens, Goran Milinkovic and John de Kuster for their support to fix stubborn issues with experimental setups when things would periodically break down. 
Also, thanks to Eldad Grady for helping me show how graphene is grown during the early days of my project. I would also like to thank my paranymphs Olena Soroka and Małgorzata Pachecka along with other colleagues, An Gao, Ani Chandrasekaran, Feng Liu and Rogier van den Bos, who were extremely supportive and a fun-loving group to work with. All of you made my time in ASML and UT extremely enjoyable to work in.

Since life is not all about work I would like to thank my friends Maartje, Huanhuan, Dinesh and Skhandhan for all the experiences during my project and my quiz group of Mikael, Bart, Erik, Ellen, Jan and Janneke.

Last but not least, I would like to thank my parents Shampashree and Sisir Mund, without whose support I would not have come this far and who have always believed in me independent of the situation. Thank you for being there and helping me through all walks of life.

Thank you all!

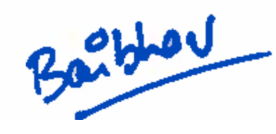




\section{About the Author}

Baibhav Mund was born on the 28th of September 1990 in Berhampur, India. In 2008, he started his Bachelor in Engineering (B.Eng.) in Electronic Engineering and Computer Science at Aston University in Birmingham, England. In 2011, he completed an internship at Airbus Industries in Filton, England. This was followed by a Masters in Science in Nanoscience and Nanotechnology at the University of Glasgow in Glasgow, Scotland. In June of 2014, he started his research in Physics and Chemistry in the Industrial Focus Group XUV Optics, within the MESA+ Institute of Nanotechnology at the University of Twente. During this time, he worked closely with ASML Research department. This Ph.D. programme was supervised by Prof.dr. F. Bijkerk, with daily supervision of Dr. C.J. Lee and Dr. J.M. Sturm. A selection of results are presented in this thesis. 